


\section{Recommended Options for Improving the Built Environment for Post-Earthquake Reoccupancy and Functional Recovery Time}

This publication is available free of charge from: https://doi.org/10.6028/NIST.SP.1254 or by calling FEMA at 1-800-480-2520

Final Report, January 2021

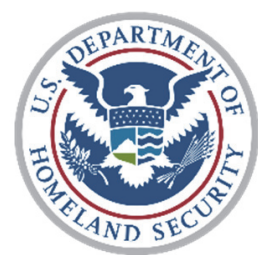

Department of Homeland Security Peter T. Gaynor, Acting Secretary

Federal Emergency Management Agency Robert J. Fenton Jr., Senior Official Performing the Duties of FEMA Administrator

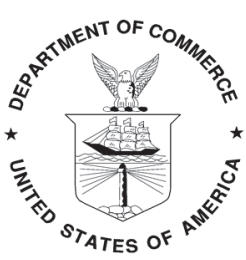

U.S. Department of Commerce Wilbur L. Ross, Jr., Secretary

National Institute of Standards and Technology Walter Copan, NIST Director and Undersecretary of Commerce for Standards and Technology 

NIST-FEMA Special Publication FEMA P-2090/NIST SP-1254

\author{
Federal Emergency Management Agency \\ Michael Mahoney \\ Robert D. Hanson \\ John (Jack) R. Hayes, Jr. \\ Pataya Scott
}

\author{
Applied Technology Council \\ Jon A. Heintz * \\ Project Technical Panel \\ Ryan A. Kersting (Chair) * \\ Lucy A. Arendt * \\ David Bonowitz * \\ Mary C. Comerio * \\ Craig A. Davis * \\ Greg G. Deierlein * \\ Susan Dowty * \\ Gary Ehrlich * \\ Ronald O. Hamburger * \\ Jon A. Heintz * \\ Katherine (Jo) Johnson * \\ Ron C. Larsen * \\ Michael Mahoney * \\ Rachel Minnery \\ Aspasia (Sissy) Nikolaou * \\ Chris D. Poland * \\ Siamak Sattar * \\ Pataya Scott * \\ Jonathan Siu * \\ Jeffrey R. Soulages * \\ Kent $\mathrm{Yu}$ *
}

\author{
National Institute of Standards and \\ Technology \\ Siamak Sattar \\ Katherine J. Johnson \\ Steven L. McCabe
}

Science and Technology Policy Institute

Leslie Abrahams *

Project Review Panel

Marissa Aho

John M. Bozeman

Dan Eschenasy

Robert Ezelle

William T. Holmes

James Kendra

Steven L. McCabe

Thomas D. O'Rourke

Marios Panagiotou

Keith Porter

Lakisha Ann Woods

\footnotetext{
* Co-authors of the report.
} 


\section{Acknowledgments}

In 2019, the Federal Emergency Management Agency (FEMA) contracted with the Applied Technology Council (ATC), and the National Institute of Standards and Technology (NIST) contracted with the Science and Technology Policy Institute (STPI), to jointly convene a Committee of Experts to develop this report to Congress. A Project Technical Panel, led by ATC, was charged with developing the report, and a Project Review Panel, led by STPI, was charged with providing review and feedback on the report during development.

FEMA and NIST greatly appreciate the efforts of the Project Technical Panel for their contributions in developing the original source material for this report, and to the leadership of Ryan Kersting (Chair), Lucy Arendt, Craig Davis, and Ron Hamburger who served as lead authors. NIST and FEMA also acknowledge the members of the Project Review Panel, under the direction of STPI, for providing peer review and comment at different stages of report development. NIST and FEMA also recognize the contributions of the many individuals who participated in a series of stakeholder workshops, facilitated by STPI, at five locations across the United States. Insights from these regional discussions helped shape the content of the final report. Finally, FEMA and NIST recognize the dedication that Jon Heintz of the Applied Technology Council showed in preparing this high-quality product under unexpected conditions and tight scheduling. The final report benefited from his leadership and guidance.

The names and affiliations of all who contributed to this report are provided in the list of participants at the end of this report.

\section{Key Words}

Building, Built Environment, Community Resilience, Critical Infrastructure, Earthquake, Functionality, Functional Recovery, Lifeline Infrastructure System, Lifeline Services, Natural Hazard, Performance-Based Design, Recovery-Based Objective, Reoccupancy, Safety.

\section{Disclaimer}

Certain commercial entities, equipment, or materials may be identified in this publication in order to describe an experimental procedure or concept adequately. Such identification is not intended to imply recommendation or endorsement by the National Institute of Standards and Technology, the Federal Emergency Management Agency, the Applied Technology Council, or the Science Technology Policy Institute, nor is it intended to imply that the entities, materials, or equipment are necessarily the best available for the purpose.

Any opinions, findings, conclusions, or recommendations expressed in this publication do not necessarily reflect the views of the Federal Emergency Management Agency, the National Institute of Standards and Technology, the Applied Technology Council, or the Science Technology Policy Institute. As the work of the Committee of Experts was conducted to provide a range of perspectives on options for improving reoccupancy and functional recovery time, this report does not represent a consensus-based opinion being provided to the government.

Cover Images: Courthouse and emergency communications buildings courtesy of R. Kersting; railway and water distribution lifeline infrastructure systems courtesy of C. Davis. 


\section{Executive Summary}

The most recent reauthorization of the National Earthquake Hazards Reduction Program (NEHRP), P.L. 115-307, includes a heightened focus on achieving community resilience and a new requirement for the National Institute of Standards and Technology (NIST) and the Federal Emergency Management Agency (FEMA) to jointly convene a Committee of Experts to assess and recommend options for improving the built environment and critical infrastructure to reflect performance goals stated in terms of post-earthquake reoccupancy and functional recovery time.

To comply with this mandate, NIST and FEMA developed a plan of action in which FEMA funded a Project Technical Panel, responsible for report development, and NIST funded a Project Review Panel, responsible for report review. The Committee of Experts consisted of the Project Technical Panel, with 17 outside experts and representation from all interest groups named in the reauthorization, and the Project Review Panel, with 10 outside experts and similar representation. To facilitate national-level stakeholder interaction, NIST hosted five stakeholder workshops that were used to gather additional information and feedback.

This report provides a set of options in the form of recommendations, tasks, and alternatives for improving the built environment, which have been developed and assessed by the Committee of Experts. It describes community resilience, defines the concepts of reoccupancy and functional recovery, and explains the relationship among these three ideas. It explains why reoccupancy and functional recovery concepts are needed, describes a target performance state, and identifies potential cost and benefits associated with implementing enhanced seismic design. To fulfill the Congressional mandate, this report addresses the issue of functional recovery for seismic hazard. Although this report does not discuss the unique challenges associated with improving functional recovery for other hazards, recommendations in this report could be leveraged and adapted for other natural hazards.

The motivation for this report is the risk that the United States faces each year from all forms of natural hazards, including hurricanes, floods, wildfires, and earthquakes. Natural hazard events can affect communities through damage that results in injury and loss of life, interruption of lifeline services, displacement of residents and businesses, and economic and socio-cultural impacts. Almost half of the U.S. population -150 million people - reside in portions of 42 states that are at risk of experiencing a damaging earthquake within the next 50 years. Earthquakes have caused disastrous impacts in the past and are expected to cause more in the future. In regions of high seismic risk where an earthquake hasn't occurred for some time, scenario studies predict deaths in the thousands, injuries in the tens of thousands, and hundreds of billions of dollars in direct economic losses, along with long-term, destabilizing impacts to community function. 
In all cases, whether historic or scenario-based, the loss of life and property, and the negative impacts to the economy, were a direct result of the inability of the built environment to withstand the effects of earthquakes and other natural hazards. Because federal, state, and local, governments have critical functions in disaster recovery, they all can play an important role in facilitating the process to reduce the costs of recovery. To protect U.S. communities and taxpayers against future losses on the scale of those experienced in Hurricane Katrina, or predicted in earthquake scenario studies, a change in building codes, building practices, and societal values is needed.

To support resilience goals at the community level, there is a need to establish a link between the design, construction, and retrofit of individual buildings and lifeline infrastructure systems, and community resilience, as measured by time to recovery of function; but this link is currently missing. The concepts of reoccupancy and functional recovery have been introduced to serve as this link, defined as follows:

Reoccupancy is a post-earthquake performance state in which a building is maintained, or restored, to allow safe re-entry for the purposes of providing shelter or protecting building contents.

Functional recovery is a post-earthquake performance state in which a building or lifeline infrastructure system is maintained, or restored, to safely and adequately support the basic intended functions associated with the pre-earthquake use or occupancy of a building, or the pre-earthquake service level of a lifeline infrastructure system.

A key concept for functional recovery is that basic intended functions are something less than full pre-earthquake functionality, but more than what would be considered the minimum sufficient for reoccupancy of buildings or temporary provision of lifeline services. For each of these performance states, it will be necessary to define recovery-based objectives in the form of acceptable target recovery times at specified levels of earthquake shaking, and these acceptable recovery times might differ for various building uses and occupancies, or lifeline services.

The evolution of seismic building codes and standards has been fueled by the development of design guidance under the National Earthquake Hazards Reduction Program. In addition, decades of research and problem-focused studies have resulted in federal publications that have served to advance hazard mitigation and improve resilience. Recent guidance such as the Community Resilience Planning Guide for Buildings and Infrastructure Systems (NIST, 2016a), FEMA P-58 Seismic Performance Assessment of Buildings, Methodology and Implementation (FEMA, 2018a), Disaster Resilience: A National Imperative (NRC, 2012), the Safe Enough to Stay (SPUR, 2012), and the Oregon Resilience Plan: Reducing Risk and Improving Recovery for the Next Cascadia Earthquake and Tsunami (OSSPAC, 2013) have advanced practice to the point that explicit design for reoccupancy and functional recovery can be considered. Wide adoption of these practices will require further changes in building codes and building practices, and a shift in societal expectations of performance.

To initiate changes in design and construction practice to improve the built environment, this report provides an overarching recommendation related to developing a framework, and six additional supporting recommendations related to improving the performance of buildings, 
improving the performance of lifeline infrastructure systems, expediting recovery through predisaster planning, and enabling action with education and financial resources. Across all recommendations, there are 17 tasks identifying necessary actions and nine possible alternative actions needed for implementation of the recommendations.

Improving the performance of buildings and lifeline infrastructure systems in terms of reoccupancy and functional recovery time will require coordinated action across all recommendations. Although each recommendation can have a positive impact, maximum effectiveness will only be achieved when all of the recommendations are fully implemented. In summary, the recommendations are:

\section{Recommendation 1: Develop a Framework for Post-Earthquake Reoccupancy and} Functional Recovery Objectives. A framework for reoccupancy and functional recovery is needed to provide a national consensus on policies and technical criteria necessary to define what services must be in place and the design requirements needed for a building or lifeline infrastructure system to be occupiable or functionally recoverable within a specified timeframe after an earthquake.

\section{Recommendation 2: Design New Buildings to Meet Recovery-Based Objectives.} Because current building codes do not specifically address recovery-based objectives and resulting designs will yield inconsistent performance results, new buildings should be designed for specific recovery-based objectives that will support reliable reoccupancy and acceptable functional recovery times following a major earthquake.

\section{Recommendation 3: Retrofit Existing Buildings to Meet Recovery-Based Objectives.}

To address known vulnerabilities in the existing building inventory, existing buildings should be retrofitted to meet recovery-based objectives that will support reliable reoccupancy and acceptable functional recovery times following a major earthquake.

Recommendation 4: Design, Upgrade, and Maintain Lifeline Infrastructure Systems to Meet Recovery-Based Objectives. To improve the performance of lifeline infrastructure systems in a major earthquake, a recovery-based approach for the design of new systems and the upgrade and maintenance of existing systems is needed. Because the operation of a lifeline infrastructure system depends on numerous components, designed and built over time, using a variety of standards, procedures, and material types, the recovery-based design, upgrade, and maintenance of a system are combined and considered under a single recommendation.

\section{Recommendation 5: Develop and Implement Pre-Disaster Recovery Planning Focused} on Recovery-Based Objectives. Pre-disaster recovery planning involves making decisions before a disaster about how a community will recover after a disaster. Predisaster recovery planning by federal, state, local, tribal, and territorial governmental authorities, building owners and managers, and lifeline infrastructure system owners and operators is needed to improve reoccupancy and functional recovery times beyond what is achievable by design and construction alone. 


\section{Recommendation 6: Provide Education and Outreach to Enhance Awareness and}

Understanding of Earthquake Risk and Recovery-Based Objectives. Many people underestimate the risks associated with earthquakes and do not understand the performance that building codes are intended to provide. Education and outreach are needed to enhance awareness and understanding of earthquake risk and recovery-based objectives, and to enable communities to make rational decisions about how the built environment should be designed and constructed.

\section{Recommendation 7: Facilitate Access to Financial Resources Needed to Achieve} Recovery-Based Objectives. The probability of mitigation increases as the financial resources needed to facilitate mitigation are created and made available. A shift to a focus on recovery-based objectives will cost money. Those who will bear these costs will need to have access to additional financial resources needed to make such a shift. Existing mechanisms to facilitate access to financial resources should be augmented with newly developed and implemented mechanisms.

Implementation will involve public and private stakeholders and support at all levels of government, so individual recommendations, tasks, and alternatives have not been assigned to any specific federal agency. In considering the overall list of recommendations, and potential actions by stakeholders at all levels, the Committee offers the following list of actions that Congress might choose to take, or might choose to encourage other federal entities to perform:

- Support Technical Development. Support the development of policies along with practical and effective methods for design and retrofit of buildings and lifeline infrastructure systems to enable the implementation of Recommendations 1, 2, 3, and 4. Past successes of the NEHRP agencies in advancing the science and practice of seismic engineering should be leveraged and expanded towards the development of recovery-based provisions, codes, and standards for buildings. Furthermore, activities identified in the Earthquake Resistant Lifelines: NEHRP Research, Development and Implementation Roadmap (NIST, 2014) should be implemented for lifeline infrastructure systems. Advocacy for incorporation and adoption of the results of developmental efforts at various levels of government, and in the private sector, should also be supported.

- Incentivize Action. Encourage state and local jurisdictions to adopt recovery-based codes and standards, and engage in recovery-based planning, mitigation, financial, and other enabling activities envisioned under Recommendations 5 and 7.

- Encourage Federal Leadership by Example. Encourage the Executive Branch to develop recovery-based seismic design and retrofit requirements for federally owned and leased buildings, similar to actions that have been taken in the past. Additionally, the federal government should require lifeline infrastructure systems that are owned, managed, funded, or operated by federal agencies to be designed or upgraded to meet new federal recoverybased requirements.

- Mount an Education Campaign. Lead the development and implementation of an education campaign as discussed under Recommendation 6 and support similar educational efforts by state and local jurisdictions. The purpose of such a campaign would be to create public awareness and a political environment that would allow other recommendations to be successful. 
Action at the federal level is strongly encouraged to improve the built environment across the nation. Although taking no action would avoid additional federal expenditures in the short term, a lack of action would lead to higher federal response and recovery costs in future disasters.

Ultimately, the improved resilience resulting from taking action will yield communities that are better prepared and better able to recover rapidly from future earthquakes and other natural hazards, while saving lives, livelihoods, money, and time. 



\section{Table of Contents}

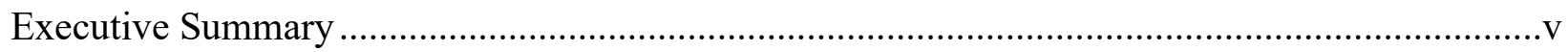

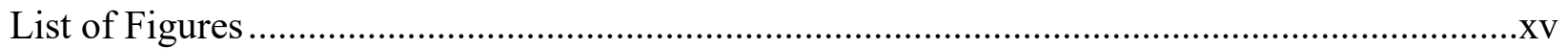

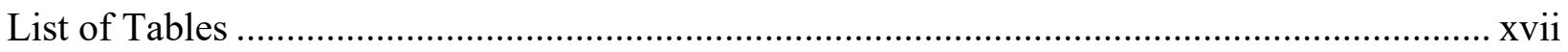

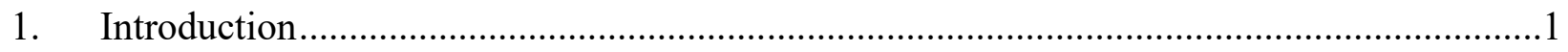

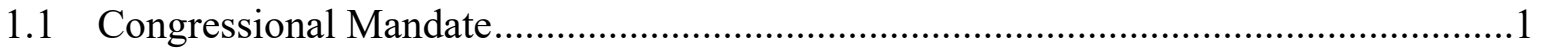

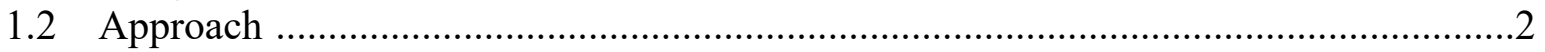

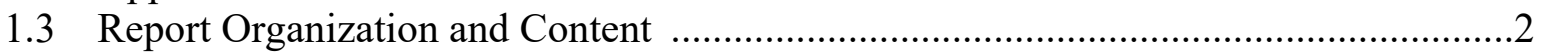

1.4. Motivation for Change ............................................................................................5

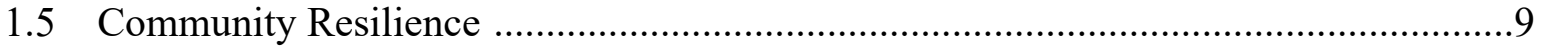

1.6 Reoccupancy and Functional Recovery ...................................................................10

1.6.1 Reoccupancy Defined ...........................................................................12

1.6.2 Functional Recovery Defined.............................................................................12

1.6.3 Description of a Target Recovery-Based Performance State ..............................13

1.7 Advancement in Design Capabilities.....................................................................

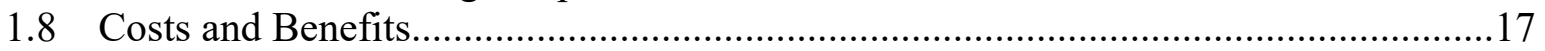

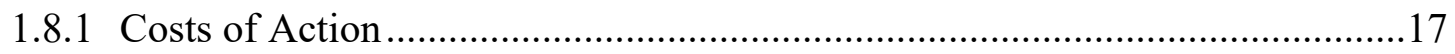

1.8.2 Benefits of Action ...................................................................................... 18

2. Framework for Reoccupancy and Functional Recovery ........................................................2

RECOMMENDATION 1: Develop a Framework for Post-Earthquake Reoccupancy and Functional Recovery Objectives .........................................................................2

Task 1.1: Develop a Policy for Recovery-Based Objectives......................................22

Task 1.2: Develop Design Criteria for Achieving Recovery-Based Objectives.........23

Task 1.3: Determine Appropriate Hazard Levels for Recovery-Based Objectives

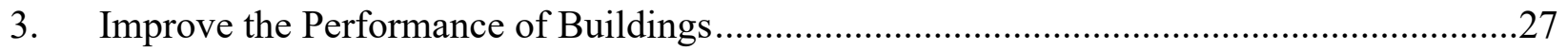

RECOMMENDATION 2: Design New Buildings to Meet Recovery-Based

Objectives..... .28

Alternative 2-1: Mandate the Design of New Buildings to Meet Recovery-Based Objectives Using Future National Model Code Provisions................30

Alternative 2-2: Mandate the Design of New Buildings to Meet Recovery-Based Objectives Using Interim Provisions ..... .30

Alternative 2-3: Encourage the Voluntary Design of New Buildings to Meet Recovery-Based Objectives .30 
RECOMMENDATION 3: Retrofit Existing Buildings to Meet Recovery-Based

Objectives

Alternative 3-1: Mandate the Retrofit of Existing Buildings to Meet RecoveryBased Objectives.

Alternative 3-2: Trigger the Retrofit of Existing Buildings to Meet RecoveryBased Objectives

Alternative 3-3: Encourage the Voluntary Retrofit of Existing Buildings to Meet Recovery-Based Objectives

4. Improve the Performance of Lifeline Infrastructure Systems.

RECOMMENDATION 4: Design, Upgrade, and Maintain Lifeline Infrastructure

Systems to Meet Recovery-Based Objectives

Task 4.1: Provide National Guidance on Regulatory Authority Across Lifeline Infrastructure Sectors

Task 4.2: Evaluate the Ability of Lifeline Infrastructure Systems to Meet

Recovery-Based Objectives

Task 4.3: Develop National Seismic Design Standards to Meet Recovery-Based Objectives for Lifeline Infrastructure Systems

Task 4.4: Create Regional Lifelines Councils

Alternative 4-1: Mandate the Design of New and Upgrade of Existing Lifeline Infrastructure Systems to Meet Recovery-Based Objectives

Alternative 4-2: Encourage the Voluntary Design of New and Upgrade of Existing Lifeline Infrastructure Systems to Meet RecoveryBased Objectives.

Alternative 4-3: Trigger the Upgrade of Existing Lifeline Infrastructure Systems to Meet Recovery-Based Objectives

5. Expedite Recovery through Pre-Disaster Planning and Implementation

RECOMMENDATION 5: Develop and Implement Pre-Disaster Recovery Planning

Focused on Recovery-Based Objectives

Task 5.1: Develop and Implement Pre-Disaster Recovery Plans ..............................48

Task 5.2: Create and Promote Seismic Continuity Programs....................................50

Task 5.3: Expand and Improve Criteria, Guidelines, and Procedures for PostEarthquake Assessments and Evaluations .51

Task 5.4: Plan for Sufficient Staffing to Expedite Post-Earthquake Recovery .........53

Task 5.5: Develop and Implement Building Occupancy Resumption Programs ......54

Task 5.6: Develop Alternative Standards for Temporary Habitability to Facilitate Reoccupancy

6. Enable Action with Education and Financial Resources

RECOMMENDATION 6: Provide Education and Outreach to Enhance Awareness and Understanding of Earthquake Risk and Recovery-Based Objectives...

Task 6.1: Educate Building and Lifeline Infrastructure System Stakeholders about Earthquake Risk and Recovery-Based Objectives. 
Task 6.2: Educate Design and Construction Industry Professionals about Earthquake Risk and Recovery-Based Objectives.

RECOMMENDATION 7: Facilitate Access to Financial Resources Needed to Achieve

Recovery-Based Objectives. .60

Task 7.1: Develop and Deploy Pre-Disaster Financial Mechanisms to Achieve Recovery-Based Objectives .... 61

Task 7.2: Develop and Deploy Post-Disaster Financial Mechanisms to Achieve Recovery-Based Objectives

7. Assessment and Conclusions .67

7.1 Qualitative Assessment of Recommendations and Alternatives ..............................67

7.2 Stakeholder Roles ....................................................................................... 70

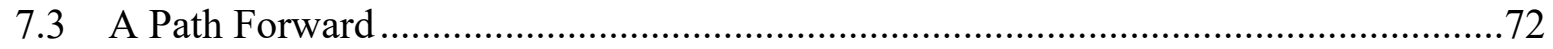

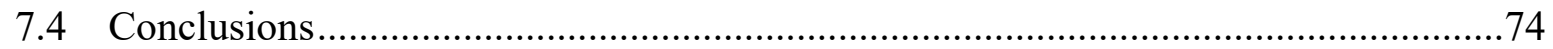

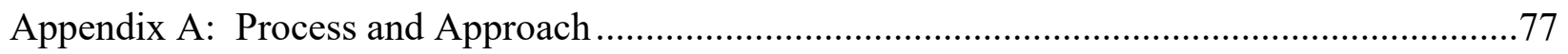

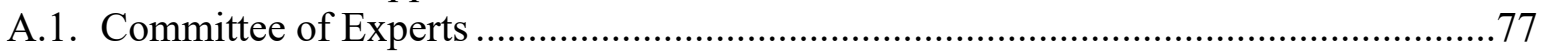

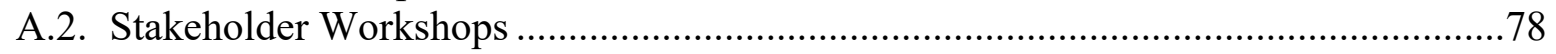

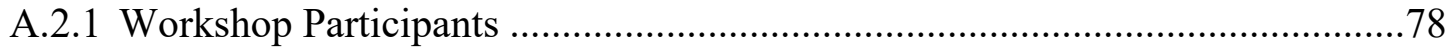

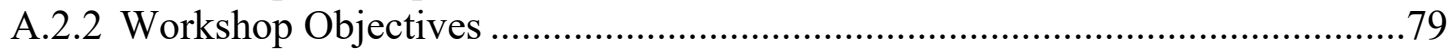

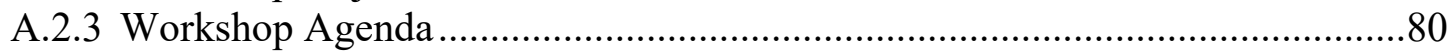

A.2.4 Breakout Session 1: Functional Recovery Framework ..................................80

A.2.5 Breakout Sessions 2 and 3: Assessing and Evaluating Options ........................80

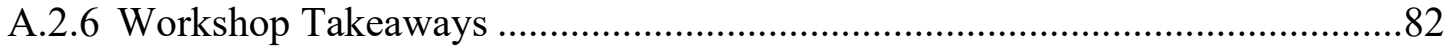

Appendix B: Supplemental Information on a Framework for Reoccupancy and Functional

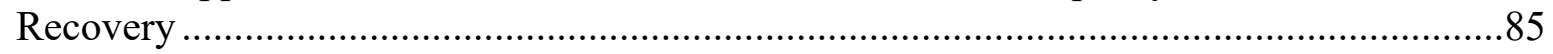

B.1 Conceptual Illustration of Recovery Categories .............................................. 85

B.2 Damage Descriptions for Buildings and Lifeline Infrastructure Systems Meeting Different Target Functional Recovery Times .....................................................86

Appendix C: Supplemental Information on Lifeline Infrastructure Systems ...........................89

C.1 Summary of Topics Identified in the NEHRP Lifelines Roadmap...........................89

C.2 Possible Tasks for a New National Lifelines Organization ....................................91

Appendix D: Supplemental Information on Pre-Disaster Planning and Implementation............93

D.1 Examples of Seismic Continuity Programs ..........................................................93

D.2 Examples of Assessment and Evaluation Guidelines ..........................................94

D.3 Seismic Instrumentation and Other Smart Technologies......................................95

D.4 Examples of Building Occupancy Resumption Programs and Other Similar

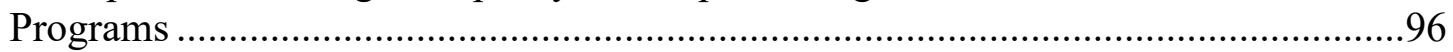

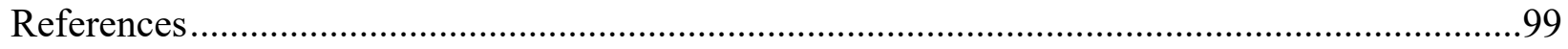

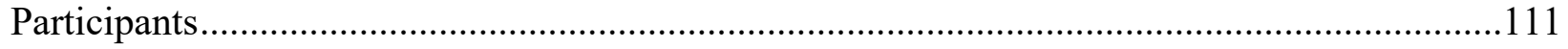





\section{List of Figures}

Figure 1-1 Regions of the United States at risk of significant earthquake shaking

Figure 1-2 Theoretical range of building performance and relative placement of safetybased and recovery-based goals.

Figure 1-3 Illustration of different size earthquakes in terms of the relative intensity of ground shaking, as observed in different earthquake recordings............................16

Figure 4-1 Interdependencies of lifeline infrastructure systems in San Francisco....................38

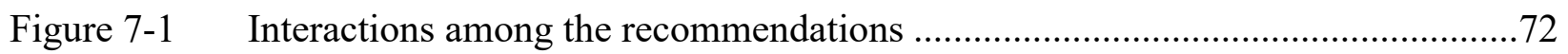

Figure A-1 Workshop attendees across the five locations: (a) by stakeholder group; and (b) as a percentage of expertise present at the workshop......................................79

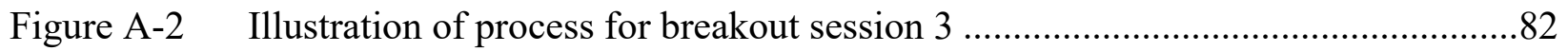

Figure D-1 Advisory Tag System process.............................................................................96 



\section{List of Tables}

Table 1-1 Summary Recommendations and Placement in Report.....................................3

Table 1-2 List of Recommendations, Tasks, and Alternatives for Improving the Built Environment to Achieve Post-Earthquake Reoccupancy and Functional

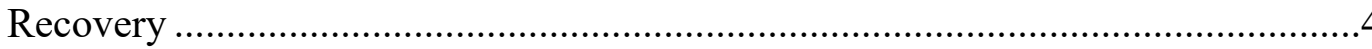

Table 7-1 Assessment of Recommendations..................................................................68

Table 7-2 Assessment of Alternatives Under Recommendation 2: Design New Buildings to Meet Recovery-Based Objectives ............................................................69

Table 7-3 Assessment of Alternatives Under Recommendation 3: Retrofit Existing Buildings to Meet Recovery-Based Objectives

Table 7-4 Assessment of Alternatives Under Recommendation 4: Design, Upgrade, and Maintain Lifeline Infrastructure Systems to Meet Recovery-Based Objectives .70

Table 7-5 Roles of Different Stakeholders in Implementation of Recommendations ...........71

Table 7-6 Timeline for Implementation ..................................................................... 73

Table B-1 Conceptual Functional Recovery Categories for a Design Hazard Level .............85

Table B-2 Possible Functional Recovery Times for Different Earthquake Hazard Levels. 



\section{Chapter 1}

\section{Introduction}

\subsection{Congressional Mandate}

The most recent reauthorization of the National Earthquake Hazards Reduction Program (NEHRP), P.L. 115-307, includes a heightened focus on achieving community resilience. It adds a new requirement under NEHRP activities for the National Institute of Standards and Technology (NIST) and the Federal Emergency Management Agency (FEMA). The new requirement reads as follows:

SEC. 5. SEISMIC STANDARDS.

(a) ASSESSMENT AND RECOMMENDATIONS.-Not later than December 1, 2019, the Director of the National Institute of Standards and Technology and the Administrator of the Federal Emergency Management Agency shall jointly convene a committee of experts from federal agencies, nongovernmental organizations, private sector entities, disaster management professional associations, engineering professional associations, and professional construction and homebuilding industry associations, to assess and recommend options for improving the built environment and critical infrastructure to reflect performance goals stated in terms of post-earthquake reoccupancy and functional recovery time.

(b) REPORT TO CONGRESS.-Not later than June 30, 2020, the committee convened under paragraph (1) shall submit to the Committee on Commerce, Science, and Transportation, the Committee on Energy and Natural Resources, and the Committee on Homeland Security and Governmental Affairs of the Senate and the Committee on Science, Space, and Technology, the Committee on Natural Resources, and the Committee on Homeland Security of the House of Representatives a report on recommended options for improving the built environment and critical infrastructure to reflect performance goals stated in terms of post-earthquake reoccupancy and functional recovery time.

Further, according to the Congressional Research Service, in their publication, The National Earthquake Hazards Reduction Program (NEHRP): Issues in Brief, Updated December 13, 20181:

Section 5 of P.L. 115-307 updates the language in 42 U.S.C. 7705 b that previously called for the adoption of seismic safety standards for buildings constructed or leased by the federal government. The new language requires, instead, an assessment and recommendations for improving the built environment and critical infrastructure specifically "to reflect

\footnotetext{
${ }^{1}$ https://crsreports.congress.gov, R43141
} 
performance goals stated in terms of post-earthquake reoccupancy and functional recovery time."

"This language highlights one of the changes in overall NEHRP program direction to enhance the aspect of earthquake resilience, meaning building structures that would allow for continued use and reoccupancy following an earthquake."

The mandate refers to "built environment" and "critical infrastructure." However, the term "built environment" is generally understood to include buildings and infrastructure. Therefore, in the context of this report, built environment is used to refer to both buildings and critical infrastructure, where critical infrastructure is taken to mean lifeline infrastructure systems, which include transportation, electric power, communication, gas and liquid fuel, water and wastewater systems.

In the context of this report, "built environment" refers to both buildings and critical infrastructure, and "critical infrastructure" refers to lifeline infrastructure systems that society depends on.

\section{$1.2 \quad$ Approach}

In response to the Congressional mandate, NIST and FEMA jointly convened a Committee of Experts including representatives from federal agencies, nongovernmental organizations, private sector entities, disaster management professional associations, engineering professional associations, and professional construction and homebuilding industry associations. The Committee of Experts included a Project Technical Panel (PTP), funded by FEMA, charged with developing a report to Congress, and a Project Review Panel (PRP), funded by NIST, charged with providing review and feedback on the developing report. In fulfilling its charge, the Committee considered current design practice and likely performance of the built environment in future earthquakes, evolving concepts of resilience, and emerging technologies for assessing and reducing future disruption and losses from earthquakes. The Committee investigated how enhanced performance could be achieved through new design, retrofit, and strategic replacement of buildings and lifeline infrastructure systems, and explored how pre-disaster recovery planning, enhanced post-disaster response, education, and access to financial resources could lead to reduced reoccupancy and functional recovery times following an earthquake.

This report is a combined effort of the PTP in developing the report and the PRP in providing review and feedback. It provides a range of perspectives from the Committee of Experts on options for improving the built environment. To facilitate national-level stakeholder interaction, five stakeholder workshops were held in St. Louis, Salt Lake City, Seattle, San Francisco, and Los Angeles. Workshop discussions were used to gather additional feedback on potential report content. Appendix A contains more detailed information on Committee and workshop processes and approaches.

\subsection{Report Organization and Content}

This report provides a set of recommended options, developed and assessed by the Committee of Experts. It describes community resilience, defines the concepts of reoccupancy and functional recovery, and explains the relationship among these three ideas. It explains why reoccupancy and functional recovery concepts are needed, describes a target performance state, and identifies 
potential costs and benefits associated with implementing enhanced seismic design. To fulfill the Congressional mandate, this report addresses the issue of functional recovery for seismic hazard. Although this report does not discuss the unique challenges associated with improving functional recovery for other hazards, recommendations in this report could be leveraged and adapted for other natural hazards.

The mandate requires the assessment and recommendation of options. In the context of this report, "recommended options" refers to the collection of recommendations, tasks, and alternatives for implementation described in the chapters that follow. Recommendations are groups of tasks and alternatives that, if implemented, would achieve a common result. Tasks are individual actions associated with implementation of a recommendation, all of which are considered necessary for achieving the intended result. Alternatives are actions for which there is choice associated with the implementation of a recommendation. Choosing among alternatives implies a tradeoff between advantages and disadvantages, and different alternatives within a

In the context of this report, "recommended options" refers to the collection of recommendations, tasks, and alternatives for implementation described in the chapters that follow. recommendation will not necessarily have the same effectiveness or achieve the same result.

This report includes an overarching recommendation related to developing a framework, and six additional supporting recommendations related to improving the performance of buildings, improving the performance of lifeline infrastructure systems, expediting recovery through predisaster planning, and enabling action with education and financial resources. The recommendations, and the chapters in which they are discussed, are summarized in Table 1-1.

Table 1-1 Summary Recommendations and Placement in Report

\begin{tabular}{|c|l|c|}
\hline Rec. & \multicolumn{1}{|c|}{ Description } & Chapter \\
\hline 1 & Develop a Framework for Post-Earthquake Reoccupancy and Functional Recovery Objectives & 2 \\
\hline 2 & Design New Buildings to Meet Recovery-Based Objectives & 3 \\
\hline 3 & Retrofit Existing Buildings to Meet Recovery-Based Objectives & 3 \\
\hline 4 & $\begin{array}{l}\text { Design, Upgrade, and Maintain Lifeline Infrastructure Systems to Meet Recovery-Based } \\
\text { Objectives }\end{array}$ & 4 \\
\hline 5 & $\begin{array}{l}\text { Develop and Implement Pre-Disaster Recovery Planning Focused on Recovery-Based } \\
\text { Objectives }\end{array}$ & 6 \\
\hline 6 & $\begin{array}{l}\text { Provide Education and Outreach to Enhance Awareness and Understanding of Earthquake } \\
\text { Risk and Recovery-Based Objectives }\end{array}$ & 6 \\
\hline 7 & \begin{tabular}{l} 
Facilitate Access to Financial Resources Needed to Achieve Recovery-Based Objectives \\
\hline
\end{tabular} & 6 \\
\hline
\end{tabular}

Across all recommendations, there are 17 tasks identifying necessary actions and nine possible alternative actions needed for implementation of the recommendations. Table 1-2 summarizes the compiled list of recommendations, tasks, and alternatives. 
Table 1-2 List of Recommendations, Tasks, and Alternatives for Improving the Built Environment to Achieve Post-Earthquake Reoccupancy and Functional Recovery

\begin{tabular}{|c|c|c|c|}
\hline Rec. & Task & Alt. & Description \\
\hline \multirow[t]{4}{*}{1} & & & $\begin{array}{l}\text { Develop a Framework for Post-Earthquake Reoccupancy and Functional } \\
\text { Recovery Objectives }\end{array}$ \\
\hline & 1.1 & & Develop a Policy for Recovery-Based Objectives \\
\hline & 1.2 & & Develop Design Criteria for Achieving Recovery-Based Objectives \\
\hline & 1.3 & & Determine Appropriate Hazard Levels for Recovery-Based Objectives \\
\hline \multirow[t]{4}{*}{2} & & & Design New Buildings to Meet Recovery-Based Objectives \\
\hline & & $2-1$ & $\begin{array}{l}\text { Mandate the Design of New Buildings to Meet Recovery-Based Objectives Using } \\
\text { Future National Model Code Provisions }\end{array}$ \\
\hline & & $2-2$ & $\begin{array}{l}\text { Mandate the Design of New Buildings to Meet Recovery-Based Objectives Using } \\
\text { Interim Provisions }\end{array}$ \\
\hline & & $2-3$ & $\begin{array}{l}\text { Encourage the Voluntary Design of New Buildings to Meet Recovery-Based } \\
\text { Objectives }\end{array}$ \\
\hline \multirow[t]{4}{*}{3} & & & Retrofit Existing Buildings to Meet Recovery-Based Objectives \\
\hline & & $3-1$ & Mandate the Retrofit of Existing Buildings to Meet Recovery-Based Objectives \\
\hline & & $3-2$ & Trigger the Retrofit of Existing Buildings to Meet Recovery-Based Objectives \\
\hline & & $3-3$ & $\begin{array}{l}\text { Encourage the Voluntary Retrofit of Existing Buildings to Meet Recovery-Based } \\
\text { Objectives }\end{array}$ \\
\hline \multirow[t]{8}{*}{4} & & & $\begin{array}{l}\text { Design, Upgrade, and Maintain Lifeline Infrastructure Systems to Meet } \\
\text { Recovery-Based Objectives }\end{array}$ \\
\hline & 4.1 & & $\begin{array}{l}\text { Provide National Guidance on Regulatory Authority Across Lifeline Infrastructure } \\
\text { Sectors }\end{array}$ \\
\hline & 4.2 & & $\begin{array}{l}\text { Evaluate the Ability of Lifeline Infrastructure Systems to Meet Recovery-Based } \\
\text { Objectives }\end{array}$ \\
\hline & 4.3 & & $\begin{array}{l}\text { Develop National Seismic Design Standards to Meet Recovery-Based Objectives for } \\
\text { Lifeline Infrastructure Systems }\end{array}$ \\
\hline & 4.4 & & Create Regional Lifelines Councils \\
\hline & & $4-1$ & $\begin{array}{l}\text { Mandate the Design of New and Upgrade of Existing Lifeline Infrastructure Systems } \\
\text { to Meet Recovery-Based Objectives }\end{array}$ \\
\hline & & $4-2$ & $\begin{array}{l}\text { Encourage the Voluntary Design of New and Upgrade of Existing Lifeline } \\
\text { Infrastructure Systems to Meet Recovery-Based Objectives }\end{array}$ \\
\hline & & $4-3$ & $\begin{array}{l}\text { Trigger the Upgrade of Existing Lifeline Infrastructure Systems to Meet Recovery- } \\
\text { Based Objectives }\end{array}$ \\
\hline
\end{tabular}


Table 1-2 List of Recommendations, Tasks, and Alternatives for Improving the Built Environment to Achieve Post-Earthquake Reoccupancy and Functional Recovery (cont'd)

\begin{tabular}{|c|c|c|}
\hline \multirow[t]{7}{*}{5} & & $\begin{array}{l}\text { Develop and Implement Pre-Disaster Recovery Planning Focused on Recovery- } \\
\text { Based Objectives }\end{array}$ \\
\hline & 5.1 & Develop and Implement Pre-Disaster Recovery Plans \\
\hline & 5.2 & Create and Promote Seismic Continuity Programs \\
\hline & 5.3 & $\begin{array}{l}\text { Expand and Improve Criteria, Guidelines, and Procedures for Post-Earthquake } \\
\text { Assessments and Evaluations }\end{array}$ \\
\hline & 5.4 & Plan for Sufficient Staffing to Expedite Post-Earthquake Recovery \\
\hline & 5.5 & Develop and Implement Building Occupancy Resumption Programs \\
\hline & 5.6 & Develop Alternative Standards for Temporary Habitability to Facilitate Reoccupancy \\
\hline \multirow[t]{3}{*}{6} & & $\begin{array}{l}\text { Provide Education and Outreach to Enhance Awareness and Understanding of } \\
\text { Earthquake Risk and Recovery-Based Objectives }\end{array}$ \\
\hline & 6.1 & $\begin{array}{l}\text { Educate Building and Lifeline Infrastructure System Stakeholders about Earthquake } \\
\text { Risk and Recovery-Based Objectives }\end{array}$ \\
\hline & 6.2 & $\begin{array}{l}\text { Educate Design and Construction Industry Professionals about Earthquake Risk and } \\
\text { Recovery-Based Objectives }\end{array}$ \\
\hline \multirow[t]{3}{*}{7} & & $\begin{array}{l}\text { Facilitate Access to Financial Resources Needed to Achieve Recovery-Based } \\
\text { Objectives }\end{array}$ \\
\hline & 7.1 & $\begin{array}{l}\text { Develop and Deploy Pre-Disaster Financial Mechanisms to Achieve Recovery-Based } \\
\text { Objectives }\end{array}$ \\
\hline & 7.2 & $\begin{array}{l}\text { Develop and Deploy Post-Disaster Financial Mechanisms to Achieve Recovery- } \\
\text { Based Objectives }\end{array}$ \\
\hline
\end{tabular}

Recommendations, tasks, and alternatives can be assessed using any number of criteria, including technical or political feasibility, initial or life-cycle costs, and net benefit or benefitcost ratios. Quantitative assessment, however, is beyond the scope of this report. Instead, recommendations, tasks, and alternatives are qualitatively assessed, based on the experience and judgement of the Committee of Experts, using the following criteria: effectiveness, feasibility, cost, and time for development. Qualitative assessments are provided in Chapter 7.

A recommendation, task, or alternative in this report is not necessarily meant to be implemented by Congress, or any other specific federal agency. A list of actions that Congress might choose to take, along with the potential roles of different stakeholder groups in the implementation of recommendations, are described in Chapter 7. Additional, more detailed background information, technical information, and commentary on the recommendations, tasks, and alternatives are provided in the Appendices.

\subsection{Motivation for Change}

Natural hazard events cost the United States an average of $\$ 100$ billion annually (Smith and Katz, 2013). In 2017 , losses exceeded $\$ 300$ billion, which was approximately $\$ 1,000$ per 
American and about $25 \%$ of the $\$ 1.3$ trillion worth of new construction put in place that year (U.S. Census Bureau, 2018). Each year the United States is at risk of experiencing damaging events from all forms of natural hazards, including hurricane, flood, wildfire, and earthquakes. These events can affect communities through damage that results in injury and loss of life, interruption of lifeline services, displacement of residents and businesses, and economic and socio-cultural impacts. They have the potential to yield negative consequences for years, even decades, and community recovery is not assured. The speed of recovery can affect whether community members decide to stay and rebuild or leave a community for good (Arendt and Alesch, 2014).

In 2005, Hurricane Katrina caused widespread damage and destruction of housing, schools, commercial and retail buildings, government facilities, and lifeline infrastructure systems in Alabama, Louisiana, and Mississippi. Direct property damage was estimated at $\$ 125$ billion (2005 dollars), and total losses, including federal assistance, lost business, and lost commerce were much larger (NOAA, 2018). Businesses closed and more than half of the population of New Orleans fled or resettled in other locations. Many stayed away permanently, in part, because recovery was slowed by a lack of safe and affordable housing, schools that remained shuttered, hospitals that were closed, jobs that were lost, issues with building and lifeline reconstruction, and politics that failed to enable swift and trustworthy decision making (Arendt and Alesch, 2014). Fifteen years later, the population of New Orleans remains at approximately $80 \%$ of what it was prior to the hurricane. One of the essential lessons learned from New Orleans and Hurricane Katrina was that the speed of recovery affects community perceptions of recovery, which, in turn, affects the availability of resources to enable recovery.

Earthquakes have caused similar disasters in the past and are expected to cause more in the future. The magnitude 7.8 earthquake and resulting fires on April 18, 1906 devastated much of San Francisco, then the nation's ninth largest city, resulting in catastrophic losses and a shift in economic growth to regions that were less affected by the earthquake (Ager et al., 2019). The magnitude 9.2 Great Alaskan earthquake on March 27, 1964 destroyed much of Anchorage, Alaska. More recent events, such as the magnitude 6.7 Northridge earthquake on January 17, 1994 caused significant damage to the built environment and direct economic losses of $\$ 42$ billion (1998 dollars). Insured losses in Northridge cost more than three times the total earthquake premiums collected in the 25 -year period prior to the disaster, which eventually led to an insurance availability crisis and collapse of the earthquake insurance industry in California (Petak and Elahi, 2001).

Almost half of the U.S. population - 150 million people - reside in portions of 42 states that are at risk of experiencing a damaging earthquake within the next 50 years. Sixteen of those states, including California, Oregon, Washington, Alaska, Hawaii, Tennessee, and Missouri, are at very high risk, and their metropolitan regions could face unprecedented life loss and catastrophic damage to buildings, critical infrastructure, and lifeline infrastructure systems with cascading social and economic consequences (Petersen et al., 2014). A disaster in one community or state can have economic and social impacts on neighboring communities or states, if not the entire nation, highlighting the importance of natural hazard mitigation at the Almost half of the U.S. population -150 million people - reside in portions of 42 states that are at risk of experiencing a damaging earthquake within the next 50 years. federal level. 
Figure 1-1 is a map produced by the United States Geological Survey (USGS) showing regions of the United States that are at risk for a level of earthquake shaking that can be expected, on average, every 500 years. In the map, earthquake shaking is measured by Modified Mercalli Intensity (MMI), which is a scale capturing the effects of earthquakes ranging from imperceptible shaking (MMI I) to extreme shaking (MMI X). MMI IV corresponds to light shaking felt mostly by people indoors, while widespread shaking corresponding to MMI VIII or higher can produce catastrophic damage like that experienced in downtown Christchurch, New Zealand from the M6.3 earthquake in 2011 (EERI, 2011). Of the cities identified in the figure, there is nearly a $60 \%$ chance that at least one, and nearly a $40 \%$ chance that two or more, will experience such an event in the next 50 years.

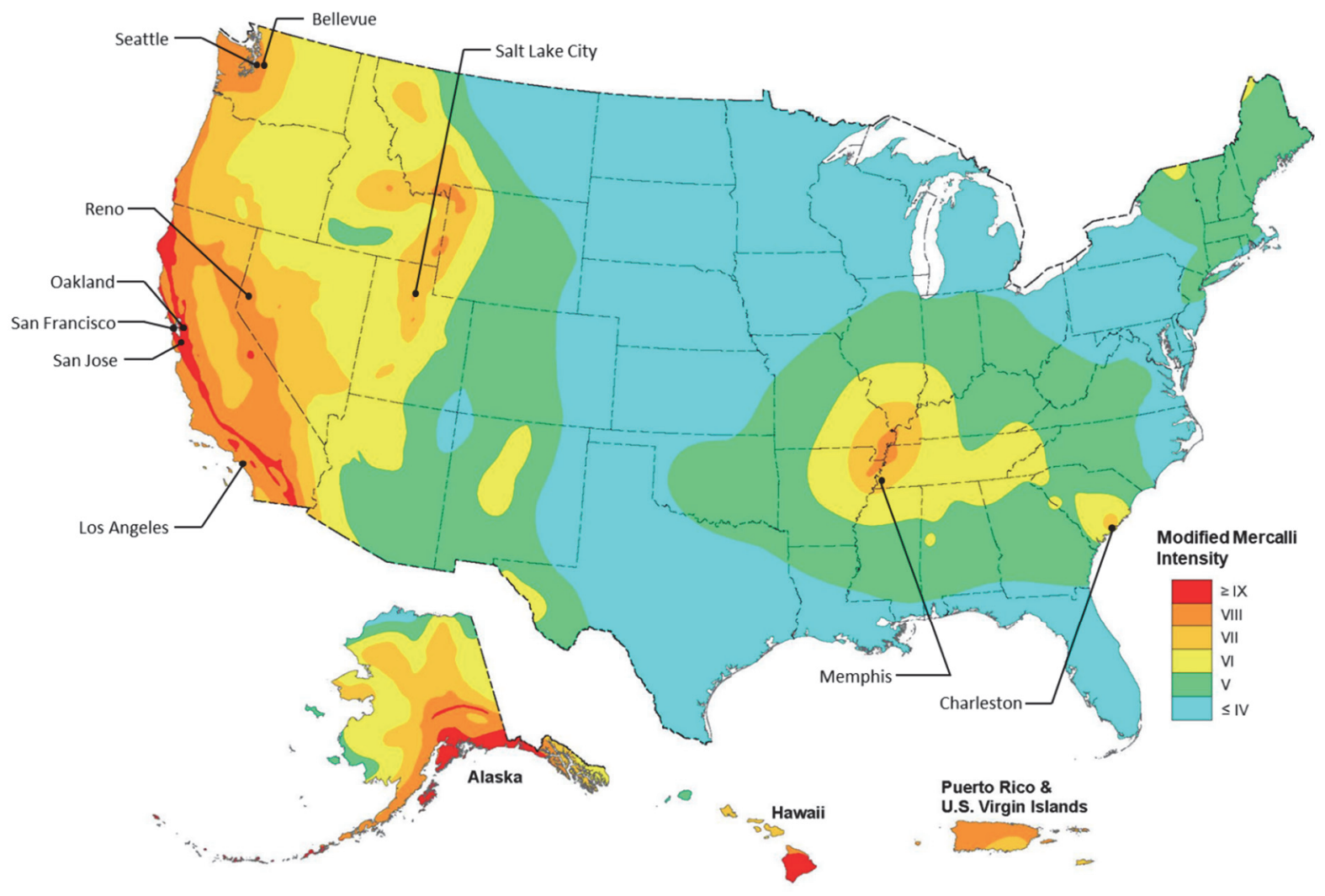

\section{Figure 1-1 Regions of the United States at risk of significant earthquake shaking (courtesy of N. Luco, USGS).}

In regions of high seismic risk where an earthquake hasn't occurred for some time, scenario studies can be used to understand the potential impacts of future large earthquakes:

- In a scenario repeating the 1906 earthquake, Kircher et al. (2006) estimates that more than 90,000 buildings in the San Francisco Bay area would be damaged, and the cost to repair and replace damage to buildings and infrastructure would be $\$ 150$ billion (2006 dollars).

- Similarly, in a USGS study of a magnitude 7.8 earthquake scenario in Southern California, Perry et al. (2008) estimates 2,000 deaths, 50,000 injuries, and $\$ 200$ billion in direct costs (2008 dollars), along with long-term, destabilizing impacts to community function. 
- In a more recent USGS study of a magnitude 7.0 earthquake scenario on the Hayward Fault along the east side of San Francisco Bay, Hudnut et al. (2018) estimates 800 deaths, 18,000 injuries, and property damage and direct economic losses of more than $\$ 82$ billion (2016 dollars).

- Other scenarios looking at potential earthquakes in Oregon, San Diego, and Salt Lake City reveal similar consequences for the built environment and for the people, economy, and culture of these communities. For example, the Oregon Resilience Plan is based on a magnitude 9.0 great Cascadia earthquake and tsunami scenario, with estimated fatalities of more than 10,000 due to the combined effects of earthquake and tsunami, tens of thousands of buildings destroyed or damaged so extensively that they will require months to years of repair, tens of thousands of displaced households, more than $\$ 30$ billion in direct and indirect economic losses (close to one-fifth of Oregon's gross state product), and more than one million truckloads of debris (Yu et al., 2014).

In all cases, whether historic or scenario-based, the loss of life and property, and the negative impacts to the economy, were a direct result of the inability of the built environment to withstand the effects of earthquakes and other natural hazards. Because federal, state, and local governments have critical functions in disaster recovery, they all can play an important role in facilitating the process to reduce the costs of recovery. Developed in response to Presidential Policy Directive 8 (PPD-8) (The White House, 2011), the National Preparedness Goal (FEMA, 2015a) envisions "a secure and resilient nation with the capabilities required across the whole community to prevent, protect against, mitigate, respond to, and recover from the threats and hazards that pose the greatest risk." The National

The cost of damage from extreme natural hazard events is extraordinarily high and the time needed for recovery is significantly longer than most people expect or are willing to accept. Preparedness Goal establishes an important objective for preparedness. It recognizes that the cost of damage from extreme natural hazard events is extraordinarily high and the time needed for recovery is long - significantly longer than most people expect or are willing to accept (Arendt and Alesch, 2014). It should be noted that the Defense Critical Electric Infrastructure (DCEI) may be a component of some lifelines infrastructure systems, and their timely recovery could minimize the potential national security implications resulting from a natural hazard event.

After decades of investment, the capability to design and construct buildings and lifeline infrastructure systems for enhanced earthquake performance has been developed. However, current building codes and lifeline infrastructure system design criteria do not explicitly protect against economic losses or require buildings or lifeline infrastructure systems to be serviceable following an earthquake. A recent FEMA study (FEMA, 2018b) suggests that $20 \%$ to $40 \%$ of modern code-conforming buildings in an affected region would be unfit for occupancy following a large earthquake, taking months or years to repair, and $15 \%$ to $20 \%$ would be economically unrepairable, taking many years to replace. Moreover, older buildings and lifeline infrastructure systems in most U.S. cities do not conform to modern design requirements

Current building codes and lifeline infrastructure system design criteria do not explicitly protect against economic losses or require systems to be serviceable following an earthquake. and would perform even worse than new buildings under strong shaking. 
To protect U.S. communities and taxpayers against future losses on the scale of those experienced in Hurricane Katrina, or predicted in earthquake scenario studies, a change in codes, standards, construction practices, and societal values is needed. Individual cities and states have the power to do this, but most do not have the resources, or the mandate, to take on such a challenge, which is why support and leadership at the federal level is necessary. In a previous report mandated by Congress, Research Needs to Support Immediate Occupancy Building Performance Objective Following Natural Hazard Events (Sattar et al., 2018), NIST outlined research and public policy needs as well as implementation activities required to improve

To protect U.S. communities and taxpayers against future losses, a change in codes, standards, construction practices, and societal values is needed. the performance of buildings immediately following natural hazard events. This information and the overall process provided important background for the earthquake-focused functional recovery concepts developed in this report.

The need to reduce vulnerability, minimize losses, and improve the ability of communities to rapidly recover after future earthquakes and other natural hazard events, without excessive use of human, financial, and material resources, is the underlying motivation for promoting concepts of community resilience, reoccupancy, and functional recovery.

\subsection{Community Resilience}

Presidential Policy Directive 21 (PPD-21) (The White House, 2013) defines community resilience as:

"The ability to prepare for and adapt to changing conditions and to withstand and recover rapidly from disruptions. Resilience includes the ability to withstand and recover from deliberate attacks, accidents, or naturally occurring threats or incidents."

The overarching purpose of community resilience is to maintain the long-term viability of a community following an earthquake or other natural hazard event. In the NIST Community Resilience Planning Guide for Buildings and Infrastructure Systems (CRPG) (NIST, 2016a), community refers to a place designated by geographical boundaries that functions under the jurisdiction of a governance structure, such as a town, city, or county. The concept of community resilience can also be applied at larger scales, such as a region or metropolitan area, or at smaller scales, such as a university campus or military base. Community resilience involves social, cultural, economic, and human considerations along with built environment considerations. For communities at any scale to function and prosper, buildings and lifeline infrastructure systems need to support the government, industry, business, education, social, cultural, and health services needed for everyday life and overall community vitality.

A key concept of community resilience is interdependency, which can be one-way, two-way, or multiple-level reliance between systems that is required for each to be functional or provide services. This includes dependencies between human systems and the supporting built environment, as well as dependencies between different components of the built environment, especially in the case of natural hazard events. For example,

A key concept of community resilience is interdependency, which is reliance between systems that is required for each to be functional or provide services. 
communities require safe and serviceable structures as well as water distribution, electrical power grids, and transportation networks, which, in turn, support other critical services like food supply chains. These systems are becoming progressively more interconnected and reliant on power systems, communication systems, and modern conveniences associated with the technological advancements of the information age (Edwards, 2009).

Improving the resilience of a community takes time and requires implementation of long-term plans that address community resilience goals, which are incorporated into all community plans (e.g., comprehensive plans, hazard mitigation plans, and economic development plans) for effective and coordinated implementation. Determining resilience goals, setting public policy, and prioritizing the investment of limited resources are challenges requiring solutions involving a range of stakeholder groups and diversity of perspectives. Although resilience may be a shared goal, the various groups involved may have competing interests and varying levels of investment or technical knowledge that require consideration.

\subsection{Reoccupancy and Functional Recovery}

Implementing community resilience goals requires leadership with a strong commitment to resilience concepts, a long-term perspective, community support for capital investment, and dedication to continual improvements in mitigation, preparedness, response, and recovery activities. Although goals of improved community resilience are desirable, and increasingly necessary, they are also challenging to achieve and difficult to enforce. The FEMA-led Mitigation Framework Leadership Group (MitFLG) takes this issue further in its "Community Resilience Indicators and National-Level Measures: A Draft Interagency Concept" :

Although goals of improved community resilience are desirable, and increasingly necessary, they are also challenging to achieve and difficult to enforce.

"Defining and quantifying community resilience capacity can be challenging at any level; however, it is especially complicated on a national scale. While most actions to improve community resilience capacity occur at the local level, federal programs provide numerous resources that support relevant community capacity building nationwide. It is important to understand how such actions improve local resilience capacity. However, federal agencies also must gauge how their efforts individually and collectively impact community resilience capacity nationwide."

To support resilience goals at the community level, there is a need to establish a link between the design, construction, and retrofit of individual buildings and lifeline infrastructure systems, and community resilience, as measured by time to recovery of function (Bruneau, et al., 2003), but this link is currently missing. The concepts of reoccupancy and functional recovery have been introduced to serve as this link.

Functionality is a measure of how well a building or lifeline infrastructure system operates, delivers its required services, or meets its intended purpose. Time to recovery of function is a measure of how long it takes before a building or lifeline infrastructure system is functioning after an earthquake or other natural hazard event. Defining necessary and critical functions for a

${ }^{2}$ https://www.fema.gov/community-resilience-indicators 
building, or services for a lifeline infrastructure system, demands a community context and occurs as part of the community resilience planning process.

In contrast with community resilience, functional recovery refers to the performance of a distinct piece of the built environment, such as an individual building or lifeline infrastructure system (NIBS, 2019b), and time to recovery of function for buildings and lifeline infrastructure systems is a means of defining performance that contributes to community resilience. The concept of functional recovery is intended to allow for the design of individual buildings and lifeline infrastructure systems in a manner that serves community resilience goals, but depends less on resilience planning and implementation activities at the community scale, and instead relies on building codes for individual buildings and industry standards for lifeline infrastructure systems. The interdependency of different buildings and lifeline infrastructure systems on the damage state of others would have to be addressed at the community level.

The concept of functional recovery is intended to allow for the design of individual buildings and lifeline infrastructure systems in a manner that serves community resilience goals, but depends less on resilience planning and implementation activities at the community scale.

Not all community services, buildings, or lifeline infrastructure systems are needed in the immediate aftermath of an event, implying different functional levels at which buildings and lifeline infrastructure systems can be expected to perform. Time to recovery of function can be considered in terms of three recovery phases: short-term, intermediate, and longterm, as defined in the FEMA National Disaster Recovery Framework (FEMA, 2016).

Recent sources have attempted to define functional recovery in an engineering context (Bonowitz, 2011; Arup, 2013) and a resilience context (Davis, 2019; EERI, 2019). In the case of buildings, functional recovery is one of three post-earthquake recovery milestones beyond basic safety, which include reoccupancy, functional recovery, and full recovery (Bonowitz, 2011):

- Reoccupancy is the ability to safely re-enter a building after evacuation, including the ability to safely occupy the building while clean-up or repairs are made. Building services are not necessarily functional, except those services required for legal occupancy and needed for safety.

- Functional recovery is a step beyond reoccupancy, which includes safe occupancy, and includes restoration of building components and services to support a significant measure of pre-earthquake functionality.

- Full recovery is restoration to the pre-earthquake safety and functionality of the building.

In the case of lifeline infrastructure systems, functional recovery is one of two recovery milestones, which include operability and functionality (Davis, 2019):

- Operability is the ability of an infrastructure system to provide near-normal services to a customer, sufficient for supporting a significant measure of pre-earthquake functionality (i.e., functional recovery).

- Functionality is a measure of an infrastructure system working normally to provide its regular and reliable pre-earthquake services. Full functionality (i.e., full recovery) is achieved when the entire system is functioning at this level. 
The ultimate goal of community resilience is to fully recover within a reasonable period of time.

\subsubsection{Reoccupancy Defined}

In the context of this report, reoccupancy is a performance state for buildings, defined as follows:

Reoccupancy is a post-earthquake performance state in which a building is maintained, or restored, to allow safe re-entry for the purposes of providing shelter or protecting building contents.

In simpler terms, reoccupancy means a building, having gone through an earthquake, is safe to enter and use for shelter, although it might not be ready to support basic functions or normal use. Using concepts from performance-based engineering, design for reoccupancy would involve the selection of a reoccupancy objective, defined as follows:

A reoccupancy objective is reoccupancy achieved within an acceptable time following a specified earthquake, where the acceptable time might differ for various building uses and occupancies.

\subsubsection{Functional Recovery Defined}

In the context of this report, functional recovery is a performance state for buildings and lifeline infrastructure systems, defined as follows:

Functional recovery is a post-earthquake performance state in which a building or lifeline infrastructure system is maintained, or restored, to safely and adequately support the basic intended functions associated with the pre-earthquake use or occupancy of a building, or the pre-earthquake service level of a lifeline infrastructure system.

Basic intended functions are less than full pre-earthquake functionality, but more than what would be considered the minimum sufficient for reoccupancy of buildings, or for temporary provision of lifeline services. In simpler terms, functional recovery for a building means it is ready to support most of its pre-earthquake uses in addition to reoccupancy, and for a lifeline infrastructure system means it is ready to provide near-normal basic services, although the system may not be as reliable or resistant to service interruptions. This means a house is ready to not only provide shelter but also meet basic safety codes and is ready to be legally lived in while repair and cleanup are taking place; a school is ready to hold classes but the auditorium might be closed; a restaurant is ready to take customers but might have reduced seating capacity; and an office building or factory is ready to get back to business but might have reduced production capacity. Similarly, for lifeline infrastructure systems, functional recovery means a water system is delivering near-normal water supplies to its pre-earthquake customers, a power grid is delivering electricity at near-normal capacity, and a bridge or street grid is ready to carry nearnormal traffic, but systems may be in a more vulnerable state and may need additional repairs to reach full functionality.

Using concepts from performance-based engineering, design for functional recovery would involve the selection of a functional recovery objective, defined as follows: 
A functional recovery objective is functional recovery achieved within an acceptable time following a specified earthquake, where the acceptable time might differ for various building uses and occupancies, or lifeline services.

Although the determination of basic intended functions is informed by a community context and considers dependencies between multiple aspects of the built environment, a functional recovery objective is applied at the individual building or lifeline infrastructure system level, and functional recovery is achieved through the design of individual buildings and lifeline infrastructure systems. Design for functional recovery should be coordinated between buildings and lifeline infrastructure systems, but functional recovery objectives are applied independently to each element (i.e., each building or lifeline infrastructure system) because they are planned, financed, and

Functional recovery will be achieved through the design of individual buildings and lifeline infrastructure systems to support community resilience. constructed by different owners at different times.

This means that the design of a building should be informed by the expected performance of lifeline infrastructure systems, but not controlled by it, and the design of an individual lifeline infrastructure system will be informed by the performance of interdependent systems and buildings, but not controlled by them. For example, the design of a building structural system would not be affected by the potential loss of the electrical power distribution system, but a decision to provide on-site emergency power generation would be informed by it. Similarly, the design of a critical pump station for water or liquid fuel distribution would be independent of the performance of the electrical power distribution system, but the potential loss of power would inform a decision to provide a back-up generator with sufficient volume of stored fuel to maintain basic functions for a defined period of time.

\subsubsection{Description of a Target Recovery-Based Performance State}

Reoccupancy and functional recovery objectives are collectively referred to as recovery-based objectives. Overall performance resulting from design of buildings and lifeline infrastructure systems for recovery-based objectives is the result of meeting a target performance state at a community scale.

Design for recovery-based objectives can lead to a target performance state in which communities across the nation are more resilient to natural hazards, with an acceptable level of disruption to lives and property. By designing and retrofitting buildings and lifeline infrastructure systems to meet recovery-based objectives, communities will have an increased likelihood of timely access to functions and services that are key to their sustained health, security, vitality, and identity.

A target recovery-based performance state is achieved at the community level when:

Reoccupancy and functional recovery objectives are collectively referred to as recovery-based objectives.

Design for recoverybased objectives can lead to a target performance state in which communities are more resilient to natural hazards.

- Under normal operating conditions (i.e., absent the occurrence of an earthquake), buildings and lifeline infrastructure systems are designed, built, operated, retrofitted, and maintained to provide intended functions and services to users. 
- Following an earthquake, buildings and lifeline infrastructure systems are able, or can be restored, to provide basic intended functions and services to users within acceptable recovery times, such as within days or weeks instead of months or possibly years.

- Acceptable recovery times vary by use, occupancy, and criticality of function or service. Not all functions and services are needed immediately, nor are all functions and services needed at the same time along a recovery timeline. Factors specific to the community (e.g., environmental conditions and socioeconomic considerations) may affect decisions on acceptable recovery times for certain functions or services.

- Community members recognize and accept that damage cannot be fully prevented in all earthquakes, and some loss of service is likely to occur, even after implementing recoverybased objectives and strategies. Furthermore, community members expect and plan for reasonable variation in actual recovery times relative to target recovery times due to inherent uncertainty and variability in the nature of the earthquake hazard and the current state of a building or lifeline infrastructure system.

- Communities are adaptable, are prepared for some loss of function in a large earthquake, and are able to temporarily utilize alternative sources for functions and services over a limited period of time following the event (e.g., temporary reconfiguration of space in undamaged buildings to replace functions lost in damaged buildings; temporary use of bottled water while tap water is unavailable).

- Communities continue working toward a return to full functionality (i.e., continue with ongoing repairs) after achieving reoccupancy and functional recovery performance states.

\subsection{Advancement in Design Capabilities}

The design and construction of buildings is regulated by building codes and standards that are developed in the private sector and adopted at the state, local, tribal, and territorial (SLTT) government levels. Recognizing that earthquakes are inevitable, and that catastrophic life loss associated with these events is unacceptable to the public, a group of professionals - code officials, design professionals, construction industry representatives, and other code users - have worked within the codes and standards development processes to implement modern building codes that include life-safety protection against the effects of earthquakes.

Although lifeline infrastructure systems have numerous regulations and regulators, there is no single authority governing design and construction across all lifeline infrastructure systems, and regulations can differ for publicly and privately owned systems. Whether designing buildings or lifeline infrastructure systems, current design objectives are primarily intended to protect occupant safety, and current design practice is not explicitly focused on avoiding economic loss, assuring rapid post-earthquake

The design and construction of buildings is regulated by building codes and standards that are developed in the private sector and adopted at the state and local levels.

There is no single authority governing design and construction across all lifeline infrastructure systems. recovery, or maintaining the availability of lifeline services in the event of an earthquake.

The evolution of seismic building codes and standards has been fueled by the development of design guidance under the National Earthquake Hazards Reduction Program. Decades of 
research and problem-focused study have resulted in many federal publications that have served to advance hazard mitigation and improve resilience. Relevant FEMA publications can be found at https://www.fema.gov/earthquake-publications, and NIST and other NEHRP partner publications can be found at https://nehrp.gov/library/index.htm.

An important advancement has been the advent of performance-based design, which is designing to achieve a specified performance outcome. Engineers recognize that building performance can range anywhere from collapse to fully functional, and that performance-based design can be used to adjust designs to meet desired performance goals. The theoretical range of building performance is illustrated in Figure 1-2. In the figure, recovery-based goals are placed relative to safety-based goals, and functional recovery is depicted as a performance state that is more than reoccupancy, but less than full functionality.

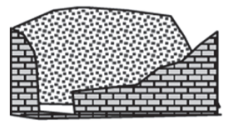

Collapse

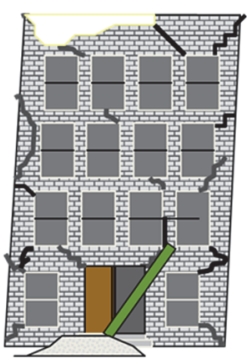

Safety

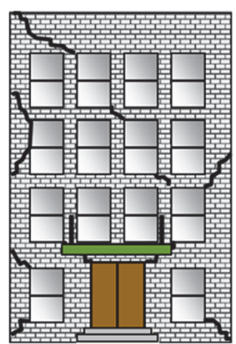

Reoccupancy

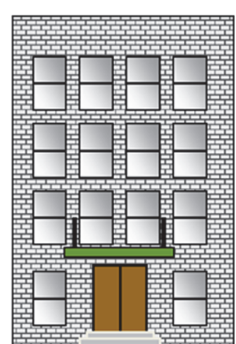

Functional Recovery

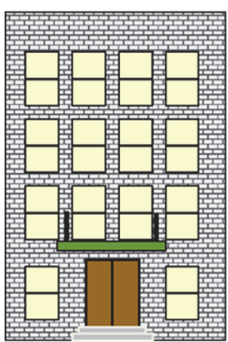

Full Functionality

Figure 1-2 Theoretical range of building performance and relative placement of safetybased and recovery-based goals (courtesy of R. Hamburger).

Recent guidance, such as the Community Resilience Planning Guide for Buildings and Infrastructure Systems (NIST, 2016a), FEMA P-58 Seismic Performance Assessment of Buildings, Methodology and Implementation (FEMA, 2018a), Disaster Resilience: A National Imperative (NRC, 2011), Safe Enough to Stay (SPUR, 2012), and the Oregon Resilience Plan: Reducing Risk and Improving Recovery for the Next Cascadia Earthquake and Tsunami (OSSPAC, 2013) have advanced practice to the point that explicit design for reoccupancy and functional recovery can be considered. Wide adoption of these practices will require further changes in building codes and building practices, and a shift in societal expectations of performance.

Current codes and standards, and recently developed guidelines, offer some criteria that can be used to achieve certain aspects of reoccupancy and functional recovery. There will, however, need to be a shift from basic safety-based considerations to recovery-based considerations that are focused on identification of necessary functions and services, estimation of damage, and consideration of potential economic losses while providing for the basic safety of occupants and users. At present, there is no national consensus standard that defines what services must be in place or what strength, stiffness, or capacity a component must have in order for a building or lifeline infrastructure system to be functionally recoverable within a certain time (NIBS, 2019b).

Developing new recovery-based design criteria will involve choosing a desired performance goal and identifying an appropriate earthquake and associated earthquake effects upon which to base the design. Engineers and seismologists quantify earthquakes using the term hazard level, which 
implies earthquakes, and earthquake effects, of different size and severity. There are many ways that the relative size of earthquakes is quantified, including magnitude, intensity, probability, and frequency of occurrence. In general, the larger the earthquake, the rarer it is, the more severe the effects are, and the harder it is to achieve an acceptable level of performance.

Earthquake effects include ground shaking, permanent ground displacement (including surface faulting, landslides, liquefaction, lateral spreading, and subsidence), as well as tsunamis and seiches. Ground shaking causes most damage to building structures, but permanent ground displacement also causes significant damage, and is especially damaging for lifeline infrastructure systems. Figure 1-3 illustrates the concept of different size earthquakes in terms of the intensity of ground shaking, as observed in recordings from actual events of different magnitude. As the earthquake magnitude increases, the relative amplitude and duration of shaking increases, as well as the potential for widespread damage. Magnitude scales are logarithmic, meaning that a magnitude 6 earthquake has ten times the measured amplitude and 32 times the energy released as compared to a magnitude 5 earthquake ${ }^{3}$.

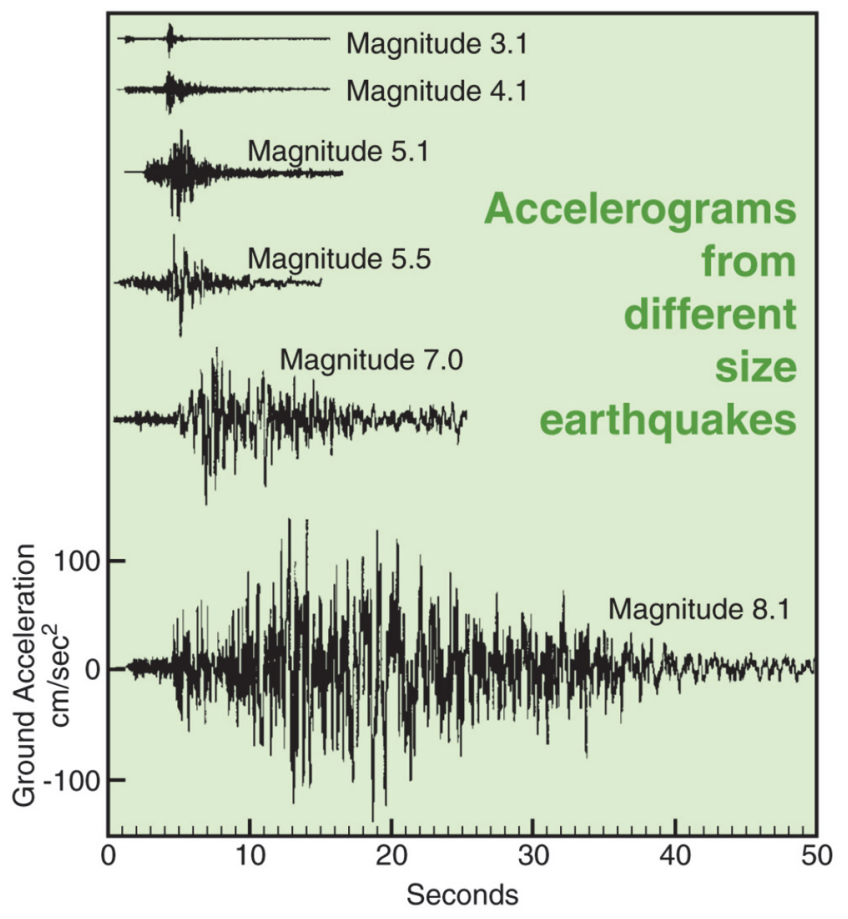

Figure 1-3 Illustration of different size earthquakes in terms of the relative intensity of ground shaking, as observed in different earthquake recordings (Nevada Bureau of Mines and Geology, 2010).

The hazard level used in current national model building codes and standards has been selected so that the intensity of shaking will produce designs with a low risk of collapse over a 50-year timeframe. The expectation is to avoid widespread building collapse and life loss in rare, but foreseeable earthquakes having return periods on the order of a few thousand years, and to

\footnotetext{
${ }^{3}$ https://www.usgs.gov/natural-hazards/earthquake-hazards/science/earthquake-magnitude-energy-release-andshaking-intensity?qt-science_center_objects=0\#qt-science_center_objects
} 
protect life safety in smaller earthquakes having return periods on the order of a few hundred years.

Although earthquake return periods might seem long, areas with seismic risk must be prepared when, rather than if, a large earthquake occurs. It is necessary to select a hazard level for recovery-based objectives that will result in an appropriate level of risk over a defined period of time for the local area under consideration. This would involve trade-offs between feasibility of construction, higher up-front costs, the time between earthquake events, the probability (risk) of damage and loss, and the benefits associated with reduced operation and maintenance costs, and future losses avoided. The determination and selection of appropriate recovery times and

The determination and selection of appropriate recovery times and hazard levels for recoverybased objectives is a key recommendation in this report. hazard levels for recovery-based objectives is a key recommendation in this report.

\subsection{Costs and Benefits}

Designing and constructing to higher performance standards can cost more for some buildings and lifeline infrastructure systems, but can bring positive return on investment over a period of many years, during which a large earthquake is likely to occur. As noted in the recent Natural Hazard Mitigation Saves: 2019 Report (NIBS, 2019a), prepared by the National Institute of Building Sciences and funded in part by FEMA:

"Not everyone is willing or able to bear the up-front construction costs for more resilient buildings, even if the long-term benefits exceed the up-front costs. Different stakeholders enjoy different parts of the costs and benefits, and the people who bear more of the costs may argue more urgently against mitigation than the people who enjoy more of the benefits. However, one set of stakeholders may be able to offer incentives to others to decrease the cost or increase the benefit, and better align the competing interests of different groups."

Owners, engineers, code officials, developers, and builders tend to focus more heavily on initial construction costs, while neglecting future ownership costs. They might also question how increased incremental costs will be managed, and whether incremental costs can be passed along to tenants, customers, and other users. A focus on initial costs, without consideration of lifecycle costs, could bias the perception of relative costs and benefits.

\subsubsection{Costs of Action}

Where current code requirements already satisfy selected recovery-based objectives, design and construction for new buildings will cost the same relative to current practice. In other cases, recovery-based objectives will require enhanced seismic design, which would be expected to cost more relative to current practice. Higher performance objectives typically require more stringent design criteria, which, in turn, can imply use of larger quantities or higher-performing materials, and increased effort during construction, resulting in higher initial construction costs. The specific cost premiums associated with designing new buildings and lifeline infrastructure systems for recovery-based objectives, however, will depend on the selected recovery times and hazard levels. 
Detailed evaluation of cost impacts is necessary, but beyond the scope of this report. Prior studies are available that can be used to help identify the order of magnitude potential cost increases associated with enhanced seismic design (i.e., design beyond current code requirements) in new construction. A cost analysis and benefit study for earthquake-resistant construction in Memphis, Tennessee was conducted by NIST in 2013. This study considered six reference building types and occupancies, including a threestory apartment, four-story office, one-story retail, one-story warehouse, six-

Studies show that construction cost premiums associated with seismic design are small overall, and on the order of $3 \%$ (or less). story hospital, and two-story elementary school. The study evaluated relative increases in construction cost for two cases: (1) changing from wind design to seismic design; and (2) changing from older regional seismic design codes to the 2012 edition of the International Building Code (ICC, 2012). The report concluded that construction cost premiums were small overall, and the cost premium associated with implementing seismic design over wind design was 3\% (or less), and the cost premium associated with implementing enhanced seismic design was an additional 1\% (or less) (NIST, 2013).

A second study consisting of two school projects in Beaverton, Oregon (Yu et al., 2015), included new high school and middle school buildings designed using enhanced seismic requirements to allow for reoccupancy (as a shelter) within 72 hours and return to function (as a school) within 30 days. The study indicated a cost premium of less than $2 \%$ over costs associated with typical seismic design requirements for new school buildings.

The cost premiums reported in these studies are in general alignment with estimated increases in new construction costs commonly understood and expected by seismic design professionals. However, experience in the code development process has shown significant opposition to code change proposals that include even modest increases in initial construction cost. Moving toward recovery-based objectives will require a strong case for benefits relative to initial costs or total lifecycle costs.

Construction cost premiums associated with enhanced seismic retrofit of existing buildings and lifeline infrastructure systems can be substantially higher than incremental costs for incorporating enhanced seismic design in new construction. Designing retrofits for higher performance objectives could result in construction cost premiums that are an order of magnitude higher than cost premiums for new construction. Specific cost premiums associated with retrofit of existing buildings and lifeline infrastructure systems will depend on how the selected recovery times and hazard levels compare to the performance provided by current seismic retrofit criteria.

Designing retrofits for higher performance objectives could result in construction cost premiums that are an order of magnitude higher than cost premiums for new construction.

\subsubsection{Benefits of Action}

Although most benefits are not realized until an earthquake occurs, many different stakeholder groups have the potential to benefit from investment in design for recovery-based objectives. These include owners, developers, and tenants in buildings, and owners, operators, and customers of lifeline infrastructure systems, who benefit from an increased likelihood of remaining in their buildings and returning to normal life routines. They also include federal, state, local, tribal, and territorial governments that benefit from lower costs associated with 
response and recovery in the aftermath of an earthquake. For lifeline infrastructure systems, investment in mitigation and enhanced seismic design can result in greatly improved reliability of services under normal operating loads. This is a large benefit that is realized under normal operating conditions.

Benefits can be measured as a reduction in future earthquake losses, particularly losses associated with prolonged downtime and delayed recovery. These include effects of disruption to housing, business, industry, education, and government services. Investment in mitigation before an earthquake also makes available a significant share of the resources that would be spent on things like insurance claims and administrative fees after an earthquake (NIBS, 2019a). Plans for improvement of the built environment should consider detailed evaluation of the economic impacts associated with potential increased initial investment versus benefits in terms of future losses avoided.

Designing for recovery-based objectives can encompass non-disaster related

Plans for improvement of the built environment should consider evaluation of the economic impacts associated with potentially increased initial investment versus benefits in terms of future losses avoided. co-benefits (i.e., resilience dividends), which occur outside of hazard events (Fung and Helgeson, 2017). Buildings and lifeline infrastructure systems that are designed to meet functional recovery objectives may increase efficiency during typical operation. An example of a direct non-hazard-related benefit would be an infrastructure improvement that reduces current operation and maintenance costs. The NIST Economic Decision Guide Software (EDGe\$) Tool (Helgeson, 2020) allows for consideration of co-benefits in a benefit-cost analysis framework that is applicable to functional recovery, although originally designed for valuation of community resilience projects.

Detailed evaluation of benefits is necessary, but beyond the scope of this report. Prior studies are available that can be used to help identify the order of magnitude potential benefits associated with enhanced seismic design. The Natural Hazard Mitigation Saves: 2019 Report (NIBS, 2019a) suggests that dollars spent on mitigating the effects of earthquakes yield positive benefitcost ratios for every mitigation strategy studied:

- Adopting and implementing provisions in recent model building codes, such as the 2018 International Building Code (ICC, 2018a) and the 2018 International Residential Code (ICC, 2018c), was projected to save approximately $\$ 12$ per $\$ 1$ spent, relative to older provisions contained in 1990s-era model codes. This suggests that ongoing advances in seismic codes and standards are effective at reducing losses in future earthquakes.

- Designing in excess of selected provisions of the 2015 International Building Code (ICC, 2015a) and the 2015 International Residential Code (ICC, 2015c) was projected to save approximately $\$ 4$ for every $\$ 1$ spent. This suggests that enhanced seismic design can further reduce losses in future earthquakes.

- Private-sector building retrofits, specifically retrofits to soft-story wood-frame multifamily dwellings, were projected to save approximately $\$ 12$ per $\$ 1$ spent. This suggests that targeted retrofits of vulnerable classes of existing buildings can be highly effective at reducing losses in future earthquakes. 
- Mitigating a select number of utilities and transportation infrastructure systems was found to save approximately $\$ 3$ for every $\$ 1$ spent. This suggests that investment in lifeline infrastructure system enhancements will yield positive results.

- Funding mitigation grants through select federal agencies was found to save $\$ 3$ for every $\$ 1$ spent on grants. This suggests that facilitating investment in mitigation through federal grant programs is effective at reducing losses in future earthquakes.

The concept of functional recovery and recovery-based design is applicable to various natural hazards. However, developing recovery-based design criteria for various hazards would require addressing unique challenges associated with each hazard. Investing in a recovery-based approach for addressing earthquake hazards could be leveraged and adapted to recoverybased approaches for other natural hazards. This effort could ultimately help in moving toward multi-hazard community resilience.

A recovery-based approach for earthquake hazards could be leveraged and adapted to other hazards and provide a key stepping stone for achieving multi-hazard community resilience. 


\section{Chapter 2}

\section{Framework for Reoccupancy and Functional Recovery}

Improving the performance of the built environment depends on the development of a framework for post-earthquake reoccupancy and functional recovery. Such a framework would address policy decisions identifying acceptable reoccupancy and functional recovery times for different building functions and lifeline services. It would also address technical criteria including design requirements and hazard levels for design, retrofit, and maintenance of buildings and lifeline infrastructure systems.

RECOMMENDATION 1: Develop a Framework for Post-Earthquake Reoccupancy and Functional Recovery Objectives

A framework for reoccupancy and functional recovery is needed to provide a national consensus that defines what services must be in place and the necessary design requirements for a building or lifeline infrastructure system to be occupiable or functionally recoverable within a specified timeframe after an earthquake. In the long term, a national perspective will bring the consistency needed for reference by national disaster assistance policies to be followed by SLTT governments, while still allowing for local customization and enhancement. In the short term, SLTT jurisdictions should be encouraged to develop their own frameworks until such a national framework becomes available. A consensus process is needed to determine what functions are critical for the recovery of a community within what timeframe, how to prioritize the investment of construction resources on buildings and lifeline infrastructure systems, and how to cost effectively design and construct them to achieve functional recovery. Additional study is needed to determine more precisely the recovery performance provided by current design practices and to develop new design criteria for buildings and lifeline infrastructure systems to achieve recovery-based objectives.

The need for a national framework is particularly urgent for lifeline infrastructure systems because there is no single authority governing design and construction across all lifeline infrastructure systems. In addition, different groups continue to work to improve lifeline recovery times at the system and community levels. Performance goals are being developed for different lifeline infrastructure systems in disparate ways, which could yield inconsistent, and possibly inefficient, approaches for achieving recovery-based objectives in the long term.

In the case of buildings, there are codes and standards that can be expanded beyond safety-based objectives to address recovery-based objectives. Although some industry groups have started independently investigating recovery-based policies and design considerations for buildings, a coordinated national effort will eventually be needed to achieve the consistency and effectiveness necessary for adoption into a national model building code. 
The resulting framework should be coordinated between buildings and lifeline infrastructure systems to target a common set of desired reoccupancy and functional recovery times at commonly designated earthquake hazard levels. Ideally, the NEHRP agencies would lead this effort while engaging appropriate experts from the professional community and a broad crosssection of public stakeholders. Implementation of this recommendation requires the completion of the following tasks, all of which are essential to a framework for post-earthquake reoccupancy and functional recovery objectives.

\section{Task 1.1: Develop a Policy for Recovery-Based Objectives}

A national, consensus-based policy for recovery-based objectives is needed to identify key functions, basic services, and target recovery times for achieving reoccupancy and functional recovery. Recovery-based policies involve assignment of target recovery times to building functions and maximum target service losses and recovery times to lifeline services that are based on societal and other needs following an earthquake. Recovery-based policies would be in addition to applicable safety-based design and construction regulations in currently available codes, standards, and other design criteria.

Not all community services, buildings, or lifeline infrastructure systems are needed immediately after an earthquake, and time to recovery of function can be considered in terms of short-term, intermediate, and long-term recovery phases. Policy decisions would be based on the identification of basic intended building functions and lifeline services, and the timeframe for which these functions and services are needed during response and recovery. Ultimately, a national perspective is needed to establish minimum standards that SLTT governments can adopt. Because reoccupancy and functional recovery needs might vary due to specific local social, economic, geographic, environmental, or other conditions within a community, jurisdictions should be encouraged to develop their own policies to supplement or enhance a national policy, if needed.

To codify policy decisions, target reoccupancy and functional recovery times for buildings and lifeline infrastructure systems could be associated with categories, termed recovery categories. Recovery categories could be used to identify priorities for functions and services following an earthquake, in a manner that is similar to the concept of Risk Categories and how they are used in current building codes. In concept, a function or service would be assigned to a certain recovery category based on an acceptable recovery time (for buildings) or maximum target service loss and recovery time (for lifeline infrastructure systems), for selected earthquake hazard levels. This assignment would be used to set design criteria for the building or lifeline infrastructure system providing the function or service. The concept of recovery categories is further developed in Appendix B.1.

Policy decisions should be based on the interests of the community at large, and the best possible outcome for the largest number of people, rather than the interests of an individual person or business enterprise. Recovery times and target service losses should be assigned in a manner that will support community-wide goals for reoccupancy and functional recovery, to ensure public health, welfare, and safety at the overall community level. Although policies establishing minimum recovery-based objectives should be determined by community interests, individual building owners or lifeline infrastructure system owners and operators would not be precluded 
from exceeding these policies and self-selecting higher objectives if shorter recovery times are desired based on individual needs and interests.

Determination of target recovery times and target service losses for buildings and lifeline infrastructure systems should be based on studies considering input and perspectives from stakeholders spanning all sectors of the public. Studies should also consider, or address, the following:

- Review of scenario and other vulnerability studies that evaluate the performance of existing buildings and lifeline infrastructure systems to identify current deficiencies and challenges associated with meeting target recovery times.

- Conduct of benefit-cost analyses, including direct and indirect benefits and costs, considering proposed target recovery times and selected earthquake hazard levels.

- Possible alternative approaches for minimizing total cost of ownership (NIBS, 2019a).

- Identification and fair representation of the major interests of all stakeholders, including consideration of public preferences within a given community (NIST, 2016a), and wholecommunity, partial-community, and individual perspectives as a basis for decision-making.

- Possible economic inefficiencies, unintended consequences, and social inequities (Helgeson, 2020).

- Integration with current regulatory environments, applicable laws and statutes, as well as business practices.

Implementation of recovery-based policies developed under this task would require the design criteria developed under Task 1.2, based on the hazard levels selected under Task 1.3.

\section{Task 1.2: Develop Design Criteria for Achieving Recovery-Based Objectives}

Design criteria for recovery-based objectives are needed to define the required strength, stiffness, or capacity needed for a building or lifeline infrastructure system to be deemed occupiable or functionally recoverable within a certain timeframe after an earthquake. Although governed by different authorities, consistent criteria must be established between buildings and lifeline infrastructure systems. Design criteria developed under this task should be set so that buildings and lifeline infrastructure systems would achieve policy goals for target recovery times identified under Task 1.1, considering one or more hazard levels selected under Task 1.3.

For new and existing buildings, this could include the development of: (1) new recovery-based provisions for design of new buildings and seismic retrofit of existing buildings in future editions of national model code and reference standards (long-term implementation); or (2) interim provisions for recovery-based design of buildings within the framework of currently available codes and standards (near-term implementation). Criteria should consider structural systems, nonstructural systems and components, contents, and back-up utility systems. Such criteria would likely take a form that is similar to the prescriptive approach in current codes and standards, but would implement different design values and additional requirements that address factors inhibiting reoccupancy or functional recovery. Criteria could also contemplate, but not necessarily require, innovative approaches to structural design, such as performance-based 
design approaches that explicitly evaluate both safety and recovery, the use of seismic protective systems including seismic isolation or energy dissipation systems that minimize damage, or the use of systems and components that are more easily and quickly repaired.

For lifeline infrastructure systems, criteria should consider system-level and component-level performance. Components are the interconnected pieces that make up a lifeline infrastructure system. There are many different types of specialized lifeline infrastructure system components that comprise a system, including buildings or building-like structures. The aggregated performance of all components determines the overall system performance. Therefore, each component, group of components, or subsystem must have criteria that are consistent with overall system performance objectives. System-level and component-level performance should be identified using a consistent set of metrics and evaluation methods for quantifying performance. Because each system has dependencies and interdependencies with other systems, consistent criteria are also needed at the system-level to ensure a consistent outcome across all lifeline infrastructure systems.

Lifeline infrastructure system criteria could also contemplate alternative methods of compliance, such as having an adequate supply of replacement components ready for immediate repair following an earthquake, when designing such components to limit damage might not be feasible. Because not all community functions and services are needed immediately after an earthquake, there is flexibility in the selection of recovery times and recovery categories. This allows lifeline infrastructure system owners and operators to implement new and innovative ways to reliably meet user needs following an earthquake (e.g., Liu et al, 2016; Davis, 2018).

A key step in developing new design criteria is understanding the performance capability provided by current design criteria. Additional, more detailed studies are needed to know if current design criteria can satisfy some recovery-based objectives for buildings and lifeline infrastructure systems, and to determine if additional criteria are needed to achieve higher performance objectives. Until new design criteria become available, interim recovery-based criteria could involve modifications to current seismic design provisions related to strength and ductility requirements, building drift limits, and bracing and deformation compatibility requirements for nonstructural components, as needed to improve potential recovery times.

Appendix B.2 provides descriptions of the type and extent of structural and nonstructural damage in buildings and lifeline infrastructure systems that have typically been associated with certain functional recovery times.

\section{Task 1.3: Determine Appropriate Hazard Levels for Recovery-Based Objectives}

Selection of appropriate earthquake hazard levels for recovery-based objectives is a tradeoff between the economic resources one is willing to invest up front, in terms of initial capital costs, the resilience dividend, the potential for future damage, the acceptability of the consequences of that damage, and the benefits associated with future losses avoided. Under this task, studies of the costs and benefits associated with earthquakes having different hazard levels, the desired level of protection for recovery, and the scale at which that protection is desired (nation, region, community, or individual) would need to be conducted to inform the selection of appropriate 
hazard levels. Selection of appropriate hazard levels would be based on policy goals for target recovery times identified under Task 1.1 and design criteria developed under Task 1.2.

Earthquake hazards include ground shaking and associated earthquake effects, such as surface faulting, landslides, liquefaction, lateral spreading, and subsidence, as well as tsunamis, and seiches (USGS, 2020). Hazard level generally refers to the size or magnitude of the earthquake and its associated effects, often measured in terms of intensity of ground shaking, amount of surface faulting or ground deformation, and likelihood of triggering related threats. Because different earthquake hazard phenomena will impact buildings and lifeline infrastructure systems differently, it is possible that hazard levels selected for design of lifeline infrastructure systems might be different from hazard levels selected for design and retrofit of buildings. Furthermore, as some earthquake effects might occur disproportionately at lower or higher hazard levels, acceptable performance might not be adequately addressed at a single hazard level, and it might be necessary to select multiple hazard levels for design. Ultimately, the selection of hazard level(s) for buildings and lifeline infrastructure systems should be coordinated so that overall recovery-based objectives are consistently met.

Selection of hazard levels will also need to consider whether risk is to be measured at the national, state, community, or individual owner level. Because seismic hazards in different regions of the country (e.g., Los Angeles, San Francisco, Seattle, and Memphis) are generally independent, and because there are many seismically independent regions, even if a design earthquake with relatively low probability of exceedance (e.g., 10\%) is selected as the basis of design, there is a significantly larger probability that at least one community in the United States will experience shaking at this level within an assumed timeframe (e.g., 50 years). If, for example, the goal is to provide the United States with a suitably low probability that any community will experience a disaster due to an earthquake within a specified timeframe, it is necessary to choose a hazard level based on an acceptable level of risk that a community will experience such a disaster.

Whatever hazard level is chosen, a different level of protection will be provided depending on the perspective being taken (e.g., national, state, community, or individual owner level). Therefore, selection of a design hazard level and a desired level of protection will require consideration of multiple perspectives, and will involve a tradeoff between initial construction costs and the magnitude of losses that the United States, a given state, a specific community, or an individual owner is willing to accept from earthquake shaking and other earthquake effects that might exceed the design hazard level. To make such a decision, it is necessary to conduct probabilistic studies of the costs and benefits of alternative hazard levels and desired levels of protection.

A risk-based approach, consistent with how seismic hazard is characterized in current building codes and standards, may be an appropriate way to characterize hazard for recovery-based objectives. Alternatively, in regions with a well-defined risk on a known fault, the use of scenario events, defined as actual historic earthquakes that have significantly impacted a region or possible future earthquakes on a nearby fault, might be more appropriate. 



\section{Chapter 3}

\section{Improve the Performance of Buildings}

In most of the United States, new buildings are regulated with state or locally adopted versions of a national model code, usually the International Building Code (IBC) (ICC, 2018a), or for one- and two-family dwellings, the International Residential Code (IRC) (ICC, 2018c). Existing buildings are regulated with a state or locally adopted version of a model existing building code, such as the International Existing Building Code (IEBC) (ICC, 2018b).

Building codes and standards are updated every 3 to 5 years, and significant changes to design requirements can occur in each update. Model codes are developed through national, open, inclusive, and balanced consensus processes that consider interests from code officials, design professionals, construction industry representatives, and other stakeholders. These processes are implemented by private sector organizations, such as the International Code Council (ICC), which leaves the final determination of code provisions in the hands of public safety officials who represent the public interest. Federal agencies participate in these processes, playing a critical role supporting the development of national model building codes and serving as a resource supporting local and statewide adoption of the codes. They operate within the same guidelines that apply to all participants, in accordance with constitutional limitations on government powers.

Except in special cases, buildings in the United States are designed and constructed to meet safety-based objectives such that they have a low probability of collapsing, or causing conditions potentially harmful to public health, in the event of an earthquake. Modern codes and standards (e.g., ASCE, 2016) have advanced to the point that they are now expected to provide reasonable levels of life-safety protection against the effects of earthquakes. However, because recoverybased objectives are not explicitly considered in current building codes, many new and existing buildings could be non-occupiable and unusable for extended periods following a major earthquake, significantly challenging the ability of a community to recover within a reasonable timeframe.

The IEBC uses "triggers" to specify when intended work on existing buildings, such as an addition, alteration, repair, change of occupancy, or relocation, must include a seismic retrofit to improve performance in an earthquake. However, few conditions require existing buildings to be brought into compliance with current building codes, and few existing buildings are voluntarily retrofitted to meet current design criteria. In practice, seismic retrofits are rarely triggered, as projects are often intentionally reduced in scope to avoid the triggers. Dwellings and townhouses are generally exempt from seismic retrofits because they are usually constructed in accordance with the IRC, which does not have triggers. As a result, most existing buildings across the United States are older structures designed to earlier versions of codes and standards that are known to lack the level of safety protection provided by modern design requirements, 
leaving some at risk of collapse, and many at risk of being unoccupiable or unusable following a major earthquake.

The challenge is not limited to older existing buildings. Past earthquakes have shown that even modern new buildings will be subject to damage and may not be suitable for occupancy or use for many months after a major earthquake until structural and nonstructural damage has been adequately repaired. To improve the performance of buildings in a major earthquake, a new recovery-based approach for the design of new buildings and the retrofit of existing buildings is needed.

\section{RECOMMENDATION 2: Design New Buildings to Meet Recovery-Based Objectives}

Because current building codes do not specifically address recovery-based objectives and resulting designs will yield inconsistent performance results, new buildings should be designed for specific recovery-based objectives that will support reliable reoccupancy and acceptable functional recovery times following a major earthquake. The development of a reoccupancy and functional recovery framework under Recommendation 1, including the policy decisions under Task 1.1, design criteria decisions under Task 1.2, and hazard level decisions under Task 1.3, are needed for implementation of Recommendation 2.

The costs, benefits, and feasibility of designing new buildings to meet recovery-based objectives can be managed through decisions addressing the following questions:

- Which buildings should be designed for which reoccupancy and functional recovery objectives?

- What building code provisions are needed to achieve certain reoccupancy or functional recovery objectives?

- Should design of new buildings to meet reoccupancy and functional recovery objectives be required or voluntary?

\section{Which buildings should be designed for which reoccupancy and functional recovery objectives?}

Assignment of recovery-based objectives to new buildings will occur as part of the policies developed under Task 1.1. In concept, buildings would be assigned to recovery categories with recovery times based on the use, function, or service they provide. The distribution of building types that are assigned to shorter or longer target recovery times will determine the scope and impact of Recommendation 2, and will scale the costs, benefits, and feasibility of implementation.

Because not all community functions and services are needed immediately after an earthquake, there is flexibility in the recovery times assigned to each building use or function. Due to the importance of this assignment in terms of costs and benefits, this assignment should be made in the context of community needs, with appropriate economic benefit-cost analyses.

Federal agencies could lead by example, providing a model for development and implementation of recovery-based objectives through adaptation of current policies for design and construction 
of new federally owned and leased buildings. This action is encouraged in Executive Order 13717, Establishing a Federal Earthquake Risk Management Standard (The White House, 2016), and commentary, technical background, and possible implementation options are presented in NIST Technical Note 1922, ICSSC Recommended Practice (RP) 9: Implementation Guidelines for Executive Order 13717 (NIST, 2017).

\section{What building code provisions are needed to achieve certain reoccupancy or functional recovery objectives?}

Evaluation of the performance capability of current design criteria, and development of new recovery-based criteria, will occur under Task 1.2, considering the hazard levels selected under Task 1.3. In concept, new recovery-based provisions for design of new buildings will be incorporated into future editions of national model code and reference standards, or interim provisions for recovery-based design of new buildings will be adapted within the framework of currently available codes and standards. Incorporating recovery-based provisions into a future edition of a national model code is expected to be a long-term implementation task (i.e., on the order of 10 years or more), likely involving the development of a design guideline, followed by development of a national consensus standard, and finally adoption into a model building code.

Ultimately, it is the responsibility of SLTT jurisdictions to adopt and enforce a building code. Jurisdictions with an interest or need to implement recovery-based objectives sooner than the availability of a national standard or policy should be encouraged to develop interim provisions. Interim provisions could be informed by progress being made under Recommendation 1 , selected provisions for enhanced seismic design available in current codes and standards, consultation with local industry experts, or examples from federal agencies leading by example.

Current building codes and standards seek to provide enhanced performance for buildings deemed to be more important or essential through classification by Risk Category, and higher Risk Categories have higher design criteria that could be used to achieve certain recovery-based objectives. In the current model code, facilities that provide essential services and support community-wide safety are assigned to Risk Category IV, including hospitals, emergency operations centers, fire stations, and other buildings supporting emergency response functions. Risk Category IV design criteria are intended to effectively provide continuous operation through, and after, earthquake shaking consistent with the design hazard level. Use of Risk Category IV design criteria could be one interim solution for moving forward on functional recovery, and extending these requirements to broader classes of buildings could substantially increase the number of buildings that are able to recover more quickly in the near term.

\section{Should design of new buildings to meet reoccupancy and functional recovery objectives be required or voluntary?}

SLTT jurisdictions will have three alternatives for implementing recovery-based objectives for new buildings. These include the mandatory use of future national model code provisions, mandatory use of interim code provisions, and voluntary use of incentives and other programs, as discussed in Alternatives 2-1, 2-2, and 2-3, below. SLTT jurisdictions may consider various factors including the effectiveness and eligibility for federal assistance in the aftermath of an earthquake in adoption of voluntary or mandatory options. For example, federal disaster 
recovery funds and hazard mitigation grants require the use of the latest version of the International Building Code or its equivalent. These issues are discussed further in Recommendation 7 and Chapter 7.

\section{Alternative 2-1: Mandate the Design of New Buildings to Meet Recovery-Based Objectives Using Future National Model Code Provisions}

Under Alternative 2-1, a jurisdiction would adopt a future version of a national model building code that requires new buildings to be designed using criteria intended to meet specific recoverybased objectives developed under Recommendation 1. Depending on how such provisions are contained within the future model code, a jurisdiction may need to intentionally adopt recoverybased provisions, particularly if they are contained within an optional appendix of the model code.

\section{Alternative 2-2: Mandate the Design of New Buildings to Meet Recovery-Based Objectives Using Interim Provisions}

Under Alternative 2-2, if a jurisdiction has an interest or need to implement recovery-based provisions in the near-term, it could choose to adopt interim provisions as a local amendment to the current edition of the model code. Interim provisions could be informed by progress being made under Recommendation 1, selected provisions for enhanced seismic design available in current codes and standards, consultation with local industry experts, or examples from federal agencies leading by example. This alternative is intended to serve as an interim step until recovery-based provisions are included in a future edition of a national model code and are adopted by the jurisdiction.

\section{Alternative 2-3: Encourage the Voluntary Design of New Buildings to Meet Recovery-Based Objectives}

Under Alternative 2-3, a jurisdiction would implement policies or programs to encourage the voluntary design of buildings to recovery-based objectives based on future model code provisions or interim provisions. In a voluntary context, all technical aspects of recovery-based objectives would be necessary, except these objectives would not be a mandatory part of the local building code.

Financial or other incentives are often necessary to encourage participation, and additional discussion of financial resources is provided under Recommendation 7. Voluntary programs have the benefit of lower thresholds for acceptance and greater political feasibility. However, experience shows that voluntary programs are generally less effective than mandatory programs because they lack a critical mass of participation needed to make meaningful progress towards community resilience.

\section{RECOMMENDATION 3: Retrofit Existing Buildings to Meet Recovery-Based Objectives}

To address known vulnerabilities in the existing building inventory, existing buildings should be retrofitted to meet recovery-based objectives that will support reliable reoccupancy and acceptable functional recovery times following a major earthquake. The development of a reoccupancy and functional recovery framework under Recommendation 1, including the policy 
decisions under Task 1.1, design criteria decisions under Task 1.2, and hazard level decisions under Task 1.3, are needed for implementation of Recommendation 3.

At a minimum, safety-based retrofit programs should continue, but the expected reoccupancy and functional recovery times achieved by that work should be evaluated and explicitly incorporated into recovery-based objectives selected for existing buildings. The costs, benefits, and feasibility of retrofitting existing buildings can be managed through decisions addressing the following questions:

- Which existing buildings should be retrofitted to meet which reoccupancy and functional recovery objectives?

- What retrofit provisions are needed to achieve certain reoccupancy or functional recovery objectives?

- Should retrofit of existing buildings to meet reoccupancy and functional recovery objectives be mandatory, triggered, or voluntary?

\section{Which existing buildings should be retrofitted to meet which reoccupancy and functional recovery objectives?}

Assignment of recovery-based objectives to existing buildings will occur as part of the policies developed under Task 1.1. As in the case of new buildings, existing buildings would be assigned to recovery categories with recovery times based on the use, functions, or services they provide. The distribution of existing buildings that are assigned to shorter or longer target recovery times will determine the scope and impact of Recommendation 3, and will scale the costs, benefits, and feasibility of implementation.

In general, it will be more difficult and expensive to achieve reoccupancy and functional recovery objectives in existing buildings than in new buildings. In the interest of costeffectiveness, most current retrofits are focused on safety, targeting specific collapse-prone structural deficiencies that are believed to represent the greatest risk. The most deficient structural systems will likely be the most challenging to retrofit to recovery-based objectives.

One way to manage the challenges posed by existing buildings is to consider alternative, lower criteria for retrofit of existing buildings relative to design for new buildings. This approach is common in safety-based retrofit programs, and can be accomplished a number of ways including: choosing lower performance goals, selecting lower earthquake hazard levels, assigning longer reoccupancy and functional recovery times, or limiting retrofits to only the most severe deficiencies.

For these reasons, it is possible that the recovery-based objectives for existing buildings established in Task 1.1 might consider different target recovery times for existing buildings, might consider only safety or reoccupancy objectives for some buildings, and might limit functional recovery objectives to existing buildings serving only the most critical functions in a community. Additionally, existing buildings can be replaced with new construction or repurposed for less-critical uses, or critical functions can be relocated to newer, more recoverable buildings to help achieve community resilience. 
Federal agencies could lead by example, providing a model for development and implementation of recovery-based objectives in existing buildings through adaptation of current policies for federally owned and leased buildings. This action is encouraged in Executive Order 13717, Establishing a Federal Earthquake Risk Management Standard (The White House, 2016), and commentary, technical background, and possible implementation options are presented in NIST Technical Note 1922, ICSSC Recommended Practice (RP) 9: Implementation Guidelines for Executive Order 13717 (NIST, 2017).

\section{What retrofit provisions are needed to achieve certain reoccupancy or functional recovery objectives?}

Evaluation of the performance capability of current retrofit criteria, and development of new recovery-based retrofit criteria, will occur under Task 1.2, considering the hazard levels selected under Task 1.3. In concept, new recovery-based provisions for retrofit of existing buildings will be incorporated into national model existing building codes and reference standards, or interim provisions for recovery-based retrofit of existing buildings will be adapted within the framework of currently available codes and standards. Incorporating recovery-based provisions into a future edition of a national model existing building code is expected to be a long-term implementation task (i.e., on the order of 10 years or more), likely involving the development of a design guideline, followed by development of a national consensus standard, and finally adoption into a model code.

Recovery-based retrofit criteria would involve current seismic retrofit strategies and available performance-based standards and guidelines for existing buildings, such as ASCE/SEI 41-17, Seismic Evaluation and Retrofit of Existing Buildings (ASCE, 2017b), addressing construction, systems, and materials specific to existing buildings. Although they cover a wide range of performance-based objectives, current standards and guidelines for existing buildings are primarily focused on safety and will likely need modification for achieving specific recovery objectives. New recovery-based retrofit criteria could include new sets of recovery-based objectives to supplement or replace current performance objectives, along with new criteria for designing retrofits to achieve target recovery times. For higher recovery-based objectives, criteria could also include protection of contents, quality assurance, and provision for backup utility services.

Ultimately, it is the responsibility of SLTT jurisdictions to adopt and enforce an existing building code and to implement retrofit programs. Jurisdictions with an interest or need to implement recovery-based objectives sooner than the availability of a national standard or policy should be encouraged to develop interim provisions. Interim provisions could be informed by progress being made under Recommendation 1, selected provisions for enhanced seismic design available in current existing building codes and reference standards, consultation with local industry experts, or examples from federal agencies leading by example. Current performance-based standards for existing buildings could be used as interim recovery-based criteria through the selection of higher performance objectives to improve the likelihood of achieving certain recovery-based objectives for a greater number of existing buildings in the near term. 


\section{Should retrofit of existing buildings to meet reoccupancy and functional recovery objectives be mandatory, triggered, or voluntary?}

Retrofit programs are typically conceived, prioritized, legislated, and implemented by SLTT jurisdictions that are most familiar with their existing building inventories and their associated risk to public safety, the available resources, and interests of owners and tenants in their communities. These programs can be designed with a lengthy compliance deadline to allow cost to be spread out over time ${ }^{4}$. An SLTT jurisdiction will have three alternatives for implementing recovery-based objectives for existing buildings. These include the use of mandatory, triggered, or voluntary retrofit programs, as discussed in Alternatives 3-1, 3-2, and 3-3, below.

Outside the adoption of model existing building codes and the use of triggers, retrofits are frequently performed under mandatory or incentivized (voluntary) programs put in place through targeted state legislation or a local ordinance adopted by proactive jurisdictions. Because work on existing buildings can be scaled to avoid triggers, current triggers in model existing building codes may need to be strengthened or supplemented to require seismic retrofit of more buildings to achieve recovery-based objectives.

\section{Alternative 3-1: Mandate the Retrofit of Existing Buildings to Meet Recovery-Based Objectives}

Under Alternative 3-1, a jurisdiction would mandate the seismic retrofit of one or more groups of existing buildings using recovery-based objectives based on future model existing building codes and reference standards, or interim provisions, developed under Recommendation 1. Groups of buildings targeted for retrofit could be defined by assigned recovery categories, or by their use, occupancy, vulnerability, presence of specific deficiencies, or a combination of construction and use representing an identified gap in a jurisdiction's resilience plan.

In general, mandates are more effective than incentives. Retrofit mandates are politically feasible where there is a large group of buildings that presents an obvious and urgent risk. By focusing on specific buildings with widely recognized deficiencies, special programs are likely to be more effective than triggered or voluntary retrofit programs.

In safety-based retrofit programs, critical building groups are identified by structural systems with a history of poor performance in past earthquakes. In recovery-based retrofit programs, the same systems will be of interest (e.g., unreinforced masonry, "soft story" woodframe, concrete "tilt-up", and non-ductile concrete), but retrofit objectives and priorities should be established from the results of a resilience-based inventory of existing buildings that considers the use, function, or service provided by a building in addition to structural system or deficiency.

Some notable retrofit programs have been adopted by leading jurisdictions, including the State of California 1986 Unreinforced Masonry Building Law ${ }^{5}$, the City of San Francisco Earthquake Safety Implementation Program (ESIP) ${ }^{6}$, and the City of Los Angeles Soft, Weak, or Open Front

\footnotetext{
${ }^{4}$ http://clkrep.lacity.org/onlinedocs/2014/14-1697-S1_ord_183893 11-22-15.pdf

5 https://ssc.ca.gov/forms pubs/cssc 92-01_urm law status.pdf

${ }^{6}$ https://onesanfrancisco.org/esip
} 
Wall and Non-ductile Concrete Building Ordinance ${ }^{7}$. Few programs, however, have attempted to target higher performance objectives that consider recovery of function for existing buildings, due to the practical challenges and higher costs associated with retrofitting to higher performance objectives. Such programs have generally only targeted essential service buildings (e.g., hospitals), such as the California Hospital Seismic Safety Program (SB 1953) ${ }^{8}$. In many of these cases, the cost of the retrofit, the limited remaining lifespan of the building, and the opportunity to upgrade obsolete systems have led to conclusions that replacement with new construction is more cost-effective than retrofit to higher performance objectives. It must also be noted that significant damage and increased risk to occupants can be caused by nonstructural systems and contents in a building.

When considering mandated retrofit programs, a balance is needed between the benefits in terms of shorter recovery times after an earthquake, and the challenges of competing community priorities, effects on economic development, displacement of residents and tenants, cost of housing, social justice concerns (e.g., poor and minority communities disproportionately impacted by disasters), preserving the character of historic districts and neighborhoods, preventing building abandonment, and reducing carbon emissions. However, leading communities have demonstrated how working with stakeholders can result in successful programs that provide reasonable timeframes to plan and implement retrofits, identify possible sources of funding to help offset costs, and provide limits on costs that can be passed to tenants.

\section{Alternative 3-2: Trigger the Retrofit of Existing Buildings to Meet Recovery-Based Objectives}

Under Alternative 3-2, a jurisdiction would regulate the seismic performance of existing buildings through current, added, or revised evaluation and retrofit triggers in a local ordinance or a locally adopted version of a model existing building code. Because of shortcomings in how current retrofit triggers are employed in practice, jurisdictions should consider expanding the scope of triggered work through the following examples for strengthening or supplementing existing triggers:

- Adjustment of triggers for current IEBC project types (addition, alteration, repair, change of occupancy, and relocation) to require retrofit in more projects.

- Realignment of seismic retrofit triggers to focus on buildings already identified as local recovery priorities and considered essential for community resilience.

- Addition of triggers outside of the building code for activities including sale, lease, or refinance.

Criteria for triggered retrofit work would be based on future model existing building codes and reference standards, or interim provisions, developed under Recommendation 1. Because instances of triggered retrofit work within a community will occur randomly throughout the community, a retrofit program that relies on code triggers is likely to be less effective than a mandatory retrofit program.

${ }^{7}$ http://clkrep.lacity.org/onlinedocs/2014/14-1697-S1_ord_183893 11-22-15.pdf

8 https://oshpd.ca.gov/construction-finance/seismic-compliance-and-safety/ 


\section{Alternative 3-3: Encourage the Voluntary Retrofit of Existing Buildings to Meet Recovery-Based Objectives}

Under Alternative 3-3, a jurisdiction would implement policies or programs to encourage the voluntary retrofit of existing buildings using recovery-based objectives based on future model existing building codes and reference standards, or interim provisions, developed under Recommendation 1. In a voluntary context, all technical aspects of recovery-based objectives for retrofit of existing buildings would be necessary, except these objectives would not be a mandatory part of the local existing building code.

Financial or other incentives are often necessary to encourage participation, and additional discussion of financial resources is provided under Recommendation 7. Voluntary retrofit programs have the benefit of lower thresholds for acceptance and greater political feasibility. However, experience shows that voluntary retrofit programs are generally less effective than mandatory retrofit programs because they lack a critical mass of participation needed to make meaningful progress towards community resilience.

If the incentive is provided from outside the jurisdiction (e.g., federal grants or subsidies), a voluntary program might be more appealing to the jurisdiction. To be effective, a voluntary program would need to be incentivized in a way that prompts a critical mass of owners to do the work. Recent safety-based programs in California have found that a positive incentive (e.g., reimbursement of a portion of the owner's cost of compliance) needs to cover up to threequarters of the project cost in order to yield participation. Some programs have had success, particularly when retrofits have a low-cost alternative, incentives cover a significant portion of the cost, and there is an effective public awareness campaign, such as the California Earthquake Authority (CEA) Brace and Bolt Program ${ }^{9}$ for retrofit of residential homes.

\footnotetext{
${ }^{9}$ https://www.earthquakebracebolt.com/
} 



\section{Chapter 4}

\section{Improve the Performance of Lifeline Infrastructure Systems}

Lifeline infrastructure systems include electric power, gas and liquid fuel, water, wastewater, telecommunication, and multi-modal transportation systems providing important resources and services for modern society to function and survive. These systems are recognized in the NEHRP reauthorization (P.L. 115-307) and are a subset of the 16 critical infrastructure sectors defined by the National Infrastructure Protection Plan (USDHS, 2013). Lifeline infrastructure systems are interdependent systems made up of the physical infrastructure and the spectrum of organizations (e.g., public, private, federal, state, and special districts) that own and operate them. They include a variety of subsystems, each of which may have separate owners and operators, all of which must coordinate to provide services to end-users. The physical infrastructure is made up of extensive interconnected components, including central nodes such as pumping and switching stations, some of which may include physical structures (including maintenance yards and offices). Many, but not all, lifeline services are provided through connections to, or interfaces with, buildings and other lifeline infrastructure systems. Volume II of the Community Resilience Planning Guide for Buildings and Infrastructure Systems (NIST, (2016b) provides a detailed reference for ways to characterize the functions and regulatory requirements for lifeline infrastructure systems, and their dependencies.

Lifeline infrastructure systems are spatially distributed networks, with some of the larger systems covering multiple cities and even states. The operation of a given lifeline infrastructure system depends on numerous components, designed and built over time, using a variety of standards, procedures, and material types. Failure of a single critical component can result in cascading failures within a system, and to other systems, as in the case of electrical power that was lost to an estimated 50 million people in the 2003 Northeast Blackout (NERC, 2004). Often, several lifeline infrastructure systems have components, or lines, that are co-located along transportation or other utility corridors. The proximity of co-located systems means that failure in one system can lead to unintended damage in adjacent systems (O'Rourke, 2007; FEMA, 1991a, 1991b). In many cases failure of lifeline infrastructure systems can result in secondary hazards, including flooding, explosion, fires, electrocution, contaminated water, and restrictions in mobility and communications.

The interconnected and interdependent nature of lifeline infrastructure systems means that the function of one system depends on, or is critical to, the services from other systems. However, lifeline infrastructure system organizations tend to operate in silos, with each making decisions independent of the others. The complexities of lifeline infrastructure system interdependencies are illustrated in Figure 4-1.

Lifeline infrastructure systems have numerous regulations and regulators, but there is no single regulating authority covering all lifeline infrastructure systems. Some lifeline infrastructure 
systems have multiple regulating authorities covering different aspects of their operations, and these may come from local, regional, state, and federal levels. Regulations may differ for publicly and privately owned lifeline infrastructure systems.

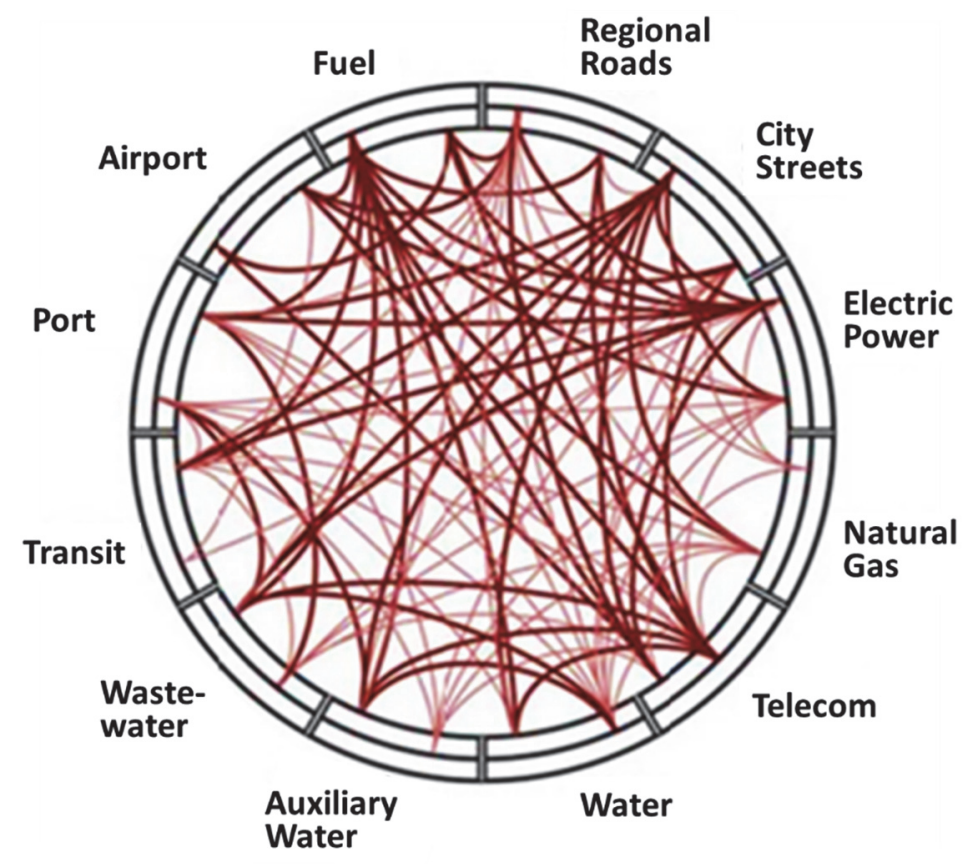

Figure 4-1 Interdependencies of lifeline infrastructure systems in San Francisco (ABAG, 2014); connection points on the outer ring show which systems rely on the designated operator, and connection points on the inner ring show which systems the designated operator relies upon.

Most regulations deal with ensuring safe and reliable operations and provision of services, but most regulations do not address earthquake hazards. Where earthquakes and other hazards are specifically addressed, requirements vary across different lifeline infrastructure systems and across state lines. Some regulations deal with certain critical safety-level components (e.g., dams and nuclear power plants) where earthquake-related design is addressed. The transport and storage of hazardous materials also cover earthquake considerations, but to different levels.

Earthquake-related performance criteria are mostly limited to structural components directly associated with human occupancy (e.g., buildings) or use (e.g., stations, bridges, piers, and control towers). System-level performance requirements are usually related to public health and life safety, property protection (including the environment), and provision for normal service. In most cases, lifeline infrastructure systems are designed for very low probability of service loss under normal serviceable conditions (e.g., wind, rain, snow, ice, annual flooding, and operational demands) and standard operational changes and repairs. Most systems are not designed to provide continuous service under more extreme conditions, such as earthquakes, tornadoes, hurricanes, unusual storms and floods, unusual operational constraints, or rare damage scenarios (e.g., an abnormally high number of pipe repairs in a water system). Rarely are services to large numbers of customers purposefully removed or reduced, although the recent wildfires in California have caused the Pacific Gas and Electric Company to shut off power to reduce the risk of fire ignition due to wind-driven impacts on their electric power distribution system (PG\&E, 
2020). Similarly, the current research activities into deployment of an earthquake early warning system offers the prospect of managing lifeline and other systems to minimize the impact of secondary hazards, such as gas fire after an earthquake, once strong shaking is detected.

A variety of manuals, guides, and standards establishing criteria for design and construction of lifeline infrastructure system components is available (NIST, 2016c). Most do not specifically address post-earthquake recovery times for components or lifeline services. Design guidelines for a few water districts (e.g., San Francisco Public Utility Commission, Willamette Water Supply Program in Oregon) and transportation agencies (e.g., Caltrans) indicate some levels of expected post-earthquake service. Where safety is dictated by regulatory requirements (e.g., bridges, buildings, dams, nuclear power plants), the level of safety protection provided is intended to prevent catastrophic failure, but does not ensure these components will function, and rarely provides information on provision of service following an earthquake.

Services are provided to a variety of customers from a single lifeline infrastructure system. With some exceptions, lifeline infrastructure systems are generally not designed to provide more reliable service to specific customers. That is, customers providing more critical community functions (e.g., hospitals) are provided with the same level of reliability as customers providing less critical functions (e.g., standard industrial buildings).

RECOMMENDATION 4: Design, Upgrade, and Maintain Lifeline Infrastructure Systems to Meet Recovery-Based Objectives

Large segments of the nation's critical infrastructure are now more than 50 to 100 years old, with many portions built before the adoption of modern earthquake codes, standards, and guidelines starting in the 1970's. In 2017, ASCE graded the nation's infrastructure as D+ across 16 categories (ASCE, 2017a).

Many new and existing lifeline infrastructure components could be unusable for an extended period of time following an earthquake. Loss of critical components can result in major disruption to large parts of the system for months to years. This is especially true for large, complicated components like bridges, subways, and treatment plants. For example, damage to bridges in the 1989 Loma Prieta earthquake significantly impacted highway transportation for nine years (FHWA, 2017). As a result, a broad program was funded by the Federal Highway Administration since the mid-1990s that supports seismic retrofit for performance improvement of transportation assets (FHWA, 2006).

A community cannot recover from an earthquake without the recovery of its lifeline services working together. Overall, and regardless of individual agencies' efforts, lifeline infrastructure systems need to be significantly upgraded, and better maintained and coordinated in order to reduce the impacts of future earthquakes and other natural hazards.

To improve the performance of lifeline infrastructure systems in a major earthquake, a recoverybased approach for the design of new systems and the upgrade and maintenance of existing systems is needed. Because the operation of a lifeline infrastructure system depends on numerous components, designed and built over time, using a variety of standards, procedures, 
and material types, the recovery-based design, upgrade, and maintenance of a system are combined and considered under this single recommendation.

The development of a recovery-based framework under Recommendation 1 is needed for implementation of Recommendation 4. The costs, benefits, and feasibility of designing new, upgrading existing, and maintaining all lifeline infrastructure systems will depend on the policy decisions under Task 1.1, design criteria decisions under Task 1.2, and hazard level decisions under Task 1.3. The manner in which the above elements are formulated into a program will dictate the cost, benefits, and feasibility relative to each lifeline infrastructure system. It is worth mentioning recent efforts across various lifeline systems to develop resilience plans for extreme events asset management; one example is the transportation asset management program developed by AASHTO (e.g., AASHTO, 2019).

Wholesale system replacement over a short timeframe is not achievable because of labor, material, and financial resource deficits. Additionally, the expense and disruption to society associated with wholesale replacement would be enormous. On an ongoing basis, however, existing components are replaced because of aging, deterioration, new requirements, or changes in demand or required capacity. If recovery-based policies and criteria are available, then as each component is replaced or added, systems could theoretically be able to meet recovery-based objectives over a longer timeframe. If these concepts are incorporated into asset management plans, this improvement process can take place over the timeframe of a normal asset replacement cycle.

Design of new lifeline infrastructure systems will not, by itself, achieve recovery-based objectives because most lifeline services depend on existing infrastructure, and most new systems continue to rely on existing system components and subsystems. Existing lifeline infrastructure systems comprise the bulk of the U.S. inventory, and their vulnerabilities are the biggest threat to achieving recovery-based objectives.

Some systems have been upgraded using practices and standards developed over the past few decades (e.g., electric power and telecommunications systems, and highway structures). Such upgrades will help in achieving recovery-based objectives, but the performance capability of these upgrades in terms of post-earthquake service continuity or recovery time is not known, except for the performance goals to which they were upgraded (e.g., life safety). Existing lifeline infrastructure systems will remain a liability until they are upgraded or replaced with new construction that is explicitly designed for recovery-based objectives.

Many federal agencies, such as the U.S. Army Corps of Engineers, Bureau of Reclamation, Department of Defense, and others, own, manage, and operate lifeline infrastructure systems, which are vulnerable to earthquake effects. Agencies such as the Department of Transportation also help fund lifeline infrastructure systems. Functional recovery is consistent with National Infrastructure Protection Plan (USDHS, 2013) joint national priorities (USDHS, 2019) through risk reduction, enhancing recovery capabilities, and resilience investment. Federal agencies could lead by example, providing a model for development and implementation of recoverybased objectives for all lifeline infrastructure system owners and operators through early adoption of the framework described under Recommendation 1. Federal leadership will encourage improvement across all lifeline infrastructure system sectors, and help prevent the 
interruption of mission critical functions like what happened at the Naval Air Weapons Station in China Lake following the 2019 Ridgecrest earthquake (Marquez, 2019).

Implementation of Recommendation 4 is not a short-term undertaking. It will require long-term commitment on the part of all lifeline infrastructure system owners and operators or regulators, the support of end users, and leadership at all government and community levels. Improvements to lifeline infrastructure systems should focus on: targeting the lifeline services to users based on importance to community-level needs; incorporating uncertainties (e.g., mean and variability of a performance level relative to a specified hazard level) over a reasonable timeframe (years or decades); and allowing for proper financing commensurate with local, state, and federal capabilities that can be budgeted by lifeline infrastructure system owners and operators.

Implementation of this recommendation includes a series of tasks, all of which are considered essential to develop and implement a program for design, upgrade, and maintenance of lifeline infrastructure systems. These include provision for federal-, state-, local-, tribal-, and territoriallevel guidance on regulatory authority (Task 4.1), evaluation of the current performance capability of existing lifeline infrastructure systems (Task 4.2), development of national design standards (Task 4.3), and creation of regional lifelines councils (Task 4.4). Additionally, an authority administering a program for design, upgrade, and maintenance of lifeline infrastructure systems will have three alternatives for implementation. These include the use of mandatory, voluntary, or triggered programs, as discussed in Alternatives 4-1, 4-2, and 4-3, below.

\section{Task 4.1: Provide National Guidance on Regulatory Authority Across Lifeline Infrastructure Sectors}

There is no common jurisdictional authority for all lifeline infrastructure systems. For some, there may be no regulatory authority to oversee or mandate improvements. The wide array of authorities having jurisdiction over different lifeline infrastructure systems requires a governance structure providing a consistent set of regulations across all systems.

A review of regulatory authorities across all lifeline infrastructure sectors should be undertaken to define where there may be overlaps and gaps at federal, state, local, tribal, and territorial government levels. Such a review should include different federal entities that regulate various lifelines infrastructure systems as well as representative state regulating entities. Based on this review, national-level guidance should be created for developing a governance structure to provide a consistent set of regulations across all lifeline infrastructure systems. Such a governance structure should be developed with proper authorities and should take into account associated federal regulations. The national-level guidance should be adopted with regional adjustments through legislation at the SLTT levels.

\section{Task 4.2: Evaluate the Ability of Lifeline Infrastructure Systems to Meet Recovery- Based Objectives}

Many lifeline infrastructure system owners and operators do not know how long it would take to restore basic services to customers after an earthquake. A small number of lifeline infrastructure systems have undertaken detailed system-level evaluations, but the problem has been simplified in most cases, and the evaluations typically do not account for some, or all, of: (1) the set of 
subsystems making up the lifeline infrastructure system; (2) upstream and downstream supply chain dependencies (e.g., wholesale water suppliers, power generation and transmission, petroleum refineries); (3) interdependencies with other lifeline infrastructure systems and social and economic systems; and (4) plausible earthquake hazards. Lifeline infrastructure system evaluations need to consider the impacts of all earthquake hazards, across the entire system, from source to distribution or collection to discharge.

Evaluation of the ability of lifeline infrastructure systems to meet recovery-based objectives should be mandated, or strongly encouraged, at the federal, state, local, tribal, and territorial levels, for systems of a certain size (e.g., serving a minimum population level) or a certain critical support function. Periodic re-evaluations would be necessary (e.g., every 5 years), based on regular asset management inspections to incorporate life cycle effects of aging and deterioration, system modifications, policy changes, and new technologies. This will help ensure that lifeline infrastructure systems are being properly maintained to meet the recovery-based objectives that they were designed for.

This task would be informed by the policies for recovery time determined under Task 1.1, and the hazard levels selected under Task 1.3, but does not depend on them. Technologies to perform evaluations could be improved and better integrated into practice, but this should not hinder an initial assessment based on current technologies. An initial evaluation is needed to identify expected service losses and the ability to restore them after an earthquake, and to identify priorities for future upgrades as well as inform work on other tasks. Considering potential redundancy, robustness, and system adaptability, not all lifeline infrastructure system components necessarily need to perform at the same level. An initial evaluation will also aid in determining which components are critical to services for different users.

The ability of each lifeline infrastructure system to achieve recovery-based objectives should be clear to all users, so that informed recovery-based decisions can be made. Lifeline infrastructure system owners and operators should publicly disclose the results of system evaluations, and the potential availability of services following an earthquake, except when disclosure could adversely impact national security. Data related to these evaluations support informed decision making by end users about the need for temporary lifeline services.

\section{Task 4.3: Develop National Seismic Design Standards to Meet Recovery-Based Objectives for Lifeline Infrastructure Systems}

A consistent set of guidelines, standards, and codes for all lifeline infrastructure systems is needed to design, upgrade, and maintain lifeline infrastructure systems to meet recovery-based objectives. As reported in NIST (2016c) and Risk and Resilience Measurement Committee (RRMC) (2019), a consistent set of documents does not currently exist. For systems or components that have design standards, the ability to meet recovery-based objectives is limited by inconsistencies in earthquake design criteria, and lack of guidance on: (1) system-level performance; and (2) component performance needed to meet the desired system-level performance.

The development of national-level seismic design guidelines, standards, and codes for lifeline infrastructure systems will ensure consistent recovery-based design, operations, and maintenance 
throughout a network of interdependent systems. A significant amount of work has been undertaken in the past few decades to create seismic design guidelines and standards for some, but not all, lifeline infrastructure system components (e.g., AASHTO, 2011; Caltrans, 2019; ASCE, 2014; Telcordia, 2017; AWWA, 2011; IEEE, 2018; and NASEM, 2020). However, all lifeline system components and assets need to be further investigated to quantify their performance capability, and their ability to maintain sufficient operability, for different earthquake hazard levels. In many instances, existing guidelines and standards can be modified to incorporate criteria for achieving recovery-based objectives. Where this cannot happen, new documents will need to be developed.

For lifeline infrastructure systems crossing state boundaries, there needs to be consistency in the recovery-based objectives to meet the overall target recovery time in an interdependent lifeline infrastructure system. Adoption of a consistent set of guidelines, standards, and codes could be challenging. Recently, the National Cooperative Highway Research Program (NCHRP) has been conducting studies on capability maturity models for adopting national guidelines on a local level, oriented towards the state DOTs resilience organization capability (NCHRP, 2020). National direction on how lifeline infrastructure systems across all sectors can be designed to meet recovery-based objectives should be developed. Federally owned lifeline infrastructure systems should move in this direction in combination with existing authority or infrastructurespecific criteria (e.g., Federal Energy Regulatory Commission seismic guidelines for dams).

Development of national-level seismic design guidelines, standards, and codes for lifeline infrastructure systems would be supported by two activities: (1) implementation of the NIST GCR 14-917-33, Earthquake Resistant Lifelines: NEHRP Research, Development and Implementation Roadmap (NIST, 2014); and (2) re-establishment of a national lifelines organization.

\section{Implementation of the NEHRP Lifelines Roadmap}

In 2014, NIST published GCR 14-917-33, Earthquake Resistant Lifelines: NEHRP Research, Development and Implementation Roadmap (NIST, 2014). The purpose of this roadmap was to "guide the NEHRP agencies in generating national performance restoration goals in concert with the development of guidelines, manuals, and standards for key lifeline systems and components." This roadmap was created with a resilience context in mind, but the recommended topics are directly applicable to recovery-based concepts. A summary of topics identified in the NEHRP lifelines roadmap is provided in Appendix C.1. Since its publication, some topics in the roadmap have been undertaken. Implementation of the roadmap should be preceded by a review of the current state of practice and the current status of topical investigations.

\section{Re-Establishment of a National Lifelines Organization}

The American Lifelines Alliance (ALA) was an organization funded by FEMA between 1999 and 2005 to provide oversight for the development of lifeline infrastructure system guidelines. Budget reallocations forced the ALA to discontinue operations, leaving a significant gap in the ability for lifeline infrastructure systems to coordinate. Given the complex, interconnected, and interdependent nature of lifeline infrastructure systems, a national lifelines organization should be re-established to plan, lead, coordinate and manage efforts to create, adopt and implement 
standards to advance lifeline earthquake engineering and improve system performance (NIST, 2014). Such an organization would be similar to the ALA, but with a different management structure, as described in NIST (2014), and with potentially different tasks, as outlined in Appendix C.2.

\section{Task 4.4: Create Regional Lifelines Councils}

Recovery after an earthquake requires proper identification of system-level interactions and interdependencies among lifeline infrastructure systems and emergency management systems, as well as the sharing of means and methods among stakeholders. Public and private lifeline infrastructure organizations should form regional lifelines councils to improve interaction between the organizations, better understand system interdependencies, and enhance post-event response and recovery coordination.

Depending on the size of the affected area, a lifelines council could include lifeline service providers within a metropolitan area, a state, or even multiple states. A national-level program can be developed to provide guidance for creating lifelines councils across the country. Some lifeline infrastructure organizations may be associated with multiple lifelines councils. Examples citing the need for lifelines councils include the following:

- In 2009, the City of San Francisco convened a lifelines council to understand dependencies of different lifeline infrastructure systems in San Francisco and establish coordination processes for lifeline infrastructure system recovery following a magnitude 7.9 earthquake on the San Andreas Fault (City and County of San Francisco, 2014).

- In 2013, the Oregon Seismic Safety Policy Advisory Committee recommended state and inter-state lifelines councils (OSSPAC, 2013).

- In 2015-2016, the Southern California Critical Lifelines Working Group was formed recognizing the need to break silos among the lifeline infrastructure systems and emergency management organizations.

- In 2015, a Seismic Resilient Water Supply Task Force was created by three agencies importing water into Southern California: the California Department of Water Resources, Metropolitan Water District of Southern California, and Los Angeles Department of Water and Power. This type of regional lifelines council was focused on a specific system with common needs for addressing water supply crossing the San Andreas Fault (Davis and Shamma, 2019).

These groups have shown how significant advancements can be made when lifeline infrastructure system organizations are able to convene regularly. For instance, the San Francisco Lifelines Council developed a comprehensive review of lifeline interdependencies. The Seismic Resilient Water Supply Task Force led to an agreement among state, regional, and city agencies to work as a single unit in an earthquake emergency to ensure water supplies can be restored to Southern California through any of the three major aqueducts regardless of who owns the lifeline infrastructure system. Similarly, the Southern California Critical Lifelines Working Group, has improved the collaboration and sharing of information among various lifelines organizations through regularly held quarterly meetings and engaging lifelines organizations 
with emergency management organizations. The above-mentioned groups have also shown that continuous effort is needed to make progress.

\section{Alternative 4-1: Mandate the Design of New and Upgrade of Existing Lifeline Infrastructure Systems to Meet Recovery-Based Objectives}

Under Alternative 4-1, an authority would mandate the design of new and upgrade of existing lifeline infrastructure systems using recovery-based objectives developed under

Recommendation 1. Requirements should include a statement regarding the probability for

meeting recovery-based objectives. A consistent set of regulations across all lifeline infrastructure systems is needed at the federal, state, local, tribal, and territorial government levels as described in Task 4.1, system evaluations are needed as described in Tasks 4.2, development of national design standards is needed, as described in Task 4.3, and coordination through regional lifelines councils is needed, as described in Task 4.4.

Mandates can be very effective, especially for the design of new lifeline infrastructure systems, if they are implemented with oversight, allowance for increased rates to cover necessary improvement costs, and when reasonable customer-driven target requirements are clearly defined and communicated to customers paying the increased rates. Mandates with undefined objectives will allow lifeline infrastructure system owners and operators to define the performance levels using metrics favorable to the existing conditions (e.g., ASCE, 1995), which is only acceptable if existing conditions meet the selected performance objectives.

\section{Alternative 4-2: Encourage the Voluntary Design of New and Upgrade of Existing Lifeline Infrastructure Systems to Meet Recovery-Based Objectives}

Under Alternative 4-2, an authority would implement policies or programs to encourage the voluntary design of new and upgrade of existing lifeline infrastructure systems using recoverybased objectives developed under Recommendation 1. In a voluntary context, all technical aspects of recovery-based objectives for lifeline infrastructure systems would be necessary, except that they would not be mandatory. Financial or other incentives are often necessary to encourage participation, and additional discussion of financial resources is provided under Recommendation 7.

Voluntary design of new or upgrade of existing lifeline infrastructure systems can be encouraged by local leadership, regulatory authorities, legislatures, users, and other stakeholder groups. Experience has shown that many lifeline infrastructure system owners and operators are receptive to making system improvements to support end user needs once they understand what is necessary and why (e.g., Davis and Shamma, 2019; EBMUD, 2020; PG\&E, 2020; Sims, 2015; BPA, 2013). However, lifeline infrastructure systems are not always maintained to ensure proper performance without appropriate oversight (e.g., CPUC, 2019). Jones and Aho (2019) describe an example of top-down leadership resulting in voluntary improvements to water and communication lifeline infrastructure systems for the City of Los Angeles.

Voluntary programs for existing lifeline infrastructure systems can be effective. Rate paying customers have commonly shown support and willingness to pay for necessary lifeline infrastructure system improvements (e.g., Taylor et al, 1999). However, not all lifeline 
infrastructure system owners and operators will voluntarily implement system improvements. Reasons include: (1) financial constraints; and (2) perception that it is not in their best interest, or in the best interest of their users, even if proven cost effective.

\section{Alternative 4-3: Trigger the Upgrade of Existing Lifeline Infrastructure Systems to Meet Recovery-Based Objectives}

Under Alternative 4-3, an authority would regulate the seismic performance capability of existing lifeline infrastructure systems through triggers that require upgrade when certain system enhancements are made. Triggers could be established through regulatory agencies, legislative processes, or as internal policy by lifeline infrastructure system owners and operators. A variety of triggers are possible, including an inability to meet recovery-based objectives as identified through a system-wide evaluation (Task 4.2), or when components are replaced or re-sized because of aging, deterioration, new requirements, or because of changes in demand.

The scope of triggered upgrade work will need to be set at a reasonable level. For example, triggers that would ultimately require wholesale upgrade or replacement may be too disruptive, too expensive, or not politically feasible. Because instances of triggered upgrade work will occur randomly throughout the system, a program that relies on triggers is likely to be less effective than a mandatory requirement. 


\section{Chapter 5}

\section{Expedite Recovery through Pre-Disaster Planning and Implementation}

The 2011 Tōhoku earthquake and tsunami illustrates the need for effective pre-disaster recovery planning and implementation. The Japanese have made considerable investment in highperformance systems (e.g. base-isolation), earthquake early warning, and other advanced earthquake technologies. Despite those investments, they still relied upon the implementation of extensive pre-disaster recovery plans to deal with the aftermath of the earthquake and tsunamiand even those generally effective plans were inadequate in dealing with the subsequent Fukushima meltdown. The Japanese example illustrates that even with good codes and standards and advanced technology for enhancing buildings and lifeline infrastructure systems, pre-disaster recovery planning is essential to expediting recovery and community resilience.

In 2011, the development of a national-level disaster recovery strategy in the United States was mandated by Presidential Policy Directive 8 (PPD- 8$)^{10}$. In response, FEMA published the first edition of the National Disaster Recovery Framework (NDRF) (FEMA, 2011) followed by the second edition in 2016 (FEMA, 2016). The NDRF defines recovery principles, roles and responsibilities of recovery coordinators and others, a coordinating structure that facilitates communication and collaboration among all stakeholders, guidance for pre- and post-disaster recovery planning, and the overall process by which communities can capitalize on opportunities to rebuild stronger, smarter, and safer (FEMA, 2011). Further, the NDRF "helps ensure that all communities can coordinate recovery efforts to address their unique needs, capabilities, demographics, and governing structures" (FEMA, 2016).

While the NDRF provides a general foundation for disaster recovery planning, communities at risk for earthquakes need to develop pre-disaster recovery plans that explicitly address the activities needed to enable reoccupancy and functional recovery of buildings and lifeline infrastructure systems after an earthquake. Pre-disaster recovery planning can be challenging for communities facing earthquake hazards, particularly when the probability of a major earthquake is considered low and decision makers have to consider multiple and sometimes competing priorities. Accommodating the shift to a focus on recovery-based objectives may add further to the challenge as people learn what these concepts mean and how they may need to adapt current policies, procedures, and practices to expedite community recovery after an earthquake. The value of making this shift will prove positive in terms of lives, livelihoods, resources, and time saved.

${ }^{10}$ https://web.archive.org/web/20120103101043/http://www.fema.gov/prepared/ppd8.shtm 


\section{RECOMMENDATION 5: Develop and Implement Pre-Disaster Recovery Planning}

Focused on Recovery-Based Objectives

In addition to designing, constructing, retrofitting, and maintaining the built environment for reoccupancy and functional recovery, pre-disaster recovery planning by governmental authorities, building owners and managers, and lifeline infrastructure system owners and operators is needed to achieve recovery-based objectives beyond that achievable by design and construction alone. Pre-disaster recovery planning involves making decisions before a disaster about how a community will recover after a disaster (Lindell, 2019). The value of such preparation cannot be overstated; even if the particulars of the pre-disaster recovery plan are not observed in detail, the exercise of having completed the plan before an earthquake will help people more effectively make and implement critical decisions in its aftermath. Strong local leadership is essential to the development and implementation of effective pre-disaster recovery planning (Arendt and Alesch, 2014).

In thinking about who might assume responsibility for addressing recovery-based objectives as part of pre-disaster recovery planning, it is likely best done within the existing administrative structure of each community. For example, reoccupancy and functional recovery efforts may be integrated into the responsibilities of existing positions such as a City Manager, Director of Planning and Development, Building Official, Chief Resilience Officer, or other administrative staff member, department, or agency. The decision where to locate these efforts will depend on the particular community's characteristics (e.g., size, urban, suburban, rural, and frequency of earthquakes). Regardless of the administrative structure used, lessons in how to mobilize and engage communities in dialogue around recovery-based objectives should be drawn from the NIST Community Resilience Planning Guide, related Guide Briefs (e.g., NIST, 2019), and reports on urban resilience strategies as documented by the 100 Resilient Cities ${ }^{11}$ effort.

With respect to lifeline infrastructure systems, pre-disaster recovery planning would be undertaken by each lifeline infrastructure system authority, individually or as part of a larger group effort. They would identify the role they expect to play, how services would be provided to users following an earthquake, and how they would interact with other lifeline infrastructure systems and emergency management organizations. This planning effort will benefit system owners and operators by improving the effectiveness of: (1) integrated asset management planning to address aging and vulnerable components to enhance system-level resilience; and (2) pre-disaster recovery plans for rapidly evaluating, repairing, and recovering the system after an earthquake.

\section{Task 5.1: Develop and Implement Pre-Disaster Recovery Plans}

State, local, tribal, and territorial governments should incorporate recovery-based objectives into existing plans such as Comprehensive Plans, General Plans, Emergency Operations Plans, Land Use Plans, Infrastructure and Transportation Plans, Housing Plans, Economic Development Plans, and plans related to the environment. Business continuity planning professionals should be tapped to help communities integrate recovery-based objectives in their existing plans. A mature field, business continuity planning has a national professional society, the Association of

${ }^{11} \mathrm{https://www.100resilientcities.org/strategies/}$ 
Continuity Planners (ACP) and well-established standards, such as National Fire Protection Association (NFPA) 1600 (NFPA, 2013), that explicitly mention planning scenarios. A consistent focus on recovery-based objectives in the community's existing planning documents should enable better understanding of, and commitment to, reoccupancy and functional recovery. Routine reviews of these planning documents should also ensure that the most current standards and guidelines for recovery-based objectives are incorporated.

In addition to augmenting these existing plans with references to recovery-based objectives, communities should consider developing and implementing a Community Resilience Plan using the NIST Community Resilience Planning Guide (NIST, 2016a; NIST, 2016b). The first step of the six-step resilience planning process is forming a collaborative planning team; the second step is understanding the situation, of which conducting a resilience-based inventory is a key part (Bonowitz, 2020). A resilience-based inventory of the community's buildings and lifeline infrastructure systems could be used to inform the implementation of Recommendations 2 through 4 in this report. Steps three through six of a Community Resilience Plan include determining goals and objectives, developing the plan (evaluating gaps and choosing solutions to close the gaps), reviewing and approving the plan, and implementing and maintaining the plan (NIST, 2016a).

In addition to developing and implementing a Community Resilience Plan, communities should incorporate recovery-based objectives into their Hazard Mitigation Plans. The Robert T. Stafford Emergency Assistance and Disaster Relief Act requires that communities file, adopt, and maintain approved Hazard Mitigation Plans to be eligible for FEMA post-earthquake aid for public and non-profit facilities following the FEMA Local Mitigation Planning Handbook (FEMA, 2013). These plans describe the community's capabilities, define the applicable hazards, assess the relevant risks, and propose a mitigation strategy that includes goals and actions. While these plans do not directly impact privately-owned buildings and lifeline infrastructure systems, they give communities an opportunity to understand their hazards and risks and determine how best to plan for their recovery. Hazard vulnerability analysis and scenario loss estimates should be used to help community leaders decide how to identify and address the community's specific priorities. Examples include the City of San Francisco's Community Action Plan for Seismic Safety (ATC, 2010) and the Oregon Resilience Plan (OSSPAC, 2013). In these documents, planners identified target recovery states for facilities providing key community functions, evaluated the ability of the built environment to meet these targets, and recommended a series of actions to close the gap between targeted and evaluated performance.

Incorporating recovery-based objectives in Hazard Mitigation Plans would provide a uniform basis for assessing community capabilities and conducting risk assessments. To help make this happen, FEMA could incorporate references to recovery-based objectives in its Local Mitigation Planning Handbook with appropriate guidance as to how to apply them to the description of community capabilities and risk assessment. A key benefit would be a clear statement of how buildings and lifeline infrastructure systems support the community's social institutions, yielding a refined basis for pre-disaster recovery planning including the development of practical alternative interim and adaptive solutions. 
Specific to lifeline infrastructure systems, a pre-disaster recovery plan for each lifeline infrastructure system should:

- determine its post-earthquake functional recovery targets (considering community response and recovery needs and dependencies and interdependence among lifeline systems);

- identify vulnerabilities within the system as well as gaps for meeting functional recovery targets; and

- develop a sustained program to reduce vulnerabilities through upgrade or replacement of critical components, or transformation and adaptation strategies to support functional recovery goals as required.

The plan should provide a solid foundation for developing emergency response plans as well as continuity of operations plans. As vulnerabilities are addressed through mitigation programs, these plans should be updated.

The appropriate federal, state, local, tribal, and territorial government entities need to be identified to help oversee a program for local plan development based on the different lifeline infrastructure system sectors. For example, based on Congressional requirements through America's Water Infrastructure Act of 2018 (AWIA; P.L. 115-270 ${ }^{12}$ ), the Environmental Protection Agency requires a risk and resilience assessment that is incorporated into emergency response plans for all drinking water systems serving more than 3,300 people. Following the recommendations of the Oregon Resilience Plan (OSSPAC, 2013), the Oregon Health Authority goes further and requires owners of water systems with moderate to heavy damage potential from a magnitude 9.0 Cascadia Subduction Zone earthquake to complete a seismic risk assessment and mitigation plan as part of the existing requirements for updates to water master plans. This has led to many Oregon water system owners making substantial investments to design or upgrade system components to support post-earthquake recovery-based objectives.

\section{Task 5.2: Create and Promote Seismic Continuity Programs}

Communities comprise many different organizations and institutions, with varying ownership structures. Buildings and lifeline infrastructure systems other than those owned by the local jurisdiction are just as likely to be affected by an earthquake. This suggests that communities should create and promote seismic continuity programs for building owners and tenants that will help them to learn about and identify the risks most likely to affect their buildings. Such programs should also enable stakeholders to develop pre-disaster recovery plans that include appropriate mitigation and preparedness strategies and empower these stakeholders to take action. Appendix D.1 describes some examples of seismic continuity programs.

Most critically, pre-disaster recovery plans should involve owners of buildings and lifeline infrastructure systems whose closure or lack of availability due to earthquake damage, perhaps by virtue of their size or occupancy, would have a significant negative impact on the community. Ideally, the plans would focus on issues beyond post-earthquake assessments to: (1) anticipate the type of building damage and disruption to building utilities and services that may occur due to earthquakes; and (2) develop plans and strategies to expedite reoccupancy and functional

12 https://www.congress.gov/115/plaws/publ270/PLAW-115publ270.pdf 
recovery initially, followed by resumption of normal operations. All business tenants should be aware of the plans and potential consequences for their ability to reopen or use the building following an earthquake. In multi-family residential buildings, the plans should be developed in collaboration with organizations representing the homeowners or residential tenants. Seismic continuity programs should also include outreach to lifeline infrastructure systems and encourage the development of business continuity and continuity of operations plans within each utility and mobility sector.

While such a seismic continuity program for residential owners and tenants should enable reoccupancy and functional recovery in the aftermath of an earthquake, other measures at the community or local jurisdiction level may be needed to ensure adequate re-housing for individuals whose housing may not meet recovery-based objectives. Community recovery depends on people having housing that is safe and that meets their daily needs for access to work, school, and more. Effective pre-disaster recovery plans include policies to ensure that buildings and lifeline infrastructure systems will support people's ongoing needs and desires for housing, education, healthcare, public safety, governance, retail, recreation, and other services. Because temporary shelters are unable to meet the long-term recovery-based needs of a community (and often delay resumption of other critical services), SLTT governments should consider actions for providing housing alternatives that can perform needed functions and restore normalcy for all community members. Failure to do so can cause outmigration and cascading impacts to the community.

\section{Task 5.3: Expand and Improve Criteria, Guidelines, and Procedures for Post- Earthquake Assessments and Evaluations}

While the criteria, guidelines, and procedures for post-earthquake assessments and evaluations exist, they need to be expanded and improved to take into account recovery-based objectives. Timely evaluations for structural safety and habitability after an earthquake are critical to reoccupancy and functional recovery for building owners, residents, and tenants. Building assessments, often necessary for reoccupancy and the initial stages of functional recovery, can be accelerated by planning to: (1) anticipate the specific types of damage that may occur in a building through inventory and evaluation of the community's building systems; (2) establish criteria for closure related to the damage that occurs; (3) engage design professionals, building contractors, construction workers, and supplemental jurisdictional staff; and (4) put programs in place to expedite review of permit materials for building repairs or reconstruction.

Earthquake damage raises immediate questions and concerns as to whether buildings are safe to reoccupy. Of primary concern is the structural integrity of the building and whether it is safe from collapse under gravity loads, earthquake aftershocks, and other hazards. Beyond the risk of structural collapse are life-safety concerns due to: (1) falling hazards from building facades, ceilings, mechanical equipment, furnishings, and other building components; (2) leakage of natural gas or other hazardous materials; (3) risk from fire that may be exacerbated by damaged fire suppression and alarm systems; (4) impediments to building egress; and (5) impacted emergency response capabilities from the neighboring community. To help allay the concerns of building owners and occupants (e.g., residents, tenants, employees), it is critically important to have guidelines and procedures in place to quickly conduct reliable assessments to evaluate building safety. While the need for this is readily apparent, and guidelines for safety evaluations 
are available, preparedness for responding in a timely fashion varies widely among SLTT jurisdictions. The cost of performing these evaluations is an allowable activity under the Stafford Act and some activities may be reimbursable by FEMA (e.g., staff overtime, contracts with outside entities who perform the evaluations).

Rapidly inspecting and evaluating buildings for safety and ability to provide services, while at the same time continuing to observe relevant standards, is key to supporting the recovery-based objectives of a community. Fortunately, there are a number of mechanisms for increasing the speed of post-earthquake safety evaluations. Some involve development of policies and procedures for long-term and sustained efforts, while others rely on temporary changes to standards or staffing.

FEMA P-2055, Post-disaster Building Safety Evaluation Guidance (FEMA, 2019a), was developed as required by the Disaster Recovery Reform Act of 2018, Section 1241: Post-disaster Building Safety Assessment. It summarizes best practice guidance documents and provides interim recommendations for issues without best practice guidance. FEMA P-2055 also identifies recommended improvements, including: a primer for SLTT governments that have the authority to set standards or policy related to the implementation of post-disaster evaluations; information on protecting design professionals who volunteer as evaluators; and legislation to create the authority to evaluate and post buildings, deputize evaluators, and restrict occupancy.

Guidance for post-earthquake safety evaluations of buildings are available, but communities may not be aware of them or of the need for pre-event training of inspectors. Both federal and state agencies can promote this information and provide training to local jurisdictions. Since some jurisdictions already have programs in place, they may serve as a model for other states and municipalities. Ideally, jurisdictions identify through their pre-disaster recovery planning efforts which evaluation guidance best suits their communities' buildings and lifeline infrastructure systems, and then take steps needed to ensure that they are ready to use the guidelines. Failure to take these actions prior to an earthquake can contribute to significant delays in community recovery with attendant negative consequences.

A consistent set of guidelines and procedures for assessment and evaluation of lifeline infrastructure systems does not exist and should be developed. Examples of assessment and evaluation guidelines for buildings include:

- ATC-20, Procedures for Post-earthquake Safety Evaluation of Buildings (ATC, 1989; 1995)

- ATC-20-1, Field Manual: Post-earthquake Safety Evaluation of Buildings, Second Edition (ATC, 2005)

- FEMA-352, Recommended Post-earthquake Evaluation and Repair Criteria for Welded Steel Moment Frame Buildings (FEMA, 2000)

- FEMA-306, Evaluation of Earthquake Damaged Concrete and Masonry Wall Buildings (FEMA, 1998)

- FEMA P-50, Simplified Seismic Assessment of Detached, Single-Family, Wood Frame Dwellings (FEMA, 2012a) 
- FEMA P-1100, Vulnerability-Based Seismic Assessment and Retrofit of One- and TwoFamily Dwellings (FEMA, 2019b)

Proper planning, management, and implementation are essential if post-earthquake evaluation programs are to work effectively. These activities include: training and certifying building safety evaluators and evaluator supervisors; training building officials and emergency managers; developing appropriate emergency management plans; and developing mutual aid resource agreements. Organizing so that professionals from outside the jurisdiction can be incorporated into response efforts can affect recovery efficacy and timeliness. Post-earthquake activities include deployment safety, management, and prioritization of appropriate evaluators, effective collection and reporting of data, and quality assurance oversight of field evaluators. Additional post-earthquake activities include policies on re-evaluation triggers, policies on placards, proper procedures for cordons and barricades, and communication strategies (FEMA, 2019a).

Even when jurisdictions are familiar with relevant safety evaluation guidelines, the reality is that existing guidelines are not suited for evaluation of functional recovery. Appendix D.2 includes brief descriptions of assessment and evaluation guidelines listed above. Appendix D. 3 contains information on the potential for seismic instrumentation and other smart technologies to affect how post-earthquake evaluations are conducted.

\section{Task 5.4: Plan for Sufficient Staffing to Expedite Post-Earthquake Recovery}

FEMA P-2055 and other guidelines highlight the need for sufficient personnel to conduct postearthquake safety evaluations. Many communities do not have enough personnel trained to perform post-earthquake safety evaluations or deal with other community recovery issues in a timely manner. The process of pre-disaster recovery planning can help to highlight these staffing issues and make them a priority for action before an earthquake occurs.

Implementation of pre-disaster recovery plans generally relies on having qualified personnel in various departments and agencies responsible for the local government's functions, such as planning and development, public works, police and fire, emergency medical services, building, public safety, community development, water, sanitation, environmental protection, roads and streets, and more. Necessarily, then, the local jurisdiction must fund and staff its departments and agencies sufficiently to enable all disaster management activities, including mitigation, preparedness, response, and recovery. Moving to a focus on recovery-based objectives may entail additional labor costs upfront to reduce costs and expedite recovery time in the aftermath of an earthquake.

For example, a jurisdiction's building department, typically responsible for enforcing building codes and standards, will need enough staff members to engage in expanded plan review and construction inspection both before and after an earthquake. A temporary increase in staffing capacity after an earthquake may be needed to accomplish the department's assessment and evaluation tasks as expeditiously as possible. An effective pre-disaster recovery plan will address the means for accomplishing this objective. One possibility is reassigning qualified staff from services that are in less demand after an earthquake to those in higher demand. Another possibility is expediting the process for making temporary hires or deputizing individuals in the private sector. Another possibility would be the development of mutual aid agreements between 
jurisdictions and counties that are close enough to facilitate effective collaboration. Since building codes and other regulations may vary by state, it may be more efficient for the agreements to be between jurisdictions within the same state or territory. Yet another possibility that should be considered in a community's pre-disaster recovery plan is the ability to secure outof-state personnel through existing Emergency Management Assistance Compact (EMAC) ${ }^{13}$.

To facilitate timely evaluations that enable recovery-based objectives, government jurisdictions need sufficient staffing capacity. They should consider enacting legislation and regulations that will enable Good Samaritans or volunteer professional inspectors (i.e., volunteer engineers, architects, and certified building inspectors) to provide post-earthquake safety evaluation services without fear of professional liability. The same legislation should cover NonGovernmental Organizations (NGOs) that organize and train volunteers to conduct postearthquake safety evaluations. States should also consider developing statewide programs for deputizing volunteer design professionals and building officials to perform post-earthquake safety evaluations. Efforts such as these will expedite reoccupancy and functional recovery while also allowing local jurisdictions to maintain manageable and affordable staffing levels when the community is not recovering from an earthquake. An example of such a program is the Safety Assessment Program (SAP) administered by California's Office of Emergency Services (Cal OES). ${ }^{14}$ SAP evaluators inspect facilities to determine if there are safety hazards to building occupants or to the general public and recommend posting of placards that indicate the condition of each structure evaluated.

\section{Task 5.5: Develop and Implement Building Occupancy Resumption Programs}

In the immediate aftermath of an earthquake, people want to know if it is safe to reenter their buildings. One approach to making this information available and expediting post-earthquake recovery is to encourage the development and implementation of building occupancy resumption programs. Building occupancy resumption programs are typically a joint responsibility shared by the local jurisdiction and building owners or major tenants. A key feature is having a privatesector engineer on retainer to immediately conduct a building safety evaluation shortly after an earthquake. Contracting with a local engineering firm before an earthquake can reduce the waiting time for evaluation, and if the building is safe, allows the building to be reoccupied without waiting for the local jurisdiction's staff to inspect the building.

At least two different models exist that allow building owners to contract with private-sector engineers. The most well-known model is based on the Building Occupancy Resumption Program (BORP) originally created by the City and County of San Francisco in cooperation with the Structural Engineers Association of Northern California, the local chapters of the Building Owners and Managers Association, and the American Institute of Architects. This voluntary program was established based on the experience of delays following the 1989 Loma Prieta earthquake. Similar programs include Southern California's Back to Business (B2B) ${ }^{15}$ and

\footnotetext{
${ }^{13}$ https://www.emacweb.org/

${ }^{14} \mathrm{https} / /$ www.caloes.ca.gov/cal-oes-divisions/recovery/disaster-mitigation-technical-support/technicalassistance/safety-assessment-program

${ }^{15} \mathrm{~B} 2 \mathrm{~B}$ : http://structuralfocus.com/blog/leading-the-way-in-post-earthquake-recovery-established-back-to-businessb2b-programs/
} 
Seattle's Advisory Tag System ${ }^{16}$, created by the City of Seattle in cooperation with the Washington Association of Building Officials and the Structural Engineers Association of Washington. Both models are designed to allow building owners to get reoccupancy information in shorter timeframes than a local jurisdiction's staff is likely to be able to provide. Appendix D. 4 offers more details on these programs.

\section{Task 5.6: Develop Alternative Standards for Temporary Habitability to Facilitate Reoccupancy}

In the aftermath of an earthquake, communities want as many of their residents as possible to be able to shelter in place in their homes. Although a home may be structurally safe to allow for reoccupancy, it may be considered "unsafe or substandard under the applicable codes, because it doesn't meet existing minimum standards for health and safety for residential housing in nonemergency times" (SPUR, 2012). Pre-disaster recovery plans should address alternative standards for temporary habitability of damaged residences so that residents are able to stay in their homes, thereby increasing the likelihood that they will choose to remain in the community.

Minimum or alternative habitability standards are intended to establish criteria and procedures whereby current building code requirements for habitability can be waived for a limited period of time to minimize resident displacement during repairs (SPUR, 2012). Alternative habitability standards enable reoccupancy of residential buildings that would otherwise be unavailable until repairs are completed. They may, for example, relax certain requirements for egress routes or electric power. Alternative habitability standards should reduce the need for emergency shelters and interim housing while also maintaining an adequate population to enable community recovery.

The challenge in developing such standards lies in balancing the increased risks associated with relaxed requirements (e.g., life-safety risks due to fire, extreme heat), especially with ongoing aftershocks, with the benefits of reduced disruption and shorter reoccupancy times. The development of alternative habitability standards should consider input from building officials, emergency response personnel, and others, while carefully considering the risk trade-offs. The standards would need to differentiate between different types of buildings and residences (e.g., single-family houses, low-rise multi-family apartments and condominiums, student dormitories, high-rise apartments, and condominiums). FEMA P-2055 provides examples of temporary habitability standards, key questions that need to be addressed in developing temporary standards, and options for implementation.

\footnotetext{
${ }^{16}$ Seattle Advisory Tag System: https://www.wabo.org/assets/SEAWPapers/wabo-seaw\%20wp-5\%20final\%20.pdf
} 



\section{Chapter 6}

\section{Enable Action with Education and Financial Resources}

Demand by government officials, construction industry professionals, building owners and managers, lifeline infrastructure system owners and managers, tenants, building and lifeline infrastructure system users, and members of the public will need to reach a critical threshold for uptake of voluntary measures and for regulatory change with regard to recovery-based objectives. Demand is facilitated by effective education and outreach that enhances awareness and understanding of earthquake risk and the expected performance of a community's buildings and lifeline infrastructure systems. Education and outreach efforts need to take into account the pre-existing knowledge and perceptions of different stakeholder groups as well as their propensity to change and adopt new ways of thinking and acting. Financial resources supplied by both public and private sources are needed to implement the design, construction, and retrofitting actions and pre-disaster recovery planning that expedite reoccupancy and functional recovery in the aftermath of an earthquake.

RECOMMENDATION 6: Provide Education and Outreach to Enhance Awareness and Understanding of Earthquake Risk and Recovery-Based Objectives

For a myriad of reasons, people across the United States underestimate risks from natural hazards, particularly low frequency events like earthquakes, and their resulting consequences. In addition, many do not understand what building codes are intended to achieve or that some number of buildings are not likely to be functional or even occupiable after an earthquake. Thus, education and outreach are needed to enhance awareness and understanding of earthquake risk as well as what improvements may be possible via recovery-based objectives.

Change in design and construction for new buildings and lifeline infrastructure systems, as well as maintenance and retrofit of existing buildings and lifeline infrastructure systems, is driven in part by public demand for a certain level of performance. With respect to earthquake risk and knowledge of potential earthquake impacts on buildings and lifeline infrastructure systems, community public awareness continues to lag behind that of design and construction industry professionals. Many average citizens and government officials at all levels (federal, state, local, tribal, and territorial) believe that buildings "built to code" provide more than life safety; many think they will be able to reoccupy these "built to code" buildings almost immediately after an earthquake, not realizing that current codes and standards are not designed with recovery-based objectives in mind. Similarly, many people assume that lifeline infrastructure system services will be available immediately following an earthquake without realizing this may not be the case. Informed awareness and understanding of the risk and benefits would enable communities to make rational decisions about how new buildings and lifeline infrastructure systems should be designed and constructed, and how existing buildings and lifeline infrastructure systems should be retrofitted or maintained in line with Recommendations 2 through 4. 


\section{Task 6.1: Educate Building and Lifeline Infrastructure System Stakeholders about Earthquake Risk and Recovery-Based Objectives}

Building and lifeline infrastructure system owners and managers, tenants, customers, and users all citizens - need information on earthquake risk, common secondary hazards triggered by earthquakes, and associated cascading effects. They also need to be aware of mitigation strategies for achieving recovery-based objectives, and the associated costs and benefits need to be conveyed using terms that make sense to everyone, not just technical professionals. In general, education efforts should focus on communicating risks and solutions in a way that is both accessible and actionable (e.g., FEMA, 2018c). Technical jargon, while accurate, creates gaps in awareness and understanding, and a lack of action on the part of those who are not familiar with the terminology.

Education can take many forms. It could range from interactive school programs in Pre-K through Grade 12 schools, to social media campaigns directed at all members of the public. With respect to the latter, public service announcements and a social media campaign similar to "Drop, Cover and Hold" should be a part of a nationwide earthquake awareness program. However, oversimplification of messaging could lead to negative unintended consequences, and developers of messaging should be careful to include critical information while also recognizing that industry-specific jargon will not be understood by most lay audiences. Research into the most effective messaging for complex subjects should be reviewed prior to implementation of such messaging. Messaging should focus on the benefits of the community adopting a focus on recovery-based objectives rather than on the negatives of maintaining the status quo.

Another campaign could take an insurance focus and dispel myths such as: (1) a homeowner's insurance policy covers earthquakes; (2) the government will rebuild their home after an earthquake; (3) earthquake insurance covers losses resulting from fire, explosion, flood, or tsunami following a covered seismic event; and (4) earthquake insurance covers pools, fences, walls, and other miscellaneous structures. Knowledgeable experts should be interviewed about reoccupancy and functional recovery, particularly as these relate to specific communities. Documentaries and short videos should be made and shared through YouTube and other popular streaming services. Apps that allow users to determine whether a given structure meets recovery-based objectives should be developed for download by individuals.

Stakeholders need transparent information about how their buildings and lifeline infrastructure systems will perform under various possible earthquakes. New building rating systems could be developed, or existing building rating systems (e.g., SEAONC Earthquake Performance Rating System (EPRS) ${ }^{17}$, U.S. Resiliency Council (USRC) ${ }^{18}$, and Arup's Resilience-Based Earthquake Design Initiative (REDi ${ }^{\mathrm{TM}}$ ) Rating System ${ }^{19}$ ) could be modified or enhanced to address both reoccupancy and functional recovery as separate concepts. The SEAONC EPRS is free and available to the public, while both the USRC and $\mathrm{REDi}{ }^{\mathrm{TM}}$ rating systems are proprietary. At present, both the SEAONC EPRS and USRC system address functional recovery but not reoccupancy. $\mathrm{REDi}^{\mathrm{TM}}$ addresses both functional recovery and reoccupancy but combines them

\footnotetext{
${ }^{17}$ Earthquake Performance Rating System ASCE 31 Translation Procedure (2015) https://www.seaonc.org/page/Publications

18 http://usrc.org/

19 https://www.arup.com/perspectives/publications/research/section/redi-rating-system
} 
into a single metric called "downtime," rather than distinguishing them as separate performance goals. Corresponding lifeline infrastructure rating systems are not readily available, but some efforts are underway (e.g., the Federal Highway Administration resilience framework for bridges and transportation structures project).

As part of pre-disaster recovery planning, community workshops and meetings could be used to educate people about recovery-based objectives and to ascertain their priorities. Such workshops should engage a wide variety of community stakeholders, including those representing schools, healthcare, financial institutions, insurance companies, social institutions, non-profits, local and state governments, business and industry, utilities, commercial and multi-family residential building owners, and homeowners. In these forums, lifeline infrastructure systems owners and operators should share and justify their expected recovery times for scenario events. Everyone participating in these educational efforts should emerge with a clear understanding of the risks, opportunities for mitigation, costs and benefits, and what their role should be in determining and adopting the standards and guidelines for reducing the negative consequences of earthquakes.

\section{Task 6.2: Educate Design and Construction Industry Professionals about Earthquake Risk and Recovery-Based Objectives}

Design and construction industry professionals and their associations have the potential to play a key role as catalysts in moving toward recovery-based objectives. These individuals include engineers, architects, urban planners, lifeline infrastructure systems owners and operators, contractors, and construction managers. They need to be aware of, and knowledgeable about, reoccupancy and functional recovery and the means for designing, constructing, and retrofitting to meet recovery-based objectives. They also need to be able to communicate the benefits of reoccupancy and functional recovery to end-users and implement the actions needed to achieve the desired performance. As a first step, the undergraduate and graduate curricula of colleges and universities for design and construction industry professionals should be modified to integrate recovery-based design concepts. The speed and efficacy of this change will depend on teacher-scholars being aware of, and committed to, researching and teaching these concepts.

Beyond their formal schooling and certifications, design and construction industry professionals will need to rely upon continuing education to learn about recovery-based objectives in the same way that they currently learn new information. Many individuals in the design and construction industry belong to their industry's professional association; examples include: AIA, APA, APTA, APWA, AREMA, ASCE, ASME, AWWA, DFI, ICC, IEEE, and NCSEA. ${ }^{20}$ In addition, there are relevant research organizations such as the Earthquake Engineering Research Institute (EERI), the Water Research Foundation (WRF), the Pipeline Research Council International (PCRI), and the Electric Power Research Institute (EPRI) that accomplish similar goals.

\footnotetext{
${ }^{20}$ AIA - American Institute of Architects, APA - American Planning Association, APTA - American Public Transportation Association, APWA - American Public Works Association, AREMA - American Railway and Maintenance of Way Association, ASCE - American Society of Civil Engineers, ASME - American Society of Mechanical Engineers, AWWA - American Waterworks Association, DFI - Deep Foundations Institute, ICC International Code Council, IEEE - Institute of Electrical and Electronics Engineers, NCSEA - National Council of Structural Engineers Association
} 
Design and construction industry professional associations could be a quick channel for reaching many technical professionals. Association meetings could be used for information sharing and education about recovery-based objectives. Education seminars and webinars could be provided that also reward attendees with requisite continuing education credits. Case studies could be used to inform clients about design and construction practices that differ from, or exceed, code minimums. Similarly, design and construction industry professional associations should advise lifeline infrastructure systems owners and operators on improving their capability for postearthquake service restoration. Association codes of ethics should be reviewed for reference to earthquake risk and recovery-based objectives. Model language for consideration by professional associations should be developed to influence the standard of care for recoverybased objectives.

Licensing boards of each state and commonwealth govern the practice of certain building and lifeline infrastructure system design professionals such as architects and engineers. The National Council of Architectural Registration Boards (NCARB) and National Council of Examiners for Engineering and Surveying (NCEES) are two organizations that advance the professional licensure of architects, engineers, and surveyors. Not only do these councils set the minimum education and experience requirements and create the examination for licensure, they also propose model law for continuing education requirements of current practitioners. The requisite number of continuing education hours on an annual basis is governed at the state level. Separately, professional associations also require a certain number of hours to maintain membership and provide continuing education. Incorporating reoccupancy and functional recovery concepts into the examination and continuing education process would allow design professionals to address the needs of existing buildings and to better achieve recovery-based objectives and the resilience of the community.

Government officials, including those at the federal, state, local, tribal, and territorial levels, code officials, transportation departments, public utilities and commissions, and those involved in emergency response activities, represent another constituency that could benefit from education and training about recovery-based objectives. While these individuals will be educated as private citizens, others will receive additional education and training through their participation in professional associations (e.g., city planners who are members of the APA, and code officials who are members of ICC). In addition to these mechanisms, these individuals should also participate in continuing education opportunities targeted at government officials. Opportunities should include webinars, professional conference and meeting presentations, interagency task force meetings, regional coalition meetings, and electronic and printed materials that might be developed at the national level by federal agencies such as FEMA, NIST, or HUD.

\section{RECOMMENDATION 7: Facilitate Access to Financial Resources Needed to Achieve Recovery-Based Objectives}

Mitigation saves lives and livelihoods (NIBS, 2019a). The probability of mitigation increases as the financial resources needed to facilitate mitigation are created and made available. A shift to a focus on recovery-based objectives will cost money. Those who will bear these costs must have access to the financial resources needed to make such a shift. Existing mechanisms to facilitate access to needed financial resources should be augmented with newly developed and implemented mechanisms. 
The costs associated with recovery-based objectives are incremental relative to the costs associated with the current safety-based criteria for designing new, retrofitting existing, or repairing damaged buildings or lifeline infrastructure systems. Potential cost increases for design of new buildings and retrofit of existing buildings are discussed in Chapter 1. Cost increases range from effectively zero (in cases where current design practice already yields buildings and lifeline infrastructure systems that satisfy recovery-based objectives) to approximately 3\% (in new construction where enhanced seismic design is necessary), or, more significant increments depending on the recovery-based objectives selected for retrofit of existing buildings.

Where higher incremental costs are incurred, they will typically come in the form of labor, materials, and financing. Specifically, these costs will fall into one of several categories, including planning and feasibility studies, architectural and engineering design, construction, insurance and taxes, and inspection and testing (Hendrickson, 2008). Operating and maintenance costs in subsequent years over the project's life cycle will include labor and material for maintenance and repairs, periodic renovations, insurance and taxes, and financing costs (Hendrickson, 2008).

Although shifting to a focus on recovery-based objectives will likely increase upfront capital costs to an incremental degree, future losses associated with damage and business interruption will likely decrease, and would be expected to offset higher initial construction costs. Operating costs could also decrease as insurance premiums might be adjusted downward and financing costs might be lower in response to an enhanced likelihood of achieving recovery-based objectives after an earthquake. Additional research is needed to quantify these costs, all of which will be affected by building type, functions provided, geographical location, materials used, and more. Those who will bear these costs include taxpayers for government-owned buildings and lifeline infrastructure systems, private owners, tenants, financial institutions, insurance companies, clients, and end-users.

Regardless of the specific costs and the ownership of those costs, sufficient and timely financial resources will be needed to implement recovery-based objectives. For communities in which there is potential for a major earthquake, it is important to investigate, clarify, and facilitate access to pre-disaster and post-disaster financial resources that are available.

\section{Task 7.1: Develop and Deploy Pre-Disaster Financial Mechanisms to Achieve Recovery-Based Objectives}

The ongoing development and deployment of pre-disaster financial mechanisms are needed to provide the financial resources necessary to implement recovery-based objectives in communities before earthquakes happen. Some building owners, particularly those with higher incomes and those in higher-risk areas who are aware of such risks, may implicitly value, and more readily afford, design and construction that complies with recovery-based objectives. In one study, for example, building owners paid up to $6 \%$ higher purchase prices for above-code design (Awando et al., 2016). To make recovery-based objectives more sought-after by a greater number of people, regardless of their socioeconomic status, basic economic theory suggests reducing owner cost, increasing owner demand, or both. 
Unfortunately, demand alone may not yield sufficient action in a community to change its resilience profile, and some incentives may be needed to cause a meaningful change in behavior. The essence of recovery-based incentivization is to make it cost less for owners to demand higher performing buildings and lifeline infrastructure systems. A way to do this is to offset owner costs using financial incentives, insurance discounts, and public-sector assistance.

While lower costs may increase uptake of desired measures, the relationship between uptake and cost can vary. For example, since vulnerable and historically underserved populations may not be able to afford additional costs themselves, their cost might be completely offset with lending and insurance incentives and public-sector assistance to result in substantial uptake. For owners with more financial resources, more modest incentives might suffice, with the various monetary, safety, and psychological benefits of resilience driving up demand.

Rather than hope that all building and lifeline infrastructure system owners will be willing to assume higher prices, a variety of mechanisms might be developed and deployed to facilitate recovery-based objectives. These mechanisms include "public private partnerships, incentive systems implemented through public policies, government grant programs, conservation easements, tax-increment financing, and incentive zoning" (Sattar et al., 2018). In a 2015 report, the Multi-Hazard Mitigation Council (MMC) of the National Institute of Building Sciences (NIBS), in conjunction with the Council on Finance, Insurance and Real Estate (CFIRE), proposed an interlocking system of incentives from the private and public sectors that would return some of the benefits of natural hazard mitigation to owners to incentivize retrofit or above-code design. The report described several incentives-based approaches to resilience, organized by decision makers (e.g., homeowners, businesses, utilities) and those who offer incentives (e.g., insurance and finance-related companies, lenders, foundations, communities, and federal and state agencies) (NIBS, 2015).

Similar approaches could be used to incentivize recovery-based objectives as well as resilience (NIBS, 2015). For example, in exchange for incorporating recovery-based strategies, homeowners could be offered reduced insurance premiums; federal, state, or local grants or loans; tax incentives; and mortgage programs that include upgrades for mitigation. Businesses could be offered interest rate reductions on loans; insurance rate reductions; tax incentives and fee waivers; and federal, state, or local grants or loans. Larger businesses might be offered higher corporate bond ratings, recovery-based Real Estate Investment Trusts (REITs) and private equity real estate funds, and recovery-based bonds. Utilities could be offered reduced insurance premiums; a public utility commission policy that allows for small rate increases; enhanced bond ratings; and federal, state, or local grants or loans. Public private partnerships that rely on private equity investments added to public investments might also enable recovery-based objectives for lifeline infrastructure systems. These efforts would not only yield lower costs, they would also send a clear signal to the community (i.e., government officials, building industry professionals, building owners and managers, lifeline infrastructure systems owners and operators, and private citizens) about the value and importance of thinking about recovery-based objectives before an earthquake.

In terms of federal programs that might incentivize recovery-based objectives, FEMA currently administers three applicable programs that provide funding for eligible earthquake mitigation planning and projects that reduce disaster losses and protect life and property from damage in 
future disasters. The three programs are the Hazard Mitigation Grant Program (HMGP), the Flood Mitigation Assistance (FMA) Program, and the Pre-Disaster Mitigation (PDM) Program (which was replaced by the Building Resilient Infrastructure and Communities (BRIC) grant program, as noted below). The HMGP assists in implementing long-term hazard mitigation planning and projects following a Presidential major disaster declaration. ${ }^{21}$ HMGP funding is generally $15 \%$ of the total amount of federal assistance provided to a state, territory, or federally recognized tribe following a major disaster declaration. The PDM provides funds for hazard mitigation planning and projects on an annual basis. ${ }^{22}$ Up until FY 2018, PDM funding depended on the amount Congress appropriated each year. Individual homeowners and business owners may not apply directly to FEMA. Instead, eligible local governments may apply on their behalf. $^{23}$

As useful as these programs have been, even greater focus on pre-disaster mitigation at the federal level is occurring. The Disaster Recovery Reform Act of 2018 (DRRA) passed important reforms to federal disaster programs and amended many sections of the Robert T. Stafford Disaster Relief and Emergency Act, including Section 203, Pre-Disaster Mitigation. ${ }^{24}$ These reforms acknowledge the shared responsibility of disaster response and recovery, aim to reduce the complexity of FEMA, and build the nation's capacity for the next catastrophic event. This includes National Public Infrastructure Pre-Disaster Hazard Mitigation (Section 1234), which authorizes the National Public Infrastructure Pre-Disaster Mitigation fund. This will be funded through the Disaster Relief Fund as a 6\% set-aside from estimated disaster grant expenditures, which allows for a greater investment in mitigation before a disaster. ${ }^{25}$ This new program is named Building Resilient Infrastructure and Communities (BRIC) and replaces PDM. As a federal disaster mitigation program, BRIC will focus on reducing the nation's risk by funding public infrastructure projects that increase a community's resilience before a disaster affects an area. ${ }^{26}$ In conjunction with other private-public incentives, the BRIC program should facilitate the achievement of recovery-based objectives in communities throughout the United States.

\section{Task 7.2: Develop and Deploy Post-Disaster Financial Mechanisms to Achieve Recovery-Based Objectives}

Swift access to financial resources after an earthquake is a useful and necessary supplement to the pre-earthquake design, construction, and retrofit of buildings and lifeline infrastructure systems focused on recovery-based objectives. The development and deployment of additional post-disaster financial mechanisms are needed to provide the financial resources necessary to expedite post-earthquake recovery.

While buildings and lifeline infrastructure systems retrofitted or constructed to achieve recoverybased objectives are more likely to be occupiable and serve their intended functions after an earthquake, there is no such thing as "earthquake-proof" design and construction. Even in the best-case scenario, financial resources will be needed as part of post-earthquake recovery.

${ }^{21} \mathrm{https} / / / \mathrm{www} \cdot$ fema.gov/hazard-mitigation-grant-program

22 https://www.fema.gov/pre-disaster-mitigation-grant-program

${ }^{23} \mathrm{https}$ ://www.fema.gov/hazard-mitigation-assistance

${ }^{24}$ https://www.fema.gov/robert-t-stafford-disaster-relief-and-emergency-assistance-act-public-law-93-288-amended

25 https://www.fema.gov/disaster-recovery-reform-act-2018

26 https://www.fema.gov/drra-bric 
However, buildings and lifeline infrastructure systems designed with recovery objectives in mind should require fewer financial resources to bring them back into service, resulting in reduced post-earthquake costs for all who would bear them (e.g., government, owners, tenants, clients, and end-users).

The current U.S. model for funding disaster recovery is a mixture of federal programs, private borrowing and savings, private developers, charity, and private insurance. While many federal agencies are involved in some form of recovery grants and loans, the primary funding agencies are FEMA, the Department of Housing and Urban Development (HUD), and the Small Business Administration (SBA). Most government assistance is targeted to publicly owned buildings and lifeline infrastructure systems. Private-sector business owners typically rely on insurance or private finance to pay for repairs. Businesses that qualify may also seek assistance from the SBA.

The current practice with respect to access to private capital could be improved by encouraging partnering with lenders and insurance companies to ensure those affected by an earthquake can quickly begin the repair process. Activities to support this goal could include new developments encouraging private mortgage companies to consider: (1) the creation of a disaster repair fund by adding additional basis points to the mortgage - an alternative that could lead to the unintended negative consequence of reducing housing affordability by making mortgages more expensive; or (2) possibly developing guidance for pre-arranged repair loans that would be available in the aftermath of an earthquake for buildings designed or retrofit to meet recovery-based objectives. Another possibility would be to encourage private lenders - or even the Federal Housing Administration, the Federal Home Loan Mortgage Corporation (i.e., Freddie Mac), or the Federal National Mortgage Association (i.e., Fannie Mae) - to develop a "resilience mortgage" along the lines of that proposed in a concept paper from the NIBS Multihazard Mitigation Council (MMC) (NIBS, 2016). ${ }^{27}$

Besides private capital, other sources of financial resources that may be used to expedite recovery after an earthquake are those provided by the federal government. Many agencies are involved in recovery support after a federally declared disaster. These include the Corps of Engineers, the Departments of Agriculture, Commerce, Defense, Education, Energy, Health and Human Services, Homeland Security, Housing and Urban Development, Justice, Labor, Transportation, State, Interior, Treasury, Veterans Affairs, the U.S. Office of Personnel Management, and the Social Security Administration. As mentioned previously, the major providers of disaster assistance in the form of funding to individuals and businesses are FEMA, HUD, and the SBA. FEMA is the primary source of funding for repair of publicly owned buildings and lifeline infrastructure systems.

Enhancing access to these agencies and department resources could take a variety of forms, from further streamlining existing programs to reduce the time for receipt of funds, to developing a Federal Case Management System and single application form that would simplify the process for applicants and speed assistance, to developing a special fund for affordable housing loans to non-profit housing developers available after earthquakes to finance the repair and replacement of affordable housing. Ideas to address the disproportionate impacts of earthquakes and other

${ }^{27}$ https://cdn.ymaws.com/www.nibs.org/resource/resmgr/mmc/MMC_IncentivizationWB_Add.pdf 
disasters on vulnerable and historically underserved populations are discussed by experts participating in the Wharton School's Digital Dialogue Number 4: Improving the Disaster Recovery of Low-Income Households. ${ }^{28}$

All of these actions would be in addition to the steps taken to launch https://www.disaster assistance.gov/, the website for the Disaster Assistance Improvement Program (DAIP), created in response to Executive Order 13411 in 2006 by former President George W. Bush. DAIP's mission is to "provide disaster survivors with information, support, services, and a means to access and apply for disaster assistance through joint data-sharing efforts between federal, state, local, tribal, territorial, and private sector partners." 29

Finally, earthquake insurance can be used to facilitate recovery after an earthquake. Currently, earthquake insurance is voluntary and available to those who choose to purchase it, which is a relatively low percentage of the population (Lazarus, 2019). Earthquake insurance premiums can be less for policyholders who have seismically retrofitted their buildings. For example, the California Earthquake Authority (CEA) ${ }^{30}$, established by the California legislature in 1996 as a privately financed, publicly managed risk bearer, provides most residential earthquake insurance in California. It offers earthquake insurance discounts up to $25 \%$ for residential retrofits. ${ }^{31}$ Those interested in purchasing earthquake insurance from CEA do not purchase it directly; rather, they buy it from insurance companies that are members of CEA. Even with support from CEA, earthquake insurance has become prohibitively expensive since the mid-1990s (after the 1994 Northridge, California earthquake). As a result, only 10 to $11 \%$ of homeowners and owners of commercial buildings in California carry earthquake insurance (Lazarus, 2019). Instead, most rely on a combination of limited federal assistance and loans arranged through banks. Very few have the savings to cover disaster repairs.

Traditional earthquake insurance policies are considered problematic for many reasons including delays in receiving funds (Hayward, 2018), high deductibles, high premiums, and limited coverage, and a focus on building back to pre-earthquake conditions rather than building back better. These issues pertain to insurance for both buildings and lifeline infrastructure systems. One step to address these issues would include educating the private insurance market on earthquake hazards and how the risk could be reduced through adoption and enforcement of building codes and retrofit programs with recovery-based objectives.

A variety of additional mechanisms might be employed to address issues of turnaround time, high deductibles, high premiums, limited coverage, and funds that are restricted to building back to pre-earthquake conditions. For example, insurance companies could be encouraged and incentivized to improve turnaround time for processing claims and issuing payments to earthquake insurance policyholders after an earthquake. Insurance companies could establish seismic retrofit triggers for earthquake insurance policies covering seismically vulnerable buildings in very high seismic areas. Insurance policies could explicitly allow for code upgrades

\footnotetext{
${ }^{28} \mathrm{https}$ //riskcenter.wharton.upenn.edu/digital-dialogues/improvingdisasterrecovery/

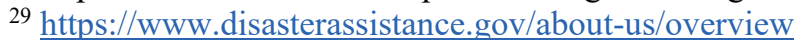

${ }^{30}$ California Earthquake Authority: https://www.earthquakeauthority.com/

${ }^{31} \mathrm{https}$ ://www.earthquakeauthority.com/California-Earthquake-Insurance-Policies/Earthquake-Insurance-PolicyPremium-Discounts
} 
and include dollar amounts needed to fund or subsidize building back better in the case of both buildings and lifeline infrastructure systems.

Insurance companies could also reimagine and explore multi-hazard insurance to balance costs and risk across geographic areas and hazards, recognizing that many disasters are a function of multiple hazards happening simultaneously or as a result of each other (e.g., fire following an earthquake, tsunami following an earthquake, flooding following a hurricane). Insurance companies might partner with non-government organizations and government agencies to research how multi-hazard insurance could be administered, what it would cost to implement, how homeowners and businesses would qualify for insurance, and whether it would be economically feasible.

Insurance companies could also explore and encourage other types of insurance plans such as parametric insurance (Elliott, 2019) and blockchain insurance (Schmid, 2018) to speed up payment times and expedite recovery. Parametric insurance provides a pre-defined payout when a certain level of ground shaking is experienced at the insured location. There is not a claim adjustment process, so payouts can happen almost immediately after an event. The policies are relatively inexpensive compared to regular earthquake insurance, but their payouts are also quite modest. They are not intended to compensate for significant property damage, but to address disruption issues and infuse money into the system immediately. There are typically no deductibles, which counters one major reason why homeowners don't purchase traditional insurance; that is most people's loss will not exceed the large (e.g., 20\%) deductible of traditional insurance. As described in a recent report by the Oregon Seismic Safety Policy Advisory Commission, there may be potential to develop a parametric product that better meets the needs of most homeowners who have modest monetary losses to their property (OSSPAC, 2018). 


\section{Chapter 7}

\section{Assessment and Conclusions}

Elected officials, public policy decision-makers, community resilience advocates, and other stakeholders will be choosing between the relative costs, benefits, strengths, and weaknesses associated with each decision on a path toward improving the seismic performance of buildings and lifeline infrastructure systems. This chapter describes a basis for comparing the recommendations, tasks, and alternatives provided in this report, delivers a qualitative assessment, identifies potential roles for stakeholders involved in implementation, and suggests a path forward.

\subsection{Qualitative Assessment of Recommendations and Alternatives}

Detailed, quantitative assessment of costs and benefits associated with the recommendations, tasks, and alternatives is a necessary step, but beyond the scope of this report. Instead, recommendations, tasks, and alternatives have been qualitatively assessed based on the experience and judgement of the Committee of Experts. A consistent set of metrics was selected as a basis for comparison using input from the five stakeholder workshops (Appendix A.2), available studies, such as the Natural Hazard Mitigation Saves: 2019 Report (NIBS, 2019a), and the experience and judgement of the Committee of Experts.

Qualitative, comparative assessments are provided in Tables 7-1 through 7-4. Footnotes in each table provide additional clarification and discussion. Assessment of the recommendations assumes that all tasks are completed. As a result, the tasks are not individually assessed. Where recommendations include alternatives for implementation, an assessment of the individual alternatives is provided. Assessment was performed considering the relative effectiveness, feasibility, cost, and time for development among the recommendations, tasks, and alternatives. The basis for these metrics, and the criteria for measurement, are described below.

- Effectiveness (Long-term, Community-level). Considers the contribution of the recommendation or alternative toward the ability of buildings and lifeline infrastructure systems to meet recovery-based objectives and support community resilience goals.

Units: Low (limited, minimal, or no improvement in recovery-based performance or ability to meet recovery-based objectives and community resilience goals); Medium (partially improves recovery-based performance or ability to meet recovery-based objectives and community resilience goals); High (significantly contributes to improvement in recovery-based performance or ability to meet recovery-based objectives and community resilience goals)

- Feasibility (Technical, Practical, and Political). Considers level of difficulty in implementation, including challenges associated with technical (state of knowledge, analytical procedures, design approaches, and construction techniques), practical (cost effectiveness), and political (adoptability, enforceability, palatability) issues. 
Units: Easy; Moderate; Difficult

- Cost (Long-term, Community-level). Considers long-term, overall financial costs across an entire community, including costs for development of provisions and programs, costs for implementation and adoption, and cost of construction.

Units: Low; Medium; High

- Time (for Development). Considers the time required for development of technical provisions, adoption of programs, and acquisition of necessary resources prior to initiation of improvements to the built environment.

Units: Short (less than 5 years); Intermediate (5 to 10 years); Long (more than 10 years)

Table 7-1 Assessment of Recommendations

\begin{tabular}{|c|c|c|c|c|}
\hline Recommendation & Effectiveness & Feasibility & Cost & Time \\
\hline $\begin{array}{l}\text { Rec 1: Develop a Framework for } \\
\text { Post-Earthquake Reoccupancy and } \\
\text { Functional Recovery Objectives }{ }^{(1)}\end{array}$ & High & Easy & Low & $\begin{array}{l}\text { Short to } \\
\text { Long }\end{array}$ \\
\hline $\begin{array}{l}\text { Rec 2: Design New Buildings to } \\
\text { Meet Recovery-Based Objectives }\end{array}$ & $\begin{array}{l}\text { Low to } \\
\text { High }\end{array}$ & $\begin{array}{l}\text { Easy to } \\
\text { Difficult }\end{array}$ & Low & $\begin{array}{l}\text { Short to } \\
\text { Long }\end{array}$ \\
\hline $\begin{array}{l}\text { Rec 3: Retrofit Existing Buildings to } \\
\text { Meet Recovery-Based Objectives }\end{array}$ & $\begin{array}{l}\text { Low to } \\
\text { High }\end{array}$ & $\begin{array}{l}\text { Easy to } \\
\text { Difficult }\end{array}$ & $\begin{array}{l}\text { Medium to } \\
\text { High }\end{array}$ & $\begin{array}{l}\text { Short to } \\
\text { Intermediate }\end{array}$ \\
\hline $\begin{array}{l}\text { Rec 4: Design, Upgrade, and } \\
\text { Maintain Lifeline Infrastructure } \\
\text { Systems to Meet Recovery-Based } \\
\text { Objectives }\end{array}$ & $\begin{array}{l}\text { Low to } \\
\text { High }\end{array}$ & $\begin{array}{l}\text { Easy to } \\
\text { Difficult }\end{array}$ & $\begin{array}{l}\text { Medium to } \\
\text { High }\end{array}$ & $\begin{array}{l}\text { Intermediate to } \\
\text { Long }\end{array}$ \\
\hline $\begin{array}{l}\text { Rec 5: Develop and Implement Pre- } \\
\text { Disaster Recovery Planning } \\
\text { Focused on Recovery-Based } \\
\text { Objectives }^{(5)}\end{array}$ & $\begin{array}{l}\text { Medium to } \\
\text { High }\end{array}$ & $\begin{array}{l}\text { Easy to } \\
\text { Moderate }\end{array}$ & Low & $\begin{array}{l}\text { Short to } \\
\text { Intermediate }\end{array}$ \\
\hline $\begin{array}{l}\text { Rec 6: Provide Education and } \\
\text { Outreach to Enhance Awareness } \\
\text { and Understanding of Earthquake } \\
\text { Risk and Recovery-Based } \\
\text { Objectives }\end{array}$ & Low & Easy & Low & Short \\
\hline $\begin{array}{l}\text { Rec 7: Facilitate Access to } \\
\text { Financial Resources Needed to } \\
\text { Achieve Recovery-Based } \\
\text { Objectives }{ }^{(6)}\end{array}$ & Medium & $\begin{array}{l}\text { Easy to } \\
\text { Moderate }\end{array}$ & $\begin{array}{l}\text { Low to } \\
\text { Medium }\end{array}$ & $\begin{array}{l}\text { Short to } \\
\text { Intermediate }\end{array}$ \\
\hline
\end{tabular}

Note 1: The effectiveness of Recommendation 1 assumes that all tasks are completed, and reflects the enabling nature of the recommendation as a critical prerequisite for the effectiveness of other recommendations. The time assessment for Recommendation 1 recognizes that progress can be made locally in the short term, but progress at the national level will occur in the long term.

Note 2: Ranges for Recommendation 2 depend on the alternative selected. See Table 7-2 for the assessment of individual alternatives.

Note 3: Ranges for Recommendation 3 depend on the alternative selected. See Table 7-3 for the assessment of individual alternatives. Assessment assumes a reoccupancy objective for most existing buildings (except for essential services) and state or local adaptation of available criteria, rather than waiting for a new national standard. 
Note 4: Ranges for Recommendation 4 depend on the alternative selected. See Table 7-4 for the assessment of individual alternatives.

Note 5: Ranges for Recommendation 5 depend on the availability of existing plans.

Note 6: Ranges for Recommendation 7 depend on the degree to which private-public partnerships are formed.

Table 7-2 Assessment of Alternatives Under Recommendation 2: Design New Buildings to Meet Recovery-Based Objectives

\begin{tabular}{|c|c|c|c|c|}
\hline $\begin{array}{l}\text { Alternatives under } \\
\text { Recommendation } 2\end{array}$ & Effectiveness & Feasibility & Cost & Time \\
\hline $\begin{array}{l}\text { Alternative 2.1: Mandate the Design } \\
\text { of New Buildings to Meet Recovery- } \\
\text { Based Objectives using Future } \\
\text { National Model Code Provisions }\end{array}$ & High & $\begin{array}{l}\text { Moderate to } \\
\text { Difficult }\end{array}$ & Low & Long \\
\hline $\begin{array}{l}\text { Alternative 2.2: Mandate the Design } \\
\text { of New Buildings to Meet Recovery- } \\
\text { Based Objectives using Interim } \\
\text { Provisions }{ }^{(2)}\end{array}$ & $\begin{array}{c}\text { Medium to } \\
\text { High }\end{array}$ & Moderate & Low & Short \\
\hline $\begin{array}{l}\text { Alternative 2.3: Encourage the } \\
\text { Voluntary Design of New Buildings } \\
\text { to Meet Recovery-Based } \\
\text { Objectives }\end{array}$ & Low & Easy & Low & Short \\
\hline
\end{tabular}

Note 1: Feasibility could be impacted by a lack of receptiveness to earthquake issues on the part of participants in the national model code development process.

Note 2: Effectiveness is expected to be high, but will depend on the consistency between interim and future national provisions.

Note 3: Although the cost of all alternatives is listed as low, some additional costs could be associated with Alternative 2.3 if significant financial incentives are used. Assessment assumes state or local adaptation of available criteria, rather than waiting for a new national standard.

Table 7-3 Assessment of Alternatives Under Recommendation 3: Retrofit Existing Buildings to Meet Recovery-Based Objectives ${ }^{(1)}$

\begin{tabular}{|c|c|c|c|c|}
\hline $\begin{array}{l}\text { Alternatives under } \\
\text { Recommendation } 3\end{array}$ & Effectiveness & Feasibility & Cost & Time \\
\hline $\begin{array}{l}\text { Alternative 3.1: Mandate the Retrofit } \\
\text { of Existing Buildings to Meet } \\
\text { Recovery-Based Objectives }{ }^{(2)}\end{array}$ & $\begin{array}{l}\text { Medium to } \\
\text { High }\end{array}$ & $\begin{array}{l}\text { Moderate to } \\
\text { Difficult }\end{array}$ & $\begin{array}{l}\text { Medium to } \\
\text { High }\end{array}$ & $\begin{array}{c}\text { Short to } \\
\text { Intermediate }\end{array}$ \\
\hline $\begin{array}{l}\text { Alternative 3.2: Trigger the Retrofit } \\
\text { of Existing Buildings to Meet } \\
\text { Recovery-Based Objectives }{ }^{(3)}\end{array}$ & Low & $\begin{array}{l}\text { Moderate to } \\
\text { Difficult }\end{array}$ & Medium & $\begin{array}{c}\text { Short to } \\
\text { Intermediate }\end{array}$ \\
\hline $\begin{array}{l}\text { Alternative 3.3: Encourage the } \\
\text { Voluntary Retrofit of Existing } \\
\text { Buildings to Meet Recovery-Based } \\
\text { Objectives }\end{array}$ & $\begin{array}{l}\text { Low to } \\
\text { Medium }\end{array}$ & $\begin{array}{l}\text { Easy to } \\
\text { Moderate }\end{array}$ & $\begin{array}{l}\text { Medium to } \\
\text { High }\end{array}$ & $\begin{array}{c}\text { Short to } \\
\text { Intermediate }\end{array}$ \\
\hline
\end{tabular}

Note 1: Assessment assumes a reoccupancy objective for most existing buildings (except for essential services), and state or local adaptation of available criteria, rather than waiting for a new national standard.

Note 2: Ranges for Alternative 3.1 depend on whether the mandatory program applies to all buildings or only applies to certain buildings.

Note 3: Ranges for Alternative 3.2 depend on whether current code-based triggers are used, or if triggers are enhanced to require more retrofits.

Note 4: Ranges for Alternative 3.3 depend on type and level of incentives provided. Significant incentives could increase effectiveness, but could result in increased difficulty in adoption, increased overall cost, and increased time for development. 
Table 7-4 Assessment of Alternatives Under Recommendation 4: Design, Upgrade, and Maintain Lifeline Infrastructure Systems to Meet Recovery-Based Objectives

\begin{tabular}{|c|c|c|c|c|}
\hline $\begin{array}{l}\text { Alternatives under } \\
\text { Recommendation } 4\end{array}$ & Effectiveness & Feasibility & Cost & Time \\
\hline $\begin{array}{l}\text { Alternative 4.1: Mandate the Design } \\
\text { of New and Upgrade of Existing } \\
\text { Lifeline Infrastructure Systems to } \\
\text { Meet Recovery-Based Objectives }\end{array}$ & High & Difficult & High & $\begin{array}{l}\text { Intermediate to } \\
\text { Long }\end{array}$ \\
\hline $\begin{array}{l}\text { Alternative 4.2: Encourage the } \\
\text { Voluntary Design of New and } \\
\text { Upgrade of Existing Lifeline } \\
\text { Infrastructure Systems to Meet } \\
\text { Recovery-Based Objectives }{ }^{(2)}\end{array}$ & $\begin{array}{l}\text { Low to } \\
\text { High }\end{array}$ & $\begin{array}{l}\text { Easy to } \\
\text { Moderate }\end{array}$ & $\begin{array}{l}\text { Medium to } \\
\text { High }\end{array}$ & $\begin{array}{l}\text { Intermediate to } \\
\text { Long }\end{array}$ \\
\hline $\begin{array}{l}\text { Alternative 4.3: Trigger the Upgrade } \\
\text { of Existing Lifeline Infrastructure } \\
\text { Systems to Meet Recovery-Based } \\
\text { Objectives }\end{array}$ & $\begin{array}{l}\text { Low to } \\
\text { High }\end{array}$ & $\begin{array}{l}\text { Moderate to } \\
\text { Difficult }\end{array}$ & $\begin{array}{l}\text { Medium to } \\
\text { High }\end{array}$ & $\begin{array}{l}\text { Intermediate to } \\
\text { Long }\end{array}$ \\
\hline
\end{tabular}

Note 1: Alternative 4.1 is a highly effective, difficult, high-cost, long-term activity. Some mitigation of costs is possible by taking advantage of normal life-cycle replacement programs and use of alternative strategies for quick recovery or temporary services following an earthquake.

Note 2: Ranges for Alternative 4.2 depend on the type and level of incentives provided. Significant incentives could increase effectiveness, but could result in increased difficulty in adoption, increased overall cost, and increased time for development.

Note 3: Ranges for Alternative 4.3 depend on how much upgrade work is triggered.

\subsection{Stakeholder Roles}

Ultimately, community resilience and successful recovery after the next major earthquake will require collaborative and comprehensive planning involving all stakeholders, and that work should begin now. Development, adoption, and enforcement of effective codes and standards requires action and coordination at different levels of government - federal, state, local, tribal, and territorial - and close partnership with private-sector stakeholders. Similarly, the design of new facilities and upgrade of existing facilities to meet recovery-based objectives requires input from owners, developers, operators, design and construction industry professionals, and the public. Thoughtful public and private pre-disaster planning, focused education efforts, and access to financial resources will enable the social preparedness, awareness, and responsiveness needed to act.

A recommendation, task, or alternative in this report is not necessarily meant to be implemented by Congress, FEMA, NIST, or any specific federal agency. Ideally, the NEHRP agencies will leverage their past success in similar activities to lead, support, and coordinate with appropriate organizations and entities; to develop policies, programs and procedures in support of these recommendations; and to influence, educate, and train for the adoption of measures that will improve the built environment in terms of reoccupancy and functional recovery time. The potential roles of different stakeholder groups in the implementation of each recommendation are summarized in Table 7-5. 
Table 7-5 Roles of Different Stakeholders in Implementation of Recommendations

\begin{tabular}{|c|c|c|c|c|c|}
\hline Recommendation & $\begin{array}{l}\text { Federal } \\
\text { Government } \\
\text { (NEHRP } \\
\text { Agencies) }\end{array}$ & $\begin{array}{c}\text { State, Local, } \\
\text { Tribal, and } \\
\text { Territorial } \\
\text { Governments }\end{array}$ & $\begin{array}{l}\text { Codes and } \\
\text { Standards } \\
\text { Development } \\
\text { Organizations }\end{array}$ & $\begin{array}{l}\text { Planning, } \\
\text { Design, and } \\
\text { Construction } \\
\text { Professionals, } \\
\text { and Industry } \\
\text { Associations }\end{array}$ & $\begin{array}{l}\text { Building and } \\
\text { Lifeline } \\
\text { System } \\
\text { Owners, } \\
\text { Developers, } \\
\text { Tenants, } \\
\text { Users, and } \\
\text { General Public }\end{array}$ \\
\hline $\begin{array}{l}\text { Rec 1: Develop a } \\
\text { Framework for Post- } \\
\text { Earthquake } \\
\text { Reoccupancy and } \\
\text { Functional Recovery } \\
\text { Objectives }\end{array}$ & $\begin{array}{l}\text { Lead or } \\
\text { Strongly } \\
\text { Support }\end{array}$ & $\begin{array}{l}\text { Participate in } \\
\text { National; } \\
\text { Lead State and } \\
\text { Local }\end{array}$ & $\begin{array}{l}\text { Strongly } \\
\text { Support, or } \\
\text { Lead }\end{array}$ & Participate & Participate \\
\hline $\begin{array}{l}\text { Rec 2: Design New } \\
\text { Buildings to Meet } \\
\text { Recovery-Based } \\
\text { Objectives }\end{array}$ & Support & $\begin{array}{l}\text { Participate in } \\
\text { National; } \\
\text { Lead State and } \\
\text { Local }\end{array}$ & $\begin{array}{l}\text { Lead Technical } \\
\text { Development }\end{array}$ & $\begin{array}{l}\text { Participate in } \\
\text { Development; } \\
\text { Lead } \\
\text { Implementation }\end{array}$ & $\begin{array}{c}\text { Participate in } \\
\text { Development; } \\
\text { Lead } \\
\text { Implementation }\end{array}$ \\
\hline $\begin{array}{l}\text { Rec 3: Retrofit Existing } \\
\text { Buildings to Meet } \\
\text { Recovery-Based } \\
\text { Objectives }\end{array}$ & Support & $\begin{array}{l}\text { Lead State and } \\
\text { Local } \\
\text { Development } \\
\text { and } \\
\text { Implementation }\end{array}$ & $\begin{array}{l}\text { Lead Technical } \\
\text { Development }\end{array}$ & $\begin{array}{l}\text { Participate in } \\
\text { Development; } \\
\text { Lead } \\
\text { Implementation }\end{array}$ & $\begin{array}{l}\text { Participate in } \\
\text { Development; } \\
\text { Lead } \\
\text { Implementation }\end{array}$ \\
\hline $\begin{array}{l}\text { Rec 4: Design, } \\
\text { Upgrade, and Maintain } \\
\text { Lifeline Infrastructure } \\
\text { Systems to Meet } \\
\text { Recovery-Based } \\
\text { Objectives }\end{array}$ & $\begin{array}{c}\text { Lead or } \\
\text { Strongly } \\
\text { Support } \\
\text { Development } \\
\text { and } \\
\text { Implementation }\end{array}$ & $\begin{array}{l}\text { Participate in } \\
\text { National; Lead } \\
\text { State and Local } \\
\text { Development } \\
\text { and } \\
\text { Implementation }\end{array}$ & $\begin{array}{c}\text { Strongly } \\
\text { Support, or Lead } \\
\text { Technical } \\
\text { Development }\end{array}$ & $\begin{array}{l}\text { Participate in } \\
\text { Development; } \\
\text { Lead } \\
\text { Implementation }\end{array}$ & $\begin{array}{c}\text { Lead } \\
\text { Development; } \\
\text { Lead } \\
\text { Implementation }\end{array}$ \\
\hline $\begin{array}{l}\text { Rec 5: Develop and } \\
\text { Implement Pre- } \\
\text { Disaster Recovery } \\
\text { Planning Focused on } \\
\text { Recovery-Based } \\
\text { Objectives }\end{array}$ & $\begin{array}{l}\text { Strongly } \\
\text { Support, or } \\
\text { Lead }\end{array}$ & $\begin{array}{l}\text { Lead State and } \\
\text { Local } \\
\text { Development } \\
\text { and } \\
\text { Implementation }\end{array}$ & $\begin{array}{c}\text { Support } \\
\text { Development }\end{array}$ & $\begin{array}{l}\text { Participate in } \\
\text { Development; } \\
\text { Lead } \\
\text { Implementation }\end{array}$ & $\begin{array}{c}\text { Participate in } \\
\text { Development; } \\
\text { Lead } \\
\text { Implementation }\end{array}$ \\
\hline $\begin{array}{l}\text { Rec 6: Provide } \\
\text { Education and } \\
\text { Outreach to Enhance } \\
\text { Awareness and } \\
\text { Understanding of } \\
\text { Earthquake Risk and } \\
\text { Recovery-Based } \\
\text { Objectives }\end{array}$ & Lead & $\begin{array}{l}\text { Lead or } \\
\text { Strongly } \\
\text { Support }\end{array}$ & $\begin{array}{l}\text { Strongly } \\
\text { Support }\end{array}$ & $\begin{array}{l}\text { Strongly } \\
\text { Support }\end{array}$ & Participate \\
\hline $\begin{array}{l}\text { Rec 7: Facilitate } \\
\text { Access to Financial } \\
\text { Resources Needed to } \\
\text { Achieve Recovery- } \\
\text { Based Objectives }\end{array}$ & $\begin{array}{l}\text { Strongly } \\
\text { Support, or } \\
\text { Lead }\end{array}$ & $\begin{array}{l}\text { Strongly } \\
\text { Support, or } \\
\text { Lead }\end{array}$ & Support & Support & Participate \\
\hline
\end{tabular}




\subsection{A Path Forward}

Improving the performance of buildings and lifeline infrastructure systems in terms of reoccupancy and functional recovery time will require coordinated action across all recommendations. Although each recommendation can have a positive impact, maximum effectiveness will only be achieved when all of the recommendations are fully implemented. Interactions among the recommendations are illustrated in Figure 7-1.

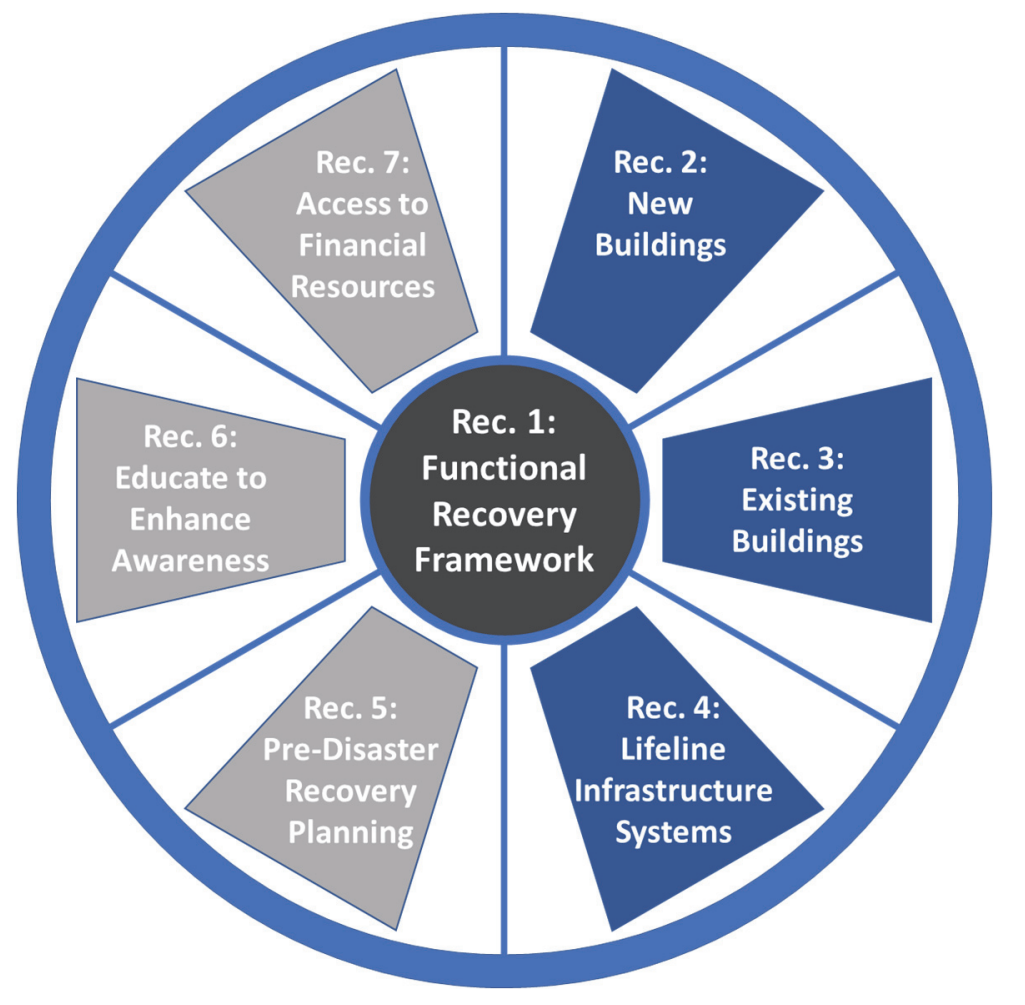

Figure 7-1 Interactions among the recommendations.

Located in the center of the figure, Recommendation 1 is key to all other recommendations. Development of a reoccupancy and functional recovery framework will provide the core policy, technical, and hazard level information needed as a basis for all other activities. On the right side of the figure, Recommendations 2, 3, and 4 address the design, construction, and upgrade of new and existing buildings and lifeline infrastructure systems. Activities under these recommendations will directly improve the performance of the built environment. On the left side of the figure, Recommendations 5, 6, and 7 address planning, education, and access to financial resources. Activities under these recommendations will affect the social, economic, and political environment. Although they do not directly impact the performance of the built environment, these activities address issues that affect implementation of the other recommendations, and serve to reduce reoccupancy and functional recovery time following an earthquake through improved pre-earthquake planning and post-earthquake recovery processes.

As community members engage in pre-disaster recovery planning under Recommendation 5 , and people are educated about risk and the benefits of recovery-based design under Recommendation 6 , it is envisioned that improved performance of the built environment under Recommendations 2, 3, and 4 will become an expectation. Access to financial resources under Recommendation 7 
will provide the means to expedite achievement of reoccupancy and functional recovery objectives.

Although Recommendation 1 is fundamental to the other recommendations, it will also benefit from ongoing progress begin made in each of the other recommendations. A national approach may be the ultimate goal, but the details and success of a national approach can benefit from actions taken by leading stakeholders at the SLTT levels, which can provide early feedback on proof of concept, best practices, and lessons learned. A shift toward recovery-based performance of the built environment will only be possible through integration of activities along multiple parallel paths, consideration of varying private-sector stakeholder perspectives, and engagement at all levels of government.

Table 7-6 provides a possible timeline of short-term, intermediate-term, and long-term activities that could be undertaken on a path forward. The table presents ideas contained in the recommendations, tasks, and alternatives, adapted into actionable examples for implementation. The timeframes listed in the table are targets for completion, with the implication that action should begin now, as some activities will take longer than others to complete.

Table 7-6 Timeline for Implementation (adapted from Bonowitz, 2020)

\begin{tabular}{|c|c|c|}
\hline Timeline & & Actions \\
\hline Short-Term & - & $\begin{array}{l}\text { TT jurisdictions and stakeholders (including federal agencies) lead with implementation, } \\
\text { ptation, and adoption of available tools and practices } \\
\text { Design of new buildings for functional recovery objectives } \\
\text { Retrofit of existing buildings for reoccupancy objectives } \\
\text { Mitigation programs/priorities informed by scenario planning considering resilience-based } \\
\text { inventory/evaluations of existing buildings and lifeline infrastructure systems } \\
\text { Development of new and enhanced existing plans, programs, and policies to expedite } \\
\text { recovery: pre-earthquake planning (business continuity and BORP plans, mutual aid } \\
\text { agreements, insurance) and post-earthquake response (safety evaluation and placarding, } \\
\text { permitting, temporary habitability standards) } \\
\text { jional lifelines councils established } \\
\text { earch and technical studies to support development of target times and appropriate hazard } \\
\text { dings and for lifeline infrastructure systems) } \\
\text { untary innovation by communities, designers, and developers } \\
\text { Shows innovation, implementation, and adaptation strategies } \\
\text { Raises ideas, issues, and possible low-cost/no-cost solutions } \\
\text { Creates public demand and political will through education campaigns } \\
\text { Changes the conversation from minimum safety to recovery and overall resilience }\end{array}$ \\
\hline
\end{tabular}




\section{Table 7-6 Timeline for Implementation (cont'd)}

\begin{tabular}{|c|c|}
\hline $\begin{array}{l}\text { Intermediate- } \\
\text { Term }\end{array}$ & $\begin{array}{l}\text { - } \begin{array}{l}\text { - } \\
\text { - }\end{array} \text { Recovery-based plans, codes, and programs in place in many jurisdictions } \\
\text { - } \quad \text { Regional lifelines councils develop and coordinate recovery-based mitigation efforts and post- } \\
\text { earthquake response planning } \\
\text { - } \quad \text { First version of functional recovery framework with target times, design guidelines, and hazard } \\
\text { levels for recovery-based objectives } \\
\text { - } \quad \text { On the path toward development of recovery-based model codes and standards for buildings } \\
\text { and for lifeline infrastructure systems } \\
\text { - } \quad \text { Approach to recovery from earthquakes leveraged to promote recovery from other hazards } \\
\text { - Financial resources made available to communities to enable widespread focus on recovery }\end{array}$ \\
\hline Long-Term & $\begin{array}{l}\text { - National functional recovery framework completed } \\
\text { - National consensus recovery-based model codes and standards available for buildings and for } \\
\text { lifeline infrastructure systems } \\
\text { - Local/state/federal programs encourage, if not require, routine use of recovery-based codes, } \\
\text { standards, and other provisions } \\
\text { - Nationwide momentum and progress informed by implementation best practices and success } \\
\text { stories }\end{array}$ \\
\hline
\end{tabular}

\subsection{Conclusions}

The Committee of Experts has provided a list of "recommended options" in the form of recommendations, tasks, and alternatives, and has qualitatively assessed those options for effectiveness, feasibility, cost, and time for development. Implementation will involve public and private stakeholders and support at all levels of government, so individual recommendations, tasks, and alternatives have not been assigned to any specific federal agency.

In considering the overall list of recommendations, and potential actions by stakeholders at all levels, the Committee offers the following list of actions that Congress might choose to take, or might choose to encourage other federal entities to perform:

\section{- Support Technical Development.}

Support the development of policies along with practical and effective methods for design and retrofit of buildings and lifeline infrastructure systems to enable the implementation of Recommendations 1,2,3, and 4. Much progress has been made in the science and practice of seismic engineering through past efforts of the NEHRP agencies, particularly with the development of NEHRP Recommended Seismic Provisions for New Buildings and Other Structures (FEMA, 2015b) and contributions to the development of codes produced by the International Code Council (ICC) and standards produced by the American Society of Civil Engineers (ASCE) for new and existing buildings. These past successes should be leveraged and expanded toward the development of recovery-based provisions, codes, and standards for buildings. Furthermore, activities identified in the Earthquake Resistant Lifelines: NEHRP Research, Development and Implementation Roadmap (NIST, 2014) should be implemented, 
particularly the development of appropriate guidelines and standards for recovery-based seismic design and upgrade of lifeline infrastructure systems. Advocacy for incorporation and adoption of the results of developmental efforts at various levels of government, and in the private sector, should also be supported.

\section{- Incentivize Action.}

Encourage SLTT jurisdictions to adopt recovery-based codes and standards, and engage in recovery-based planning, mitigation, financial, and other enabling activities envisioned under Recommendations 5 and 7, by offering incentives, possibly in the form of:

- additional levels of Stafford Act mitigation funding for communities that implement recovery-based policies and programs;

- expanded federal support of earthquake or multi-hazard insurance for properties and systems that meet recovery-based objectives; and

0 tax incentives for communities and owners that conform to recovery-based policies and other requirements.

\section{- Encourage Federal Leadership by Example.}

Encourage the Executive Branch to develop recovery-based seismic design and retrofit requirements for federally owned and leased buildings, similar to Executive Order 13717 (The White House, 2016). This would include development of a timeline and implementation plan for: (1) requiring all federal agencies to comply with the requirements for new buildings (near-term) and existing buildings (phased over time); and (2) prohibiting the lease of new space (near-term) or renewal of existing leases (phased over time) in buildings that do not meet new requirements.

Additionally, the federal government should require the design of new and upgrade of existing lifeline infrastructure systems that are owned, managed, funded, or operated by federal agencies. This would involve integrating the framework developed under Recommendation 1 across all lifeline infrastructure system sectors in the National Infrastructure Protection Plan (USDHS, 2013), and would include development of a timeline and implementation plan for all federally owned, managed, and operated lifeline infrastructure systems to be newly designed (near-term), upgraded (phased over time), or maintained (near-term and long-term).

\section{- Mount an Education Campaign.}

Lead the development and implementation of an education campaign as discussed under Recommendation 6, and support similar educational efforts by SLTT jurisdictions. Messaging should be focused on current risks to society and the need to improve the resilience of the nation. The purpose of such a campaign would be to create public awareness and an environment that would allow other recommendations to be successful.

Action at the federal level is strongly encouraged. Taking no action would be equivalent to relying only on an SLTT jurisdiction to implement the recommendations on their own. Some jurisdictions are ready and able to do this, but many will need federal agency support. Although taking no action would avoid additional federal expenditures in the short term, a lack of action 
will have limited impact on improving the built environment overall, and lead to higher federal expenditures for response and recovery in future disasters.

Improving the built environment in terms of reoccupancy and functional recovery will require involvement from many stakeholders, dedicated effort, and commitment of resources toward making incremental, consistent, and measurable progress over time. Ultimately, the improved resilience resulting from taking action will yield communities that are better prepared and better able to recover rapidly from future earthquakes and other natural hazards, while saving lives, livelihoods, money, and time. 


\section{Appendix A}

\section{Process and Approach}

\section{A.1 Committee of Experts}

In 2019, the FEMA contracted with the Applied Technology Council (ATC), and NIST contracted with the Science and Technology Policy Institute (STPI), to assist in convening a Committee of Experts to develop a report to Congress assessing and recommending options for improving the built environment to reflect performance goals in terms of post-earthquake reoccupancy and functional recovery time. As directed under the NEHRP Reauthorization, the Committee of Experts included representatives from federal agencies, nongovernmental organizations, private sector entities, disaster management professional associations, engineering professional associations, and professional construction and homebuilding industry associations.

The Committee of Experts included a Project Technical Panel (PTP) and a Project Review Panel (PRP). The Project Technical Panel, led by ATC, was charged with developing the report, and the Project Review Panel, led by STPI, was charged with providing review and feedback on the report during development. In addition to FEMA and NIST representatives participating as members of the Committee, the Project Technical Panel included 17 outside subject matter experts, and the Project Review Panel included 10 additional outside experts. The individual members of the Committee of Experts, and their affiliations, are provided in the list of Participants at the end of this report.

In performing its work, the PTP met seven times over a period of 10 months to brainstorm initial ideas, develop key concepts, and successively refine the resulting recommendations and alternatives. The report was developed in a series of drafts: first, 50\%, 75\%, 100\%, and final draft iterations. Over a similar period, the PRP met twice, and participated in reviews of the first, $75 \%$, and $100 \%$ draft iterations. Material comprising the $50 \%$ draft was presented to Stakeholder Workshop participants to receive input on potential report content, as described in the sections that follow. The final draft was submitted for federal agency review and preparation of the final report for submittal to Congress.

Each draft iteration was subjected to extensive review and comment. In all, over 2000 review comments were received from the PTP, PRP, and other reviewers, and all comments were recorded and addressed by a lead author group appointed by FEMA and NIST. This final report is a combined effort of the PTP in developing the report and the PRP in providing review and feedback on its development. It provides a range of perspectives from the Committee of Experts on options for improving the built environment in terms of reoccupancy and functional recovery time and does not represent a consensus opinion provided to the government. Although a formal consensus process was not followed, all comments were considered by the lead author group in developing the final report content, which was based on overall majority opinions expressed by the Committee of Experts, relationship to the Congressional mandate, clarity of messaging, and appropriateness of the information to the primary audiences. 


\section{A.2 Stakeholder Workshops}

Because functional recovery inherently incorporates risk tolerance, community preferences, and societal values, it was considered critical to gather feedback from stakeholders to inform the report to Congress. To gather stakeholder input, five stakeholder workshops were held across five cities: St. Louis (on January 27, 2020); Salt Lake City (on January 29, 2020); Seattle (on January 31, 2020); San Francisco (on February 4, 2020); and Los Angeles (on February 6, 2020). The workshops were hosted in cities across the central and western portions of the United States to capture perspectives from different localities, and to ensure that a range of dates and geographic opportunities were available to attract a diverse set of stakeholders. The workshops were not intended to serve as community listening sessions, nor to receive detailed feedback on the line-by-line text in the report.

\section{A.2.1 Workshop Participants}

The workshops convened a broad range of stakeholders and subject matter experts, including local officials, private consultants, structural engineers, social scientists, utility and lifeline system representatives, among others. The range of expertise represented on the day of each workshop varied based on attendance. Workshop invitees were identified based on the following considerations:

- Geographic Representation. Emergency management, city building and planning officials, public safety, and utility managers were identified in each of the workshop locations. To add regional diversity, relevant officials from other areas of seismic risk were invited, including Puerto Rico, South Carolina, Colorado, Oregon, Missouri, Tennessee, and Illinois.

- Expertise. Workshop invitees were selected with regard to a strong foundation in seismic hazard and the built environment, as well as knowledge and experience spanning lifelines, social sciences, policy, and community planning to provide diverse perspectives on societal aspects of functional recovery.

- Stakeholder Groups. Workshop invitees also reflected a range of stakeholders groups to ensure that viewpoints from across sectors could be incorporated into the overall thinking about functional recovery. Workshop invitees included stakeholders representing the private sector, federal, state, and local governments, academia, and various non-profits.

- Prior Participation. Attendee lists from relevant meetings and workshops convened by earthquake-relevant groups in the past several years were reviewed to identify potential workshop invitees. Prior events included those organized by the National Earthquake Hazards Reduction Program (NEHRP), the Earthquake Engineering Research Institute (EERI), and the NIST Immediate Occupancy workshop (Sattar et al., 2018).

Out of over 230 invitees, approximately 70 attendees participated across the five workshops. The attributes of attendees are summarized in Figures A-1a and A-1b. Figure A-1a shows that the workshop in San Francisco was the largest with 21 attendees, while Los Angeles was the smallest with 10 attendees (Figure A-1a). San Francisco also had the largest proportion of structural engineers present (50\%), while the workshop in St. Louis had the smallest, with $80 \%$ of attendees having expertise in areas other than structural engineering (Figure A-1b). 


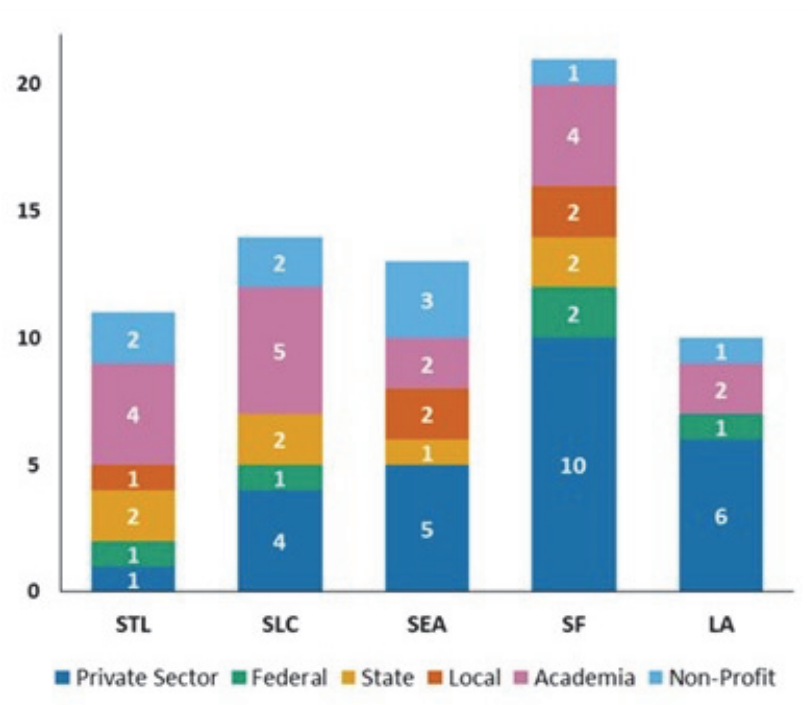

(a)

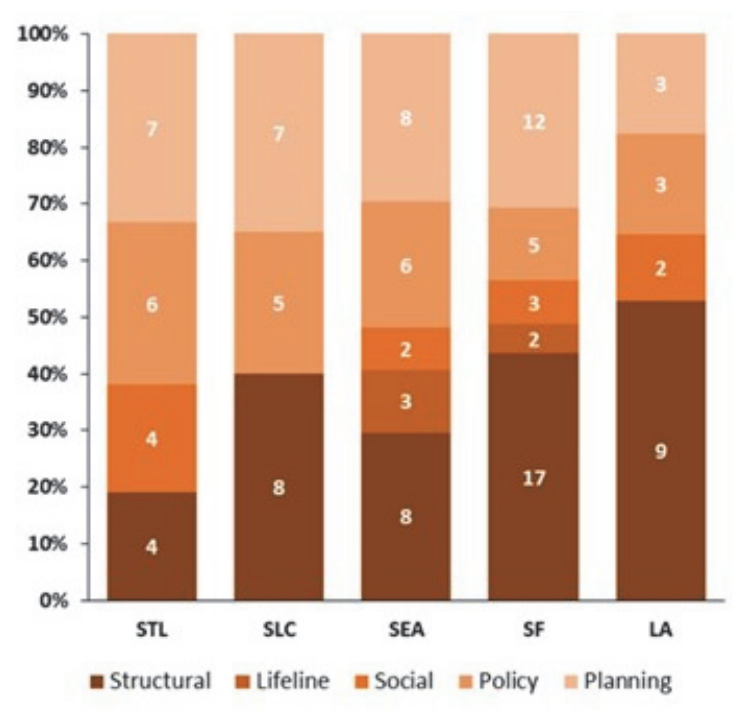

(b)

Figure A-1 Workshop attendees across the five locations: (a) by stakeholder group; and (b) as a percentage of expertise present at the workshop. The numbers in Figure A-1b do not sum to the number of participants in Figure A-1a because participants were characterized in one or more areas of expertise based on their past experience and current position.

Each workshop (and the workshops in total) did not attempt to create representative sample populations. While the subset of individuals who attended the workshops did not constitute a representative sample of community resilience or functional recovery professionals, most workshop attendees possessed some level of expertise in community resilience or functional recovery. Therefore, the workshops attendance was not representative of the general public. For these reasons, the workshop output cannot necessarily be extended or generalized to represent the views of the public, and geographic comparisons across workshop locations, or comparisons across sectors and expertise of attendees, should be avoided without appropriate context for the discussion.

\section{A.2.2 Workshop Objectives}

The workshops had two primary objectives. The first was to receive input on the functional recovery framework with a focus on exploring the maximum amount of time acceptable to achieve a basic level of function for various components of the built environment. The second was to investigate key criteria for assessing options for achieving functional recovery and how value judgements might differ among participant groups when evaluating different options.

These objectives were selected in collaboration with the Project Technical Panel (PTP) to target topics in the report that were inherently value-based and could likely vary across communities. The purpose was to gain insight on how these materials could be presented in a national-level report while maintaining their relevance across communities with different needs and values. 


\section{A.2.3 Workshop Agenda}

The workshops began with an overview of the PTP's progress in developing the report and providing context for how the workshop discussions would support the development of the report to Congress. Following introductory presentations, workshops were structured around three breakout sessions which are discussed below.

\section{A.2.4 Breakout Session 1: Functional Recovery Framework}

\section{Objective}

The objective of Breakout Session 1 was to gain feedback on development of a framework for functional recovery, described as the acceptable amount of time that a function can be out of service before there is a lasting impact on a community. The session was structured around the concept of recovery categories, and aimed at validating or disputing the notion of hours, days, weeks, or months as appropriate timeframes for each categories. Furthermore, the session sought to have participants develop distinct concepts and descriptions for each recovery category (i.e., to describe fundamental differences in the components of the built environment placed in the hours category versus those placed in the days category).

\section{Process}

The session was framed by discussing the ultimate goal of functional recovery: to support basic societal needs following an earthquake such that the community avoids population displacement and retains its economic and societal growth trajectory.

- Participants were first asked to brainstorm community functions that are necessary to maintain the population following an earthquake, thinking in terms of activities and processes rather than buildings and infrastructure.

- The group was then asked to brainstorm components of the built environment (hereafter referred to as "components") that enabled those functions.

- Participants were then asked to place components into the appropriate recovery category (hours, days, weeks, and months) and were reminded that the time category should represent the longest acceptable time a community could go without that component of the built environment. To ensure internal consistency, each group was asked to define hours, days, weeks, and months.

- Once all components were placed in a recovery category, the groups discussed the placement of components and revision of initial placements. Participants then discussed what situations would cause some of the components to shift (i.e., how local contexts may alter the results).

\section{A.2.5 Breakout Sessions 2 and 3: Assessing and Evaluating Options}

\section{Objective}

The objective of Breakout Sessions 2 and 3 was to gather more information on the different types of value judgements needed when evaluating and comparing functional recovery options. This value-based input was intended to be used by the PTP in assessing the options included in the 
report to Congress, and the results of these sessions could also be used to identify metrics for policy makers to better understand individual options and compare across options.

\section{Process}

In Breakout Session 2, facilitators asked participants to consider what information a policy maker would need to effectively compare different functional recovery options. Participants identified a list of criteria that could be considered in evaluating options for functional recovery.

- Criteria were brainstormed until participants felt they had produced a reasonably comprehensive list.

- Once the list of criteria had been developed, each participant voted for the two criteria he or she thought were most important.

- The top five criteria from Breakout Session 2 were then determined based on the number of votes.

In Breakout Session 3, the criteria identified in Breakout Session 2 were used as a basis for evaluating example options from the $50 \%$ draft report. The purpose of this exercise was to explore whether the criteria selected and defined in Session 2 could be consistently weighted when assessing various options.

- The top five criteria from Breakout Session 2 were each was assigned a unique color.

- Workshop facilitators then described one of four options being evaluated. On a scale of least important to most important, participants were asked to indicate how important each criterion was in evaluating the option. The process is illustrated in Figure A-2. The four options used to test evaluation criteria included:

1. Design all new buildings using new codes/standards with specific functional recovery performance objectives.

2. Incentivize pre-disaster retrofits of existing buildings through federal or state tax breaks.

3. Educate building owners and tenants on the seismic risk to their building and community.

4. Maintain the status quo of designing buildings for life safety performance (i.e., business as usual). This option was discussed as time permitted.

After each round of voting, participants discussed trends and explained thought processes. Time was typically provided at the end of each exercise to reflect on results: whether they looked as anticipated, if there were similarities and differences across options, and what criteria might be missing. 


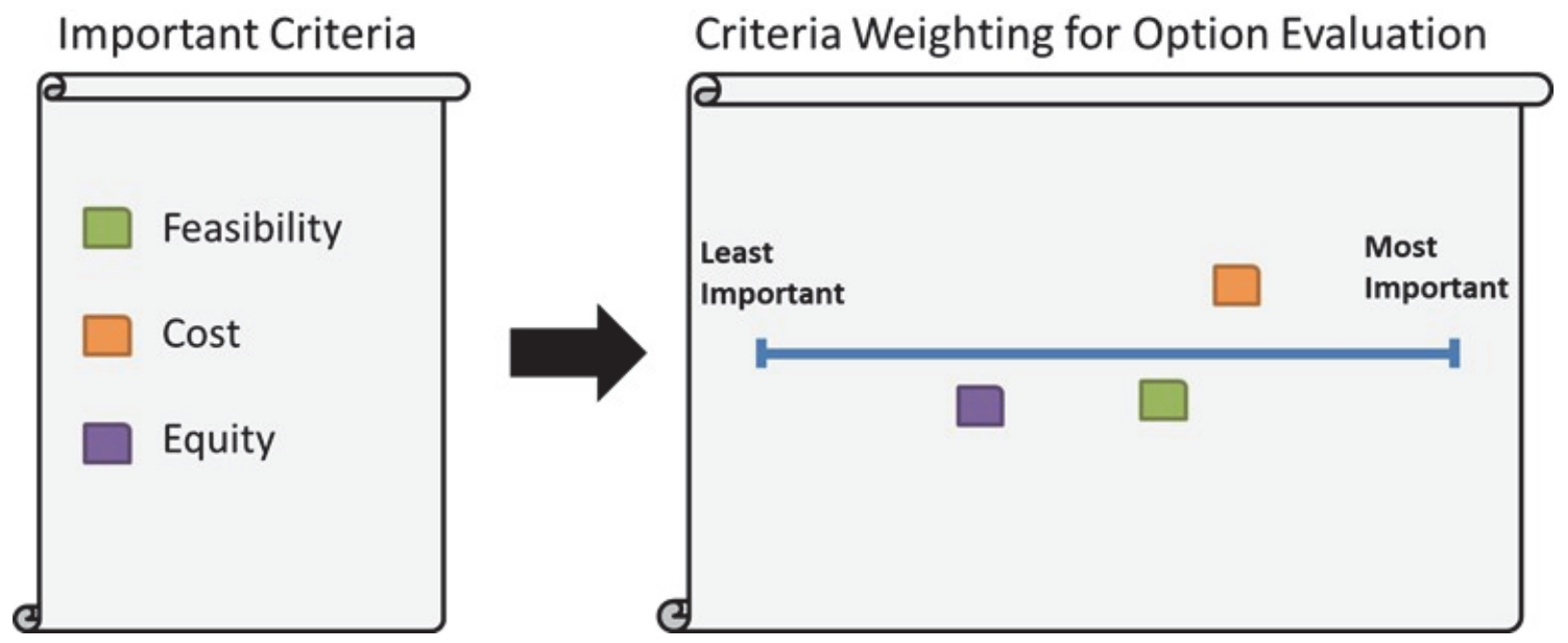

Figure A-2 Illustration of process for breakout session 3.

\section{A.2.6 Workshop Takeaways}

The PTP reviewed a comprehensive discussion of participant feedback and recommendations based on workshop discussions as input to the report development process. A summary of main takeaways is provided below.

\section{Breakout Session 1: Functional Recovery Framework}

Throughout the discussions surrounding Breakout Session 1, participants were consistently supportive of the notion of a national functional recovery framework to provide guidance for individual communities at the local level. However, participants voiced a preference that this guidance be flexible and adaptable such that it can appropriately incorporate local community needs and values. Participants noted that designating recovery time frames for community functions as opposed to specific components of the built environment could facilitate this flexibility (e.g., "access to finances" vs. banks; "ability to conduct office work" vs. office buildings). Participants also noted that although this current effort is specific to seismic hazards, communities would benefit from a functional recovery framework that was defined in a multihazard context for all natural hazards.

\section{Breakout Session 2 and 3: Assessing and Evaluating Options}

Throughout the activities in Breakout Sessions 2 and 3, participants expressed strong support for the use of a consistent set of criteria for the evaluation of options presented in the report. The five criteria most frequently ranked as being most important were: cost, benefit, feasibility, effectiveness, and equity. As these criteria are value-based, participants recognized that there was no single set of criteria that could be identified as the standard. It was suggested that the report describe how evaluation criteria were selected. To facilitate consistent evaluation of the options, participants noted that the criteria should be clearly defined, and the options should be as specific and actionable as possible. 
As they considered how specific criteria applied to a set of example options, participants noted that the relationship between the options was important. Participants articulated that not every option can, or should, be expected to meet a functional recovery objective independently. Some options complemented one another and were considered more effective in tandem than in isolation. Additionally, participants suggested that options could be presented as a portfolio addressing a variety of needs and might be more effective if described as a strategic progression towards achieving a functional recovery objective.

\section{Overarching Takeaways}

In addition to specific takeaways from each breakout session, relevant themes emerged from plenary discussions throughout the day. One general observation was that the relationship between functional recovery and community resilience should be clearly articulated, to better explain how functional recovery complements community resilience, and how it can be used to achieve a consistent end goal, which is community resilience.

Additionally, participants wondered if the report to Congress should identify an aspirational performance standard to guide leading communities on a path towards functional recovery, or if the report should instead focus on establishing a minimum acceptable performance standard for use across the country. Embedded in this discussion was a concern that targeting a higher functional recovery performance standard might distract from ongoing efforts to achieve life safety performance in the existing built environment, which has yet to be completed in many parts of the country.

Another key theme from plenary discussions was the need to incorporate local community values and local jurisdictional needs to successfully identify and maintain critical community functions. This requires flexibility in guidelines and regulations such that communities can adapt the actions to meet individual situations. This is particularly important for local jurisdictions to be able to meet the needs of their most vulnerable residents.

Finally, in reference to the inherent value-based nature of a functional recovery objective, participants suggested the report be explicit about the choices made in prioritizing among options, and discuss relevant limitations in the report development process.

The information captured during these workshops provided insight to the PTP on topics in the report that were inherently value-based and likely varied across communities. Participant feedback and recommendations were compiled into an internal workshop report and presented to the PTP to serve as input to the development of the report to Congress. 



\section{Appendix B}

\section{Supplemental Information on a Framework for Reoccupancy and Functional Recovery}

\section{B.1 Conceptual Illustration of Recovery Categories}

Recovery categories could address both reoccupancy time and functional recovery time within a single category, or there could be separate reoccupancy categories and functional recovery categories. Conceptual functional recovery categories for buildings and lifeline infrastructure systems are illustrated in Table B-1, which is generally consistent with guidance offered in the NIST Community Resilience Planning Guide. The table shows how each functional recovery category might be associated with functions or services, and how buildings or lifeline infrastructure systems might be assigned to each category based on a general policy on acceptable functional recovery times (Mahoney, 2019). The entries in the table presume an intensity of shaking that is generally consistent with the design hazard level used in current building codes and standards.

Table B-1 Conceptual Functional Recovery Categories for a Design Hazard Level

\begin{tabular}{|c|c|c|c|}
\hline $\begin{array}{l}\text { Functional } \\
\text { Recovery } \\
\text { Category }\end{array}$ & $\begin{array}{l}\text { Target } \\
\text { Functional } \\
\text { Recovery } \\
\text { Time }\end{array}$ & $\begin{array}{l}\text { Recovery Phase and } \\
\text { Associated Functions } \\
\text { and Services (1) }\end{array}$ & $\begin{array}{l}\text { Examples of } \\
\text { Buildings and Lifeline Infrastructure Systems }\end{array}$ \\
\hline $\begin{array}{l}\text { Functional } \\
\text { Recovery } \\
\text { Category A } \\
\text { (FRC-A) }\end{array}$ & $\begin{array}{l}\text { Hours } \\
\text { (or Less) }\end{array}$ & $\begin{array}{l}\text { Near-Term (Nearly } \\
\text { Immediate) and } \\
\text { Emergency Response - } \\
\text { rescue, safety, security, } \\
\text { and event stabilization }\end{array}$ & $\begin{array}{l}\text { Emergency and first-responder facilities (e.g., hospitals, } \\
\text { fire and police stations), designated shelters, emergency } \\
\text { operations centers, and lifeline infrastructure systems } \\
\text { supporting emergency response (e.g., power, } \\
\text { communication, critical transportation) }\end{array}$ \\
\hline $\begin{array}{l}\text { Functional } \\
\text { Recovery } \\
\text { Category B } \\
\text { (FRC-B) }\end{array}$ & $\begin{array}{l}\text { Days to } \\
\text { Weeks }\end{array}$ & $\begin{array}{l}\text { Short-Term - shelter, } \\
\text { governance, daily } \\
\text { necessities, and care } \\
\text { for vulnerable } \\
\text { populations }\end{array}$ & $\begin{array}{l}\text { Single- and multi-family residential, local government, } \\
\text { schools, outpatient medical facilities, nursing homes, } \\
\text { critical retail (e.g., food distribution, pharmacy, home } \\
\text { improvement), and lifeline infrastructure systems } \\
\text { supporting short-term activities }\end{array}$ \\
\hline $\begin{array}{l}\text { Functional } \\
\text { Recovery } \\
\text { Category C } \\
\text { (FRC-C) }\end{array}$ & $\begin{array}{l}\text { Weeks to } \\
\text { Months }\end{array}$ & $\begin{array}{l}\text { Intermediate-Term - } \\
\text { restoration of } \\
\text { neighborhood activities } \\
\text { and economic vitality }\end{array}$ & $\begin{array}{l}\text { Critical business enterprises, possibly exceeding a certain } \\
\text { size threshold, and lifeline infrastructure system services } \\
\text { supporting intermediate-term activities }\end{array}$ \\
\hline $\begin{array}{l}\text { Functional } \\
\text { Recovery } \\
\text { Category D } \\
\text { (FRC-D) }\end{array}$ & $\begin{array}{l}\text { Months to } \\
\text { Years }\end{array}$ & $\begin{array}{l}\text { Long-Term - cultural, } \\
\text { quality of life, and } \\
\text { leisure activities }\end{array}$ & $\begin{array}{l}\text { Buildings not assigned to other categories, possibly } \\
\text { including less critical business enterprises, less-critical } \\
\text { retail, entertainment, leisure, and cultural facilities, and } \\
\text { lifeline infrastructure system services supporting long-term } \\
\text { activities }\end{array}$ \\
\hline
\end{tabular}

Note 1: Recovery phases refer to the FEMA National Disaster Recovery Framework, Second Edition (FEMA, 2016) 
It is noted that building codes already imply a target recovery time of hours or less for achieving near-full functionality (if not continuous operation) in facilities that are deemed to provide essential services. These Risk Category IV buildings include emergency response, hospitals, and other buildings with this designation.

Although recovery objectives might be set for a specified earthquake hazard level, actual recovery times following an earthquake may be different because of uncertainty associated with the occurrence and severity of earthquakes. Further, it may be appropriate to establish different target recovery times that vary based on earthquake hazard level. This is particularly true for lifeline infrastructure systems that could be impacted differently by earthquake effects that occur at lower or higher frequencies, which might not be adequately addressed through consideration of a single hazard level. Table B-2 provides an example of possible ranges of target recovery times for different earthquake hazard levels.

Table B-2 Possible Functional Recovery Times for Different Earthquake Hazard Levels

\begin{tabular}{|l|c|c|c|}
\hline \multirow{2}{*}{$\begin{array}{l}\text { Functional } \\
\text { Recovery Category }\end{array}$} & $\begin{array}{c}|c| \\
\text { Earthquake Hazard Level } \\
\text { (Frequency of Occurrence) }\end{array}$ \\
\cline { 2 - 4 } & $\begin{array}{c}\text { Frequent } \\
\text { (return period of 50-100 } \\
\text { years) }\end{array}$ & $\begin{array}{c}\text { Design } \\
\text { (return period of 300-700 } \\
\text { years) }\end{array}$ & $\begin{array}{c}\text { Maximum Considered } \\
\text { (return period of 1,000- } \\
3,000 \text { years) }\end{array}$ \\
\hline $\begin{array}{l}\text { Functional Recovery } \\
\text { Category A } \\
\text { (FRC-A) }\end{array}$ & Hours (or less) & Hours (or less) & Days to Weeks \\
\hline $\begin{array}{l}\text { Functional Recovery } \\
\text { Category B } \\
\text { (FRC-B) }\end{array}$ & Hours to Days & Days to Weeks & Weeks to Months \\
\hline $\begin{array}{l}\text { Functional Recovery } \\
\text { Category C } \\
\text { (FRC-C) }\end{array}$ & Days to Weeks & Weeks to Months & Months to Years \\
\hline $\begin{array}{l}\text { Functional Recovery } \\
\text { Category D } \\
\text { (FRC-D) }\end{array}$ & Weeks to Months & Months to Years & \\
\hline
\end{tabular}

It is possible that economic and other benefit-cost considerations might result in different recovery-based objectives for existing buildings relative to new buildings, as further discussed in Chapter 3.

\section{B.2 Damage Descriptions for Buildings and Lifeline Infrastructure Systems Meeting Different Target Functional Recovery Times}

Studies have shown that repair of buildings suffering limited nonstructural damage can be done in days or weeks, while repair of buildings suffering significant structural or nonstructural damage can take months or even years (Comerio, 2000; 2005). Whether a building will take months or years to recover often depends on whether it has sustained structural damage that would require an engineering evaluation and building permit to begin the repair process. In the case of lifeline infrastructure systems, experience has shown that systems can be designed, maintained, and operated to continuously provide basic services to users, or to recover them in a short period, depending on how robust, redundant, and adaptive the system is. 
Descriptions of the type and extent of structural and nonstructural damage in buildings and lifeline infrastructure systems that have typically been associated with certain functional recovery times are as follows (Mahoney, 2019):

- Hours: A building would suffer no, or very minimal, structural damage with very minor nonstructural damage, and such damage would not affect occupancy. If repairs are needed, an engineering evaluation and building permit would not be necessary, and in-house labor could perform the work immediately or at some later date. Nonstructural damage would not impact basic functions. The facility would likely receive a green tag (ATC-20-1 INSPECTED placard) in a post-earthquake safety evaluation, indicating that occupancy is permitted without restriction. Lifeline infrastructure systems would not be impacted, or onsite backup services would be operational.

- Days: A building would suffer minimal to minor structural damage, and such damage would not affect occupancy. If repairs are needed, an engineering evaluation or building permit would not be necessary, and in-house labor could perform the work immediately or at some later date. Nonstructural damage would be minor to moderate, with some impact to basic function, but such damage could be repaired within days. The facility would likely receive a green tag (ATC-20-1 INSPECTED placard), or yellow tag (ATC-20-1 RESTRICTED USE placard) in areas not affecting basic function. Lifeline infrastructure systems would not be impacted, or repairs could be made resume basic services within days.

- Weeks: A building would suffer minor structural damage, and such damage could temporarily impact occupancy until a limited engineering evaluation was performed and possibly a building permit was obtained for repairs. Nonstructural damage would be moderate, with impact to basic function, but such damage could be repaired within weeks. The facility would likely receive a yellow tag (ATC-20-1 RESTRICTED USE placard) in a post-earthquake safety evaluation, identifying damage or hazards that would require some level of repair, restricting occupancy and functionality until repairs are made. Lifeline infrastructure systems could be impacted, and repairs would be needed to resume basic services within weeks.

- Months: A building would suffer moderate to significant structural damage affecting occupancy and functionality, and an engineering evaluation would be required.

Nonstructural damage could be significant and could also affect occupancy and functionality. The level of repairs could be significant, and would require a building permit and months to complete. The facility could receive a yellow tag (ATC-20-1 RESTRICTED USE placard) in a post-earthquake safety evaluation, restricting occupancy and functionality until repairs are made. The facility might also receive a red-tag (ATC-20-1 UNSAFE placard) indicating it is unsafe to occupy until significant repairs are made, with the possibility that such repairs could be economically infeasible. Lifeline infrastructure systems would be adversely impacted for an extended period of time. 



\section{Supplemental Information on Lifeline Infrastructure Systems}

\section{C.1 Summary of Topics Identified in the NEHRP Lifelines Roadmap}

Responding to the need for earthquake-resilient lifeline infrastructure systems, NIST published GCR 14-917-33, Earthquake Resistant Lifelines: NEHRP Research, Development and Implementation Roadmap (NIST, 2014). The roadmap focuses on six key lifeline infrastructure systems: electric power, gas and liquid fuel, water, wastewater, telecommunications, and transportation networks. It also addresses lifeline infrastructure system interdependencies and socioeconomic, institutional research, and implementation priorities that are needed to support resilient lifeline infrastructure system practices and improved performance during extreme events. High priority needs for industry practice as well as recommendations for guidelines and consensus standards are included in the roadmap.

The roadmap is intended to guide the investments made by NIST and other NEHRP agencies in generating national performance and restoration goals in concert with the development of guidelines, manuals, and standards for key lifeline infrastructure systems and components. These efforts are accompanied by a coherent and well-coordinated plan to promote voluntary adoption by communities and lifeline infrastructure system service providers. Key socioeconomic factors, institutional issues, and lifeline infrastructure system interdependencies, as well as research, development, and implementation needs are addressed for both individual and collective lifeline infrastructure systems. While the roadmap focuses primarily on lifeline infrastructure system earthquake resilience issues, it also considers the multi-hazard aspects of lifeline infrastructure system performance as well as the integration of NEHRP-supported technology into an all-hazards framework for lifeline infrastructure systems. Many of the priority topics identified in the roadmap have a direct bearing on an overall strategy and plan to recovery-based objectives for lifeline infrastructure systems.

The roadmap consists of four key program elements that define the range of proposed priority topics for research, development, and implementation to be pursued. A total of 28 recommended research, development and implementation priority topics are embedded within these four program elements. The following list summarizes the program elements and topics recommended in the roadmap (NIST, 2014):

- Program Element I. Establish national lifeline system performance and restoration goals.

- Topic No. 1: Develop an overarching framework for national lifeline performance and restoration goals

- Topic No. 2: Assess current societal expectations of acceptable lifeline performance levels and restoration times informed by the phases of response and recovery 
- Topic No. 3: Establish procedures to quantify hazards over spatially distributed lifeline systems

- Topic No. 4: Develop modeling tools to support design approaches, planning, and restoration for interdependent lifeline systems

- Topic No. 5: Develop tools to quantify and rank the societal benefits and costs of different lifeline system performance levels and restoration times, as well as prioritize lifeline upgrades and investments

- Program Element II. Develop lifeline system specific performance manuals, guidelines, standards, and codes.

- Topic No. 6: Develop guidelines for the analysis, design, and planning of electric power infrastructure in seismically vulnerable regions

- Topic No. 7: Develop guidelines for improving telecommunication system resilience under earthquake conditions

- Topic No. 8: Develop water system seismic guidelines and standards

- Topic No. 9: Develop wastewater system seismic guidelines and standards

- Topic No. 10: Develop a manual of best seismic practices for gas and liquid fuel transmission pipelines

- Topic No. 11: Develop a manual for improving the seismic performance of natural gas distribution systems

- Topic No. 12: Develop guidelines for mitigating damage to lifelines from tsunamis and other flood-related hazards

- Topic No. 13: Develop guidelines for post-earthquake lifeline assessment, response, and recovery

- Topic No. 14: Develop geohazard guidelines for owners and contractors for engineering, procurement, and construction of pipelines

- Topic No. 15: Develop seismic qualification standards for lifeline components and systems

- Program Element III. Conduct problem focused research for various lifeline systems.

- Topic No. 16: Evaluate the feasibility of new interdependent lifeline system configurations

- Topic No. 17: Develop methods for analysis and mitigation of damage from fire following earthquake and hazardous material releases

- Topic No. 18: Improve and extend methods for mitigating the effects of earthquakeinduced ground displacement on underground pipelines, conduits, and cables

- Topic No. 19: Evaluate distributed power generation and energy storage to reduce earthquake/natural hazard effects on electric power systems

- Topic No. 20: Develop a multi-hazard, multi-modal dynamic transportation network risk assessment model 
- Topic No. 21: Develop water and wastewater system evaluation methods for earthquake impacts

○ Topic No. 22: Develop tensile and compressive strain limits for welded steel pipelines in permanent ground displacement zones

- Program Element IV. Enable the adoption and implementation of lifeline system performance goals and standards.

$\circ$ Topic No. 23: Develop tools, guidance, incentives, and funding mechanisms for voluntary adoption and implementation of lifeline seismic resilience programs and earthquake-resilient design and construction standards

○ Topic No. 24: Develop strategies and techniques for the public and key customers to engage lifeline system providers to define acceptable performance levels and restoration timeframes

- Topic No. 25: Assess the direct and indirect socioeconomic consequences and financial implications of different lifeline performance levels and restoration timeframes

- Topic No. 26: Implement post-earthquake information and response services for lifeline systems

- Topic No. 27: Develop and deploy intelligent lifeline monitoring, advanced sensors, and emergency response and restoration decision support systems

○ Topic No. 28: Develop and deploy better tools, training, and guidance for emergency operation planning, response, and restoration of lifeline systems

\section{C.2 Possible Tasks for a New National Lifelines Organization}

As recommended under Task 4.3, given the complex, interconnected, and interdependent nature of lifeline infrastructure systems, a national lifelines organization should be re-established to plan, lead, coordinate, and manage efforts to create, adopt and implement standards to advance lifeline engineering and improve system performance (NIST, 2014). Such an organization would be similar to the American Lifelines Alliance, originally funded by FEMA, but with a different management structure as described in NIST (2014), and with potentially different tasks, as outlined below:

- Provide stewardship of a national resilience program advancing the state of practice for lifeline infrastructure systems to meet recovery-based objectives.

- Assist in implementing the Earthquake Resilient Lifelines: NEHRP Research, Development and Implementation Roadmap (NIST, 2014).

- Aid in continued advancement and update of a reoccupancy and functional recovery framework (Recommendation 1).

- Coordinate stakeholders (e.g., industry, academia, practitioners, regulators) in the development of lifeline infrastructure system guidelines.

- Initiate and, when practicable, usher guidelines through a consensus-based standards development process for lifeline infrastructure systems and their interdependencies. 
- Advance needed improvements to lifeline infrastructure system resilience through planning, mitigation, response, recovery, and rebuilding (i.e., building back better).

- Develop tools to aid lifeline infrastructure systems in implementing performance-based recovery actions (initial planning through restoring post-event full functionality).

- Engage with communities and document their evolving needs in relation to existing and future planned performance goals, embracing multi-hazard approaches where appropriate to improve lifeline infrastructure system recovery-based performance.

- Educate lifeline infrastructure system owners and operators and the public at large on the importance of designing lifeline infrastructure systems for recovery-based objectives.

- Advance the state-of-practice through training and technology transfer.

- Assist in the creation and management of a national-level lifelines council program and related guidelines (related to Task 4.4).

- Target results and products that can assist in shaping and implementing national policy, legislation, and regulatory developments aiming to meet lifeline infrastructure system performance objectives.

- Engage in post-event investigations documenting good and poor performances of lifeline infrastructure systems and their components, including long-term longitudinal studies with social and economic impacts.

- Develop, promote and encourage effective working relationships among lifeline infrastructure system authorities, their state officials, and other stakeholders responsible for various aspects of infrastructure system operations.

- Develop strategies to embed functional recovery goals in the approach to recovery planning that accounts for identified risks, recognizes long-term priorities and opportunities to build back better, with the needs of the affected population.

- Facilitate peer exchange in collaboration with the leadership of lifeline infrastructure system authorities that will include: creation of consistent terminology, identification of hazard/recovery goals and knowledge gaps, development of standards and toolkits to be used by state/regional authorities in their efforts to adopt the reoccupancy and functional recovery framework (Recommendation 1).

- Promote the creation of a national database of seismic performance observations of lifeline infrastructure systems (damage and successful behaviors) through earthquake reconnaissance, which will include asset management data from regular life-cycle inspections.

- Advance the use of remote and other technologies that can enhance asset utilization and maintenance, while improving the opportunity for continued operation or quick return to service. 


\section{Appendix D}

\section{Supplemental Information on Pre-Disaster Planning and Implementation}

\section{D.1 Examples of Seismic Continuity Programs}

QuakeSmart ${ }^{32}$ is an existing nationwide seismic continuity program designed specifically for businesses. The QuakeSmart program encourages businesses that are at risk from earthquakes to take actions that will mitigate damage to their businesses, provide greater safety for customers and employees, and speed recovery in the event of an earthquake. QuakeSmart (FEMA P-811) was introduced by FEMA through the NEHRP program in 2008. In 2013, FEMA, in partnership with the Federal Alliance for Safe Homes, Inc. (FLASH), launched a nationwide campaign to put the QuakeSmart Toolkit ${ }^{33}$ into the hands of as many small businesses as possible. The program provides a step-by-step process to identify the risk, develop preparedness and mitigation plans, take action, and be recognized and inspire others. To continue and expand upon the success of the program, a robust marketing strategy could be pursued.

Similar nationwide programs to QuakeSmart, or an extension of QuakeSmart, could be developed for other occupancies, including residential occupancies, institutional occupancies, high hazard occupancies, and factories.

A good example of a seismic continuity program for residences that could be adapted and adopted by other communities is the City and County of San Francisco's Seismic Safety Outreach Program (SSOP). This program educates and awards residential building owners and tenants that complete the program with the title of "Seismic Safety Ambassador." The San Francisco Department of Building Inspection (SFDBI) started this program in 2015 and partners with the Self Help for the Elderly and the Community Youth Center to provide San Francisco's diverse populations with hands-on training and education on how they can prepare before, during, and after an earthquake.

The City and County of San Francisco's SSOP could serve as a model for development of a nationwide seismic continuity program for residential occupancies. Such a nationwide program should include educating building owners and tenants on: risk; the limits of building code philosophy, emphasizing that the code is a minimum and they can always do more; and the benefits of nonstructural component anchorage so that they are motivated to develop appropriate plans and take action.

32 https://www.fema.gov/media-library/assets/documents/23902

33 https://flash.org/readybusiness/quake smart.php 


\section{D.2 Examples of Assessment and Evaluation Guidelines}

The ATC-20 Procedures for Postearthquake Safety Evaluation of Buildings (ATC, 1989; 1995) and the accompanying ATC-20-1 Field Manual: Postearthquake Safety Evaluation of Buildings, Second Edition (ATC, 2005) are the primary resources used by trained volunteers and government officials in conducting rapid evaluation of the extent and significance of reductions in lateral force-resisting and gravity load-carrying capacity of buildings. It is premised on safety rather than reoccupancy or functional recovery, and the procedures and guidance in the document are not well suited for evaluation of tall buildings and other large specialized structures.

FEMA P-50 Simplified Seismic Assessment of Detached, Single-Family, Wood Frame Dwellings (FEMA, 2012a) and FEMA P-50-1 Seismic Retrofit Guidelines for Detached, Single-Family, Wood-Frame Dwellings (FEMA, 2012b) were developed in response to earthquakes where typical wood-frame residential structures were observed to have suffered more damage than had traditionally been thought possible. The potential negative impact for communities is magnified by the sheer numbers of these buildings that exist in moderate and high seismic regions in the United States. FEMA supported the development of a residential rating system (FEMA P-50) and its accompanying retrofit guidelines (FEMA P-50-1) to be applicable in all high seismic areas. FEMA supported this work to provide a tool that communities or other entities could then use to encourage the seismic retrofitting of residential structures, thereby reducing future earthquake losses.

FEMA 352 Recommended Post-earthquake Evaluation and Repair Criteria for Welded Steel Moment Frame Buildings (FEMA, 2000) was developed as part of the FEMA-funded SAC Joint Venture $^{34}$ following the Northridge Earthquake to address the unique vulnerabilities of this construction to fractures in welded connections. The procedures include quantitative criteria to relate observed damage to guidance regarding continued occupancy. Although a good example to illustrate this type of procedure, the methods in this document were developed without the benefit of modern seismic risk assessment procedures, and since their development, the method has not been applied in any significant post-earthquake evaluations or trial studies. As such, it is ripe for updating based on state-of-the-art risk assessment procedures and expansion to other types of buildings beyond steel welded moment frames.

FEMA 306 Evaluation of Earthquake Damaged Concrete and Masonry Wall Buildings (FEMA, 1998) was developed to address the evaluation of concrete and masonry buildings using emerging performance-based engineering methods. As noted in the introduction to the document, "The procedures in this manual are intended to characterize the observed damage caused by the earthquake in terms of the loss in building performance capability. This information may be used to facilitate the settlement of insurance claims, the development of strategies for repair, or other purposes." Although the evaluation method has implications for building safety, the primary focus of the document is on developing repair strategies. As the document determines whether a building is safe for occupancy during repairs, it does not fully address the question of reoccupancy or functional recovery.

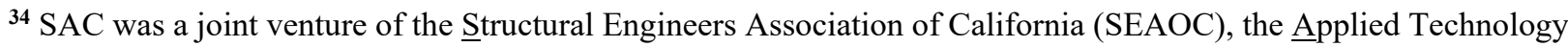

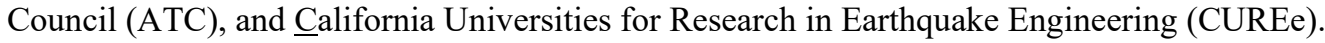


FEMA P-1100 Vulnerability-Based Seismic Assessment and Retrofit of One- and Two- Family Dwellings (FEMA, 2019b) is the result of a project jointly funded by the California Earthquake Authority (CEA) and FEMA to develop a prestandard for the evaluation and retrofit of one- and two-family wood light-frame residential buildings. This class of structure represents the most common type of dwelling in the United States. Although this type of construction has generally provided good performance in past earthquakes, there are well-known vulnerabilities that have led to large numbers of homes being rendered uninhabitable or even unrepairable following an earthquake. Improved seismic design and seismic retrofitting of vulnerable configurations is expected to increase the probability that homes are available to provide shelter immediately following moderate to large seismic events. P-1100 provides a methodology to identify and retrofit specific known vulnerabilities in wood light-frame dwellings. Studies included use of the best available numerical modeling tools and engineering practices to assist in development of assessment methods and to identify retrofit criteria to best achieve targeted performance objectives. Retrofit using the provisions is anticipated to improve earthquake performance but is not intended to prevent earthquake damage.

\section{D.3 Seismic Instrumentation and Other Smart Technologies}

Beyond adapting post-earthquake assessments to incorporate reoccupancy and functional recovery concepts, and finding and training people to use those guidelines, it may be possible to use technology to facilitate the assessment and evaluation process. To that end, pre-disaster recovery plans might promote the installation, maintenance, and use of seismic instrumentation and other smart technologies to help facilitate the assessment process for buildings and lifeline infrastructure systems. Significant advancements in seismic instrumentation, statistical data processing, and communication technologies are expected to make seismic instrumentation a more cost-effective and viable technology to rapidly evaluate structural response to earthquakes. Since the 2011 Tohoku earthquake, monitoring for rapid evaluation following earthquakes has become more popular in Japan, and there are some examples of its use in the United States. The q-NAVIGATOR ${ }^{35}$ system by Kobori Research Complex is an example of a system that has been deployed in about 400 buildings in Japan (personal communication with M. Nakashima). Similar systems have been employed on a more limited scale by other building developers in Japan. Recently, the U.S. Department of Veterans Affairs (VA) has contracted with the USGS to install strong motion monitoring systems in several major VA hospitals to facilitate reoccupancy after earthquakes ${ }^{36}$ The installation of seismic instrumentation is covered in Appendix $\mathrm{L}$ of the International Building Code (ICC, 2018a).

Building and lifeline infrastructure systems owners should be encouraged to investigate the use of instrumentation and advanced technologies to create smart infrastructure and to have a better understanding of their ability to function after an earthquake. This information, linked with structural information provided by an engineer, could be used to predict how badly a building or lifeline infrastructure system may be damaged in an earthquake. It is possible that such damage predictions could then be linked to whether the structure should receive an ATC-20-1 UNSAFE (red), RESTRICTED USE (yellow), or INSPECTED (green) placard (Mitrani-Reiser et al., 2016). Tools utilizing artificial intelligence to make these links are currently under development

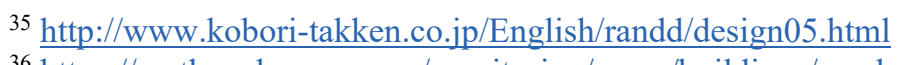

36 https://earthquake.usgs.gov/monitoring/nsmp/buildings/va.php 
by private-sector organizations. In the future, these tools could provide nearly instantaneous information to an owner or manager after an earthquake as to whether the structure is safe enough to re-occupy or meets a given functional recovery standard. Smart buildings and lifeline infrastructure systems might even placard themselves, thereby reducing the need for people to conduct safety evaluations and the need for temporary staff surges following an earthquake. These technologies, while potentially promising, are not yet available or tested under real conditions. Preliminary cost estimates remain high and accuracy is not yet assured (Sattar et al., 2018).

\section{D.4 Examples of Building Occupancy Resumption Programs and Other Similar Programs}

In a building occupancy resumption programs (BORP) model, the building owner contracts with individual engineers to conduct a pre-event evaluation and to provide a post-earthquake evaluation of a building. After going through a formal approval process, engineers are authorized to post the building with ATC-20-1 placards under the authority of the local jurisdiction. In an earthquake response, engineers essentially act as deputies of the local jurisdiction. Participation in the program requires annual maintenance. The full process is documented on the San Francisco Department of Building Inspection's website. ${ }^{37}$ This model has been adopted by many jurisdictions outside of San Francisco. For example, several cities in Southern California have adopted programs called Back to Business (B2B), modeled after BORP.

In contrast to the BORP model, the Advisory Tag System (Figure D-1) is less formal. In this model, agreements between the building owner and the engineer or engineering firm are only between the two entities, and not reviewed by the local jurisdiction. Although formal

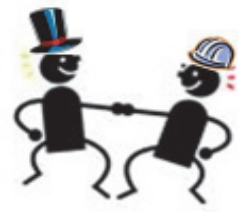

1. Contract (Owner/Professional) /agreement (Owner/Jurisdiction)

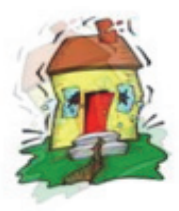

2. Event

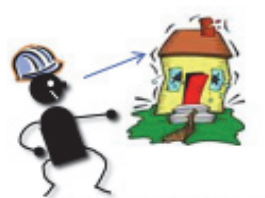

3. Professional ATC-20 eval

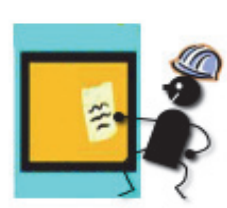

4. Professional Posts Advisory Placard

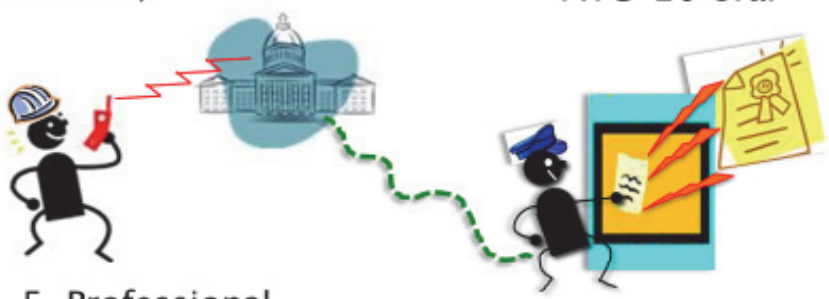

5. Professional Notifies Jurisdiction
6. Jurisdiction Posts Official Placard

Figure D-1 Advisory Tag System process (courtesy of DCI Engineers).

agreements can be developed between the building owner and the jurisdiction prior to an event, documentation is not required. A pre-event building assessment is recommended. In an

${ }^{37}$ https://sfdbi.org/borp 
earthquake response, the engineer performs an ATC-20 evaluation, but posts an "advisory tag" instead of the jurisdiction's placard. The advisory tag does not carry the legal authority of the jurisdiction, so at some point in time, the jurisdiction must follow up with its official placard. However, the advisory tag serves two purposes: (1) it gives building safety information to the building owner and building occupants in the time between the event and the time the jurisdiction can evaluate the building; and (2) it can serve as a screening and prioritization tool for the responding jurisdiction.

The Advisory Tag System process is documented in a white paper published by the Washington Association of Building Officials ${ }^{38}$ and the Structural Engineers Association of Washington ${ }^{39}$. The expectation is that local jurisdictions will rely on the engineer's conclusions in most cases and post the building accordingly. The process also includes a recommendation that in the event the jurisdiction disagrees with the engineer who posted the advisory tag, the jurisdiction should contact the engineer to discuss the different conclusions. This system has been adopted by the City of Seattle Department of Construction and Inspections, and is being promoted in the state of Washington through building safety evaluator training and presentations to emergency managers.

Local governments need to consider the cost of administering such programs and building owners need to consider the direct cost of participating in these programs. For example, an engineering firm is likely to charge a fee to be placed on a retainer, and to do any preliminary structural evaluations. The benefit should be faster determination of whether a building can be reoccupied. BORP and other similar program arrangements must be made before an earthquake, since engineering firms are unlikely to be available for immediate hire following an earthquake, and time is needed to conduct per-event building assessments. Engineering firms must be careful to guard against over-commitment in the event of a large, nearby earthquake; they may discover that they have more exposure than anticipated as a result of their agreements for conducting post-earthquake evaluations.

${ }^{38} \mathrm{https}: / / \mathrm{www} . w a b o . o r g / a s s e t s / S E A W P a p e r s / w a b o-s e a w \% 20 \mathrm{wp}-5 \% 20$ final $\% 20$.pdf

39 https://www.seaw.org/s/WABO-SEAW-WP-5.pdf 



\section{References}

AASHTO, 2011, LRFD Seismic Bridge Design, 2nd Edition, with 2012, 2014 and 2015 Interim Revisions, American Association of State and Highway Transportation Officials, Washington, D.C.

AASHTO, 2019, "Building Extreme Weather Resilience Into Transportation Asset Management Programs," AASHTO Journal, American Association of State Highway and Transportation Officials, https://aashtojournal.org/2019/01/18/building-extreme-weatherresilience-into-transportation-asset-management-programs/, accessed November 9, 2020.

ABAG, 2014, Cascading Failures: Earthquake Threats to Transportation and Utilities, Publication Number P14001EQK, Association of Bay Area Governments, http://resilience.abag.ca.gov/projects/transportation_utilities_2014/, accessed March 20, 2020.

Ager, P., Eriksson, K., Hansen, C.W., and Lønstrup, L., 2019, How the 1906 San Francisco Earthquake Shaped Economic Activity in the American West, NBER Working Paper No. 25727, National Bureau of Economic Research, Cambridge, Massachusetts.

Arendt, L.A., and Alesch, D., 2014, Long-term Community Recovery from Natural Disasters, CRC Press, Boca Raton, Florida.

Arup, 2013, REDi ${ }^{\mathrm{TM}}$ Rating System, Resilience-based Earthquake Design Initiative for the Next Generation of Buildings, Arup, San Francisco, California.

ASCE, 1995, "Policy on Acceptable Levels of Earthquake Risk for California Gas and Electric Utilities," Lifeline earthquake engineering: Proceedings of the Fourth U.S. Conference, San Francisco, California, American Society of Civil Engineers, Technical Council on Lifeline Earthquake Engineering.

ASCE, 2014, Seismic Design of Piers and Wharves, ASCE/COPRI Standard 61-14, American Society of Civil Engineers, Reston, Virginia.

ASCE, 2016, Minimum Design Loads and Associated Criteria for Buildings and Other Structures, ASCE/SEI Standard 7-16, American Society of Civil Engineers, Reston, Virginia.

ASCE, 2017a, “America's Infrastructure Grade," 2017 Infrastructure Report Card, American Society of Civil Engineers, https://www.infrastructurereportcard.org/americas-grades/, last accessed on March 26, 2020. 
ASCE, 2017b, Seismic Evaluation and Retrofit of Existing Buildings, ASCE/SEI Standard 41-17, American Society of Civil Engineers, Reston, Virginia.

ATC, 1989, 1995, ATC-20 Set: ATC-20, Procedures for Postearthquake Safety Evaluation of Buildings, and ATC-20-2, Addendum to the ATC-20 Postearthquake Building Safety Evaluation Procedures, Applied Technology Council, Redwood City, California.

ATC, 2005, ATC-20-1, Field Manual: Postearthquake Safety Evaluation of Buildings Second Edition, Applied Technology Council, Redwood City, California.

ATC, 2010, Here Today-Here Tomorrow: The Road to Earthquake Resilience in San Francisco, A Community Action Plan for Seismic Safety, prepared for the Department of Building Inspection, City and County of San Francisco, by the Applied Technology Council, Redwood City, California.

Awando, S., Hollans, H., Powell, L., and Wade, C., 2016, Estimating the Effect of FORTIFIED Home $^{T M}$ Construction on Home Resale Value, University of Alabama, https://www.smarthomeamerica.org/assets/uploads/UniversityofAL_ValueStudy_FORTIFIEDReport_V2 2.pdf, accessed March 25, 2020.

AWWA, 2011, Welded Carbon Steel Tanks for Water Storage, ANSI/AWWA D100-11, American Water Works Association, Denver, Colorado.

BPA, 2013, "BPA's ground-shaking research could better protect power transformers in quake," Bonneville Power Administration (BPA), https://www.bpa.gov/news/newsroom/Pages /BPAs-ground-shaking-research-could-better-protect-power-transformers-in-quake.aspx, accessed March 22, 2020.

Bonowitz, D., 2011, Resilience Criteria for Seismic Evaluation of Existing Buildings, A 2008 Special Projects Initiative Report, Structural Engineers Association of Northern California, San Francisco, California.

Bonowitz, D., 2020, "Functional Recovery - What it means to design for community resilience," EERI Distinguished Lecture, 2020 National Earthquake Conference, San Diego, California.

Bruneau, M., Chang, S.E., Eguchi, R.T., Lee, G.C., O’Rourke, T.D., Reinhorn, A.M., Shinozuka, M., Tierney, K., Wallace, W.A., and von Winterfeldt, D., 2003, "A Framework to Quantitatively Assess and Enhance the Seismic Resilience of Communities," Earthquake Spectra, Vol. 19, No. 4, pp. 733-752.

Caltrans, 2019, Caltrans Seismic Design Criteria, Version 2.0 (SDC 2.0), California Department of Transportation, Sacramento, California.

City and County of San Francisco, 2014, Lifelines Interdependency Study I Report, The Lifelines Council, City and County of San Francisco, https://sfgov.org/orr/sites/default /files/documents/Lifelines\%20Council\%20Interdependency\%20Study.pdf, accessed December 4, 2020. 
Comerio, M.C., 2000, The Economic Benefits of a Disaster Resistant University: Earthquake Loss Estimation for U.C. Berkeley, IURD Working Paper 2000-02, Institute of Urban and Regional Development, University of California, Berkeley, California.

Comerio, M.C., 2005, "Downtime Modeling for Risk Management," Safety and Reliability of Engineering Systems and Structures, G. Augusti, G.I. Schueller, M. Ciampoli (eds.) ICOSSAR 2005, Rome, Italy.

CPUC, 2019, SED Incident Investigation Report for 2018 Camp Fire with Attachments, California Public Utilities Commission, Safety and Enforcement Division, Electric Safety and Reliability Branch, Incident Number E20181108-1, Sacramento, California.

Davis, C.A., 2018, "Creating a Seismic Resilient Pipe Network for Los Angeles," Proceedings, Pipelines 2018 Conference, Toronto, Canada, American Society of Civil Engineers, Utility Engineering and Surveying Institute.

Davis, C.A., 2019, "Infrastructure System Resilience: Functionality and Operability," Proceedings, ${ }^{\text {nd }}$ International Conference on Natural Hazards \& Infrastructure (ICONHIC 2019), Chania, Greece.

Davis, C.A., and Shamma, J., 2019, "Improving Resilience of Southern California Water Supply Aqueduct Systems to Regional Earthquake Threats," T.D. O'Rourke special editor, C. Fletcher ed., The Bridge, Vol. 49, No. 2, pp. 60-67.

EBMUD, 2020, "Protecting Life Safety and Public Health," Earthquake Readiness, East Bay Municipal Utility District (EBMUD), https://www.ebmud.com/index.php/download_file /force/1108/220/?Earthquake_Readiness_0.pdf, accessed March 22, 2020.

Edwards, C., 2009, Resilient Nation, DEMOS, London, United Kingdom.

Elliott, M.W., 2019, “Rethinking the Limits of Parametric Insurance," Insurance Journal, https://www.insurancejournal.com/news/international/2019/09/24/540903.htm, accessed December 24, 2019.

EERI, 2011, The M 6.3 Christchurch, New Zealand Earthquake of February 22, 2011, Earthquake Engineering Research Institute, Oakland, California, https://www.eeri.org /site/images/eeri_newsletter/2011_pdf/EERI_NewZealand_EQRpt_web.pdf, accessed June 1, 2020.

EERI, 2019, Functional Recovery: A Conceptual Framework with Policy Options, Earthquake Engineering Research Institute, Oakland, California.

FEMA, 1991a, Collocation Impacts on the Vulnerability of Lifelines During Earthquakes with Applications to the Cajon Pass, California, FEMA 221, Earthquake Hazard Reduction Series 59, Federal Emergency Management Agency, Washington, D.C. 
FEMA, 1991b, Seismic Vulnerability and Impact of Disruption of Lifelines in the Conterminous United States, FEMA 224, prepared by the Applied Technology Council for the Federal Emergency Management Agency, Washington, D.C.

FEMA, 1998, Evaluation of Earthquake Damaged Concrete and Masonry Wall Buildings, FEMA 306, prepared by the Applied Technology Council for the Federal Emergency Management Agency, Washington, D.C.

FEMA, 2000, Recommended Post-earthquake Evaluation and Repair Criteria for Welded Steel Moment Frame Buildings, FEMA-352, Federal Emergency Management Agency, Washington, D.C.

FEMA, 2011, National Disaster Recovery Framework: Strengthening Disaster Recovery for the Nation, Federal Emergency Management Agency, Washington, D.C., https://www.fema.gov/pdf/recoveryframework/ndrf.pdf, accessed February 29, 2020.

FEMA, 2012a, Simplified Seismic Assessment of Detached, Single-Family, Wood Frame Dwellings, FEMA P-50, prepared by the Applied Technology Council for the Federal Emergency Management Agency, Washington, D.C.

FEMA, 2012b, Seismic Retrofit Guidelines for Detached, Single-Family, Wood-Frame Dwellings, FEMA P-50-1, prepared by the Applied Technology Council for the Federal Emergency Management Agency, Washington, D.C.

FEMA, 2013, Local Mitigation Planning Handbook, Federal Emergency Management Agency, Washington, D.C., https:/www.fema.gov/media-library-data/20130726-1910-250459160/fema local_mitigation_handbook.pdf, accessed December 24, 2019.

FEMA, 2015a, National Preparedness Goal, Federal Emergency Management Agency, Washington, D.C., https://www.fema.gov/nationalpreparedness-goal, accessed December 19, 2019.

FEMA, 2015b, FEMA P-1050-1 NEHRP Recommended Seismic Provisions for New Buildings and Other Structures Volume I: Part 1 Provisions, Part 2 Commentary, 2015 edition, prepared by the Building Seismic Safety Council for the Federal Emergency Management Agency, Washington, D.C., https://www.fema.gov/media-library-data /1440422982611-3b5aa529affd883a41fbdc89c5ddb7d3/fema_p-1050-1.pdf, accessed March 29, 2020.

FEMA, 2016, National Disaster Recovery Framework, Second Edition, Federal Emergency Management Agency, Washington, D.C., https://www.fema.gov/media-librarydata/1466014998123-4bec8550930f774269e0c5968b120ba2/National Disaster Recovery_Framework2nd.pdf, accessed February 29, 2020.

FEMA, 2018a, Seismic Performance Assessment of Buildings, Methodology and Implementation, FEMA P-58 Series, prepared by the Applied Technology Council for the Federal Emergency Management Agency, Washington, D.C. 
FEMA, 2018b, Seismic Performance Assessment of Buildings, Volume 5 - Expected Seismic Performance of Code-Conforming Buildings, FEMA P-58-5, prepared by the Applied Technology Council for the Federal Emergency Management Agency, Washington, D.C., https://www.fema.gov/media-library-data/1557508346821-d67f745e88e04e54a1f40f8 e94835042/FEMA P-58-5 Volume5 ExpectedPerformance.pdf, accessed March 28, 2020.

FEMA, 2018c, Building the Performance You Need, A Guide to State-of-the-Art Tools for Seismic Design and Assessment, FEMA P-58-7, prepared by the Applied Technology Council for the Federal Emergency Management Agency, Washington, D.C.

FEMA, 2019a, Post-disaster Building Safety Evaluation Guidance, Report on the Current State of Practice, including Recommendations Related to Structural and Nonstructural Safety and Habitability, FEMA P-2055, prepared by the Applied Technology Council for the Federal Emergency Management Agency, Washington, D.C., https://www.fema.gov /media-library-data/1582075507794-f81a6bc7e3214ae9b2988687fce3d2cb/FEMA_P2055 Post-disasterBuildingSafetyEvaluation_508.pdf, accessed March 25, 2020.

FEMA, 2019b, Vulnerability-Based Seismic Assessment and Retrofit of One- and Two-Family Dwellings, FEMA P-1100, prepared by the Applied Technology Council for the Federal Emergency Management Agency, Washington, D.C., https://www.fema.gov/medialibrary-data/1573748320613-32715813376ea5ed8655ae827bc6e2ca/FEMAP-1100 508.pdf, accessed March 25, 2020.

Fung, J., and Helgeson, J., 2017, Defining the Resilience Dividend: Accounting for Co-benefits of Resilience Planning, NIST Technical Note 1959, National Institute of Standards and Technology, Gaithersburg, Maryland, https://doi.org/10.6028/NIST.TN.1959.

FHWA, 2006, Seismic Retrofitting Manual for Highway Structures: Part I-Bridges, Publication No. FHWA-HRT-06-032, Federal Highway Administration, U.S. Department of Transportation, https://www.fhwa.dot.gov/publications/research/infrastructure/bridge 106032/06032.pdf, accessed November 10, 2020.

FHWA, 2017, "Replacing Oakland's Cypress Freeway,” Federal Highway Administration, U.S. Department of Transportation, https://www.fhwa.dot.gov/publications/publicroads 198marapr/cypress.cfm, accessed April 30, 2020.

Hayward, M., 2018, "Nearly seven years on, thousands of Christchurch earthquake insurance claims remain," Stuff, New Zealand, https://www.stuff.co.nz/national/101036282/nearlyseven-years-on-thousands-of-christchurch-earthquake-insurance-claims-remain, accessed December 24, 2019.

Helgeson, J., 2020, EDGe\$ (Economic Decision Guide Software) Online Tool, Version 1.0. National Institute of Standards and Technology, https:/www.nist.gov/servicesresources/software/edge-economic-decision-guide-software-online-tool, accessed December 4, 2020. 
Hendrickson, C., 2008, Project Management for Construction: Fundamental Concepts for Owners, Engineers, Architects and Builders, Version 2.2, https://www.cmu.edu /cee/projects/PMbook/index.html, accessed April 29, 2020.

Hudnut, K.W., Wein, A.M., Cox, D.A., Porter, K.A., Johnson, L.A., Perry, S.C., Bruce, J.L., LaPointe, D., 2018, The HayWired Earthquake Scenario - We Can Outsmart Disaster, https://doi.org/10.3133/fs20183016.

ICC, 2012, International Building Code, International Code Council, Inc., Country Club Hills, Illinois (view the publication cited at: https://codes.iccsafe.org/content/IBC2012).

ICC, 2015a, International Building Code, (7th ed. 2015), International Code Council, Inc., Country Club Hills, Illinois (view the publication cited at: https://codes.iccsafe.org /content/IBC2015).

ICC, 2015b, International Existing Building Code, (5th ed. 2015), International Code Council, Inc., Country Club Hills, Illinois (view the publication cited at: https://codes.iccsafe.org /content/IEBC2015).

ICC, 2015c, International Residential Code, (6th ed. 2015), International Code Council, Inc., Country Club Hills, Illinois (view the publication cited at: https://codes.iccsafe.org /content/IRC2015).

ICC, 2018a, International Building Code, (8th ed. 2018), International Code Council, Inc., Country Club Hills, Illinois, (view the publication cited at: https://codes.iccsafe.org /content/IBC2018P4).

ICC, 2018b, International Existing Building Code, (6th ed. 2018), International Code Council, Inc., Country Club Hills, Illinois, (view the publication cited at: https://codes.iccsafe.org /content/IEBC2018P3).

ICC, 2018c, International Residential Code, (7th ed. 2018), International Code Council, Inc., Country Club Hills, Illinois (view the publication cited at: https://codes.iccsafe.org /content/IRC2018P3).

IEEE, 2018, Recommended Practice for Seismic Design of Substations, IEEE Standard 693, Institute of Electrical and Electronics Engineers, Piscataway, New Jersey.

Jones, L.M., and Aho, M., 2019, "Resilience by Design,” The Bridge, Vol. 49, No. 2, pp. 52-59, https://www.nae.edu/212175/Resilience-by-Design, accessed April 30, 2020.

Kircher, C.A., Seligson, H.A., Bouabid, J., and Morrow, G.C., 2006, When the Big One Strikes Again - Estimated Losses due to a Repeat of the 1906 San Francisco Earthquake, http://www.nehrpscenario.org/wp-content/uploads/2009/03/kircher_etal.pdf, accessed April 5, 2020. 
Lazarus, D., 2019, “Most Californians Don't Have Earthquake Insurance. Should They?” Government Technology: Emergency Management, https://www.govtech.com/em /disaster/Most-Californians-Dont-Have-Earthquake-Insurance-Should-They.html, accessed February 28, 2020.

Lindell, M.K., 2019, "Recovery Planning with U.S. Cities," The Routledge Handbook of Urban Disaster Resilience: Integrating Mitigation, Preparedness, and Recovery Planning, Lindell and Peacock (Eds.), Routledge.

Liu, X., Shahidehpour, M., Li, Z., Liu, X., Cao, Y., and Bie, Z., 2016, “Microgrids for Enhancing the Power Grid Resilience in Extreme Conditions," IEEE Transactions on Smart Grid, Vol. 8, No. 2, pp. 589-597.

Mitrani-Reiser, J., Wu, S., and Beck, J.L., 2016, "Virtual Inspector and its application to immediate pre-event and post-event earthquake loss and safety assessment of buildings," Natural Hazards, Vol. 81, No. 3, pp. 1861-1878.

Mahoney, M., 2019, NEHRP Functional Recovery Project, Senior Geophysicist, Federal Emergency Management Agency (unpublished).

Marquez, A. 2019, "NAWS China Lake Public Works Department Restores Base Utilities," America's Navy Forged by the Sea, United States Navy, https://www.navy.mil/submit /display.asp?story id=110231, accessed April 22, 2020.

NASEM, 2020, NCHRP Research Report 949: Proposed AASHTO Guidelines for PerformanceBased Seismic Bridge Design, National Academies of Sciences, Engineering, and Medicine, The National Academies Press, Washington, D.C., https://doi.org/10.17226 125913.

NCHRP, 2020, Mainstreaming System Resilience Concepts into Transportation Agencies: A Guidebook (Final Draft), The National Cooperative Highway Research Program (NCHRP) Award for Deploying Transportation Resilience Practices in State DOTs (NCHRP 20-117), https://apps.trb.org/cmsfeed/TRBNetProjectDisplay.asp ?ProjectID=4208, accessed November 10, 2020.

NERC, 2004, Technical Analysis of the August 14, 2003, Blackout: What Happened, Why, and What Did We Learn? North American Electric Reliability Council, Princeton, New Jersey.

Nevada Bureau of Mines and Geology, 2010, Living with Earthquakes in Nevada, Special Publication 27, Third Edition, University of Nevada, Reno, Nevada.

NFPA, 2013, Standard on Disaster/Emergency Management and Business Continuity Programs, National Fire Protection Association (NFPA), Quincy, Massachusetts. 
NIBS, 2015, Developing Pre-Disaster Resilience Based on Public and Private Incentivization, National Institute of Building Sciences, Washington, D.C., https://cdn.ymaws.com /www.nibs.org/resource/resmgr/MMC/MMC ResilienceIncentivesWP.pdf, accessed April 29, 2020.

NIBS, 2016, An Addendum to Developing Pre-Disaster Resilience Based on Public and Private Incentivization, National Institute of Building Sciences, Multihazard Mitigation Council, in conjunction with the Council on Finance, Insurance and Real Estate, Washington, D.C., https://cdn.ymaws.com/www.nibs.org/resource/resmgr/mmc/MMC IncentivizationWB Add.pdf, accessed March 26, 2020.

NIBS, 2019a, Natural Hazard Mitigation Saves: 2019 Report, National Institute of Building Sciences, Washington, D.C.

NIBS, 2019b, Resource Paper: Resilience-Based Design and the NEHRP Provisions, developed by the National Institute of Building Sciences, Building Seismic Safety Council for the Federal Emergency Management Agency, Washington, D.C., https://cdn.ymaws.com /www.nibs.org/resource/resmgr/bssc3/BSSC_Resilience_Based_Design.pdf, accessed March 28, 2020.

NIST, 2013, Cost Analyses and Benefit Studies for Earthquake-Resistant Construction in Memphis, Tennessee, NIST GCR 14-917-26, prepared by the NEHRP Consultants Joint Venture, a partnership of the Applied Technology Council and the Consortium of Universities for Research in Earthquake Engineering, for the National Institute of Standards and Technology, Gaithersburg, Maryland.

NIST, 2014, Earthquake Resilient Lifelines: NEHRP Research, Development, and Implementation Roadmap, NIST GCR 14-917-33, prepared by the Applied Technology Council for the National Institute of Standards and Technology, Gaithersburg, Maryland.

NIST, 2016a, Community Resilience Planning Guide for Buildings and Infrastructure Systems, Volume I, NIST Special Publication 1190, National Institute of Standards and Technology, Gaithersburg, Maryland.

NIST, 2016b, Community Resilience Planning Guide for Buildings and Infrastructure Systems, Volume II, NIST Special Publication 1190, National Institute of Standards and Technology, Gaithersburg, Maryland.

NIST, 2016c, Critical Assessment of Lifeline System Performance: Understanding Societal Needs in Disaster Recovery, NIST GCR 16-917-39, prepared by the Applied Technology Council for the National Institute of Standards and Technology, Gaithersburg, Maryland.

NIST, 2017, ICSSC Recommended Practice (RP) 9: Implementation Guidelines for Executive Order 13717: Establishing a Federal Earthquake Risk Management Standard, NIST Technical Note 1922, National Institute of Standards and Technology, Gaithersburg, Maryland. https://doi.org/10.6028/NIST.TN.1922. 
NIST, 2019, Guide Brief 14 - Forming a Collaborative Planning Team and Engaging the Community, NIST Special Publication 1190GB-14, National Institute of Standards and Technology, Gaithersburg, Maryland, https://doi.org/10.6028/NIST.SP.1190GB-14.

NOAA, 2018, Costliest U.S. Tropical Cyclones Tables Updated, National Oceanic and Atmospheric Administration (NOAA), National Centers for Environmental Information (NCEI), National Hurricane Center (NHC), https://www.nhc.noaa.gov/news/Updated Costliest.pdf, accessed April 5, 2020.

NRC, 2012, Disaster Resilience: A National Imperative, National Research Council, Washington, D.C., The National Academies Press, https://doi.org/10.17226/13457.

O’Rourke, T.D., 2007, “Critical Infrastructure, Interdependencies, and Resilience,” The Bridge, Vol. 37, No. 1, https://www.nae.edu/File.aspx?id=7405, accessed April 29, 2020.

OSSPAC, 2013, The Oregon Resilience Plan, Reducing Risk and Improving Recovery for the Next Cascadia Earthquake and Tsunami, Oregon Seismic Safety Policy Advisory Committee, https://www.oregon.gov/gov/policy/orr/pages/index.aspx, accessed April 29, 2020.

OSSPAC, 2018, Encouraging Homeowner Resilience through Earthquake Insurance and Seismic Retrofit, OSSPAC Publication 18-01, Oregon Seismic Safety Policy Advisory Committee, https://www.oregon.gov/oem/Documents/OSSPAC-1801\%20Insurance\%20Final\%20Report.pdf, accessed December 23, 2019.

Perry, S., Cox, D., Jones, L., Bernknopf, R., Goltz, J., Hudnut, K., Mileti, D., Ponti, D., Porter, K., Reichle, M., Seligson, H., Shoaf, K., Treiman, J., and Wein, A., 2008, The ShakeOut Earthquake Scenario - A Story That Southern Californians Are Writing, U.S. Geological Survey Circular 1324, https://pubs.usgs.gov/circ/1324/, accessed April 5, 2020.

Petak, W., and Elahi, S., 2001, The Northridge Earthquake, USA, and its Economic and Social Impacts, http://resilience.abag.ca.gov/wp-content/documents/resilience/toolkit/The $\% 20$ Northridge $\% 20$ Earthquake $\% 20$ and $\% 20$ its $\% 20$ Economic $\% 20$ and $\% 20$ Social $\% 20$ Imp acts.pdf, accessed April 5, 2020.

Petersen, M.D., Moschetti, M.P., Powers, P.M., Mueller, C.S., Haller, K.M., Frankel, A.D., Zeng, Y., Rezaeian, S., Harmsen, S.C., Boyd, O.S., Field, E.H., Chen, R., Rukstales, K.S., Luco, N., Wheeler, R.L., Williams, R.A., and Olsen, A.H., 2014, Documentation for the 2014 Update of the United States National Seismic Hazard Maps, U.S. Geological Survey Open-File Report 2014-1091, https://dx.doi.org/10.3133/ofr20141091.

PG\&E, 2020, "Seismic Information," https://www.pge.com/myhome/edusafety/systemworks /dcpp/newsmedia/seismic/, accessed March 22, 2020.

RRMC, 2019, Resilience-Based Performance: Next Generation Guidelines for Buildings and Lifeline Standards, Infrastructure Resilience Publication No. 3, Risk and Resilience Measurement Committee (RRMC), Infrastructure Resilience Division, American Society of Civil Engineers, Reston, Virginia. 
Sattar, S., McAllister, T., Johnson, K., Clavin, C., Segura, C., McCabe, S., Fung, J., Abrahams, L., Sylak-Glassman, E., Levitan, M., Harrison, K., and Harris, J., 2018, Research Needs to Support Immediate Occupancy Building Performance Objective Following Natural Hazard Events, NIST Special Publication 1224, National Institute of Standards and Technology, Gaithersburg, Maryland, https://dx.doi.org/10.6028/NIST.SP.1224.

SCEC, 2011, Putting Down Roots in Earthquake Country, Southern California Earthquake Center, University of Southern California, Los Angeles, California, https://www.earthquakecountry.org/library/PuttingDownRootsSoCal2011.pdf, accessed April 5, 2020.

Schmid, P.G., 2018, "Ignore the Naysayers: Blockchain's Potential Touches Every Aspect of Insurance," Carrier Management, https://www.carriermanagement.com /features/2018/07/10/181495.htm, accessed December 24, 2019.

Sims, B., 2015, "Seismic shifts and retrofits: Scale and complexity in the seismic retrofit of California bridges," Retrofitting Cities : Priorities, Governance and Experimentation, M. Hodson and S. Marvin eds., Taylor and Francis Group, London, United Kingdom, https://doi.org/10.4324/9781315678238.

Smith, A.B., and Katz, R.W., 2013, "U.S. billion-dollar weather and climate disasters: data sources, trends, accuracy, and biases," Natural Hazards, Vol. 67, pp. 387-410, https://doi.org/10.1007/s11069-013-0566-5.

SPUR, 2012, Safe Enough to Stay, San Francisco Bay Area Planning and Urban Research Association, San Francisco, California.

Taylor, C., Mittler, E., and Lund, L., 1999, Overcoming Barriers: Lifeline Seismic Improvement Programs, Technical Council on Lifeline Earthquake Engineering, Monograph No. 13, American Society of Civil Engineers, Reston, Virginia.

Telcordia, 2017, NEBS Requirements: Physical Protection, SR-3580, Issue 5, Telcordia Technologies.

The White House, 2011, Presidential Policy Directive/PPD-8: National Preparedness, https://www.dhs.gov/presidential-policy-directive-8-national-preparedness, accessed April 29, 2020.

The White House, 2013, Presidential Policy Directive/PPD-21, https://obamawhitehouse .archives.gov/the-press-office/2013/02/12/presidential-policy-directive-criticalinfrastructure-security-and-resil, accessed April 29, 2020.

The White House, 2016, Executive Order 13717: Establishing a Federal Earthquake Risk Management Standard, https://obamawhitehouse.archives.gov/the-pressoffice/2016/02/02/executive-order-establishing-federal-earthquake-risk-managementstandard), accessed April 29, 2020. 
U.S. Census Bureau, 2018, Monthly Construction Spending, January 2018, Release Number CB18-29, https://www.census.gov/construction/c30/pdf/pr201801.pdf, accessed April 29, 2020.

USDHS, 2013, National Infrastructure Protection Plan, U.S. Department of Homeland Security, Washington, D.C., https://www.dhs.gov/xlibrary/assets/nipp_consolidated_snapshot.pdf, accessed April 29, 2020.

USDHS, 2019, Joint National Priorities for Critical Infrastructure Security and Resilience, U.S. Department of Homeland Security, Washington, D.C., https://www.cisa.gov/publication /joint-national-priorities, accessed April 30, 2020.

USGS, 2020, “Earthquake Hazards," Earthquake Glossary, https://earthquake.usgs.gov/learn /glossary/?term=earthquake\%20hazard, accessed March 13, 2020.

Yu, K., Newell, J., Beyer, D., Poland, C., and Raskin, J., 2015, Beaverton School District Resilience Planning for High School at South Cooper Mountain and Middle School at Timberland, SEFT Consulting Group, Beaverton, Oregon, https://www.researchgate .net/publication/315791565 Beaverton_School_District_Resilience Plan, accessed April $29,2020$.

Yu, Q.-S., Wilson, J., and Wang, Y., 2014, "Overview of the Oregon Resilience Plan for the Next Cascadia Earthquake and Tsunami," Proceedings, $10^{\text {th }}$ National Conference on Earthquake Engineering, Anchorage, Alaska. 



\section{Participants}

\section{Federal Emergency Management Agency}

Michael Mahoney

Federal Emergency Management Agency

400 C Street, SW

Washington, D.C. 20472

Robert D. Hanson (Technical Monitor)

5885 Dunabbey Loop

Dublin, Ohio 43017

National Institute of Standards and Technology

Siamak Sattar

Engineering Laboratory (MS8604)

National Institute of Standards and

Technology

100 Bureau Drive

Gaithersburg, Maryland 20899

Steven L. McCabe

Engineering Laboratory (MS8604)

National Institute of Standards and

Technology

100 Bureau Drive

Gaithersburg, Maryland 20899

\section{Applied Technology Council}

Jon A. Heintz

Applied Technology Council

201 Redwood Shores Parkway, Suite 240

Redwood City, California 94065
John R. Hayes, Jr. (Technical Monitor)

P.O. Box 1295

Crozet, Virginia 22932

Pataya Scott

Federal Emergency Management Agency 400 C Street, SW

Washington, D.C. 20472
Katherine J. Johnson

Engineering Laboratory (MS8604)

National Institute of Standards and

Technology

100 Bureau Drive

Gaithersburg, Maryland 20899

\section{Science and Technology Policy Institute}

Leslie Abrahams

Institute for Defense Analyses

Science and Technology Policy Institute

1701 Pennsylvania Ave. NW, Suite 500

Washington, D.C. 20006 


\section{Project Technical Panel}

Ryan A. Kersting (Chair)

Buehler

600 Q Street, Suite 200

Sacramento, California 95811

(Structural Engineers Association of

California)

Lucy A. Arendt

St. Norbert College

Dept. of Business Administration-Mgmt.

100 Grant Street

Cofrin Hall, 323

De Pere, Wisconsin 54115

(Social Science Extreme Events Research)

David Bonowitz

605A Baker Street

San Francisco, California 94117

(Provisions Update Committee)

Mary C. Comerio

University of California, Berkeley

Dept. of Architecture

232 Wurster Hall

Berkeley, California 94720

(Pacific Earthquake Engineering Research

Center)

Craig A. Davis

27017 Vista Encantada Drive

Valencia, California 91354

(Los Angeles Department of Water and

Power-retired)

Greg G. Deierlein

Stanford University

Dept. of Civil \& Environmental Engineering

Blume Earthquake Engin. Center, MC 3037

Stanford, California 94305

(Stanford Urban Resilience Initiative)
Susan Dowty

International Code Council

3060 Saturn Street, Suite 100

Brea, California 92821

(International Code Council)

Gary Ehrlich

National Association of Home Builders

1201 15th Street, NW

Washington, D.C. 20005

(National Association of Home Builders)

Ronald O. Hamburger

Simpson Gumpertz \& Heger, Inc.

100 Pine Street, Suite 1600

San Francisco, California 94111

(American Society of Civil Engineers/

Structural Engineering Institute)

Jon A. Heintz

Applied Technology Council

201 Redwood Shores Parkway, Suite 240

Redwood City, California 94065

(Private Sector, Non-Profit Organization)

Ron C. Larsen

General Services Administration

50 United Nations Plaza

MB\# 9, Suite 3520

San Francisco, California 94102

(General Services Administration)

Rachel Minnery

The American Institute of Architects

1735 New York Avenue, NW

Washington, D.C. 20006

(American Institute of Architects)

Aspasia (Sissy) Nikolaou

WSP USA, Inc.

One Penn Plaza

New York, New York 10119

(Structural Engineers Association of

New York) 
Chris D. Poland

Chris D. Poland, Consulting Engineer

30688 Spyglass Way

Canyon Lake, California 92587

(Earthquake Engineering Research

Institute)

Jonathan Siu

City of Seattle

Department of Construction and Inspections

P.O. Box 34019

Seattle, Washington 98124

(Building Officials)

\section{Project Review Panel}

Marissa Aho

City of Huston

901 Bagby

Houston, Texas 77002

John M. Bozeman

Building Owners and Managers Association of San Francisco

233 Sansome Street, 8th Floor

San Francisco, California 94104

Dan Eschenasy

New York City Department of Buildings

1 Centre Street, Suite 530

New York, New York 10007

Robert Ezelle

Washington Military Department

Building 1

1 Militia Drive

Camp Murray, Washington 98430

William T. Holmes

Rutherford + Chekene

375 Beale Street, Suite 310

San Francisco, California 94105
Jeffrey R. Soulages

Intel Corporation

2501 NW 229th Street MS: RA1-220

Hillsboro, Oregon 97124

(Private Sector, For-Profit Business)

Kent $\mathrm{Yu}$

SEFT Consulting Group

4800 SW Griffith Drive, Suite 100

Beaverton, Oregon 97005

(Structural Engineers Association of

Oregon)

James Kendra

University of Delaware

School of Public Policy and Administration

184 Graham Hall

Newark, Delaware 19716

Thomas D. O'Rourke

Cornell University

School of Civil and Environ. Engineering

273 Hollister Hall

Ithaca, New York 14853

Marios Panagiotou

Nabih Youssef Associates

550 South Hope Street, Suite 1700

Los Angeles, California 90071

Keith Porter

University of Colorado

Dept. of Civil, Environ., and Arch. Engin.

1111 Engineering Drive

Boulder, Colorado 80309

Lakisha Ann Woods

National Institute of Building Sciences

1090 Vermont Avenue Northwest, Suite 700

Washington, D.C. 20005 


\section{Additional Reviewers}

Philip J. Caldwell

Schneider Electric

7 Sleepy Hollow Lane

Six Mile, South Carolina 29682

David W. Cocke

Structural Focus

19210 S. Vermont Ave., Bldg. B, Suite 210

Gardena, California 90248

Ayse Hortacsu

Applied Technology Council

201 Redwood Shores Parkway, Suite 240

Redwood City, California 94065

\section{Workshop Participants}

Ibbi Almufti, Arup

American Society of Civil Engineers, Structural Engineering Institute

Andre Barbosa, Oregon State University

Russell Berkowitz, Forell/Elsesser

Engineers, Inc.

Jeffrey Berman, University of Washington

BHW Engineers

Brian Blake, Central U.S. Earthquake

Consortium

Steve Bowman, Utah Geological Survey

Burns \& McDonnell

California State University, Chico

Nnenia Campbell, Natural Hazard Center

Robert Carey, Utah Division of Emergency

Management

Amal Centers, Federal Emergency

Management Agency

Divya Chandrasekhar, University of Utah

Jessica Chappell, Reaveley Engineers
Gabriel (David) Javier

Federal Emergency Management Agency

400 C Street, SW

Washington, D.C. 20472

Bret Lizundia

Rutherford + Chekene

375 Beale Street, Suite 310

San Francisco, California 94105

Therese P. McAllister

National Institute of Standards and Technology

100 Bureau Drive

Gaithersburg, Maryland 20899

Genda Chen, Missouri University of Science and Technology

City and County of San Francisco

City of St. Louis Emergency Management

Agency

Dustin Cook, University of Colorado,

Boulder

Englekirk

Nicole Errett, Earthquake Engineering

Research Institute

Geologic Hazards Group

Michael Griffin, CCS Group, Inc.

Garrett Hagen, Degenkolb Engineers

Sara Hamideh, Stony Brook University

James Harris, J.R. Harris \& Company

Tasha Harvey, Arup

John Hooper, Magnusson Klemencic

Associates

Sandra Hyde, International Code Council

Mahmoud Khater, CoreLogic 
Laurie Johnson Consulting Research

Norman Levine, South Carolina Earthquake

Education and Preparedness

Roy Lobo, Office of Statewide Health

Planning and Development

Nicolas Luco, U.S. Geological Survey

Brent Maxfield, Earthquake Engineering

Research Institute - Utah

Therese McAllister, National Institute of

Standards and Technology

Mehrain Naeim International

Missouri State Emergency Management

Agency

Steven Moddemeyer, Collins Woermann

Negar Mohammadgholibeyki, Texas A\&M University

Nabih Youssef Structural Engineers

NW Natural

Kristine Pankow, University of Utah

Chris Pantelides, University of Utah

Jonna Papaefthimiou, City of Portland

Michael Pfeiffer, International Code Council

RAND Corporation

Adam Rose, University of Southern

California
Anne Rosinski, Federal Emergency

Management Agency

Rutherford + Chekene

Zahraa Saiyed, University of San Francisco and Scyma Consulting

Donald Scott, PCS Structural Solution

Stanford University

Kate Stillwell, Jumpstart Insurance

Solutions, Inc.

Structural Focus

Andrew Taylor, KPFF Consulting Engineers

Edward Thomas, Natural Hazard Mitigation Association

Chris Tokas, Office of Statewide Health and Planning Department

Heidi Tremayne, Earthquake Engineering

Research Institute

University of Auckland

University of California, Berkeley

U.S. Resiliency Council

Walter P. Moore

Jay Wilson, Clackamas County Disaster

Management

Daniel Zepeda, Degenkolb Engineers 